\title{
Confiabilidad en la medición de caries dental
}

Remedios Guadalupe Valdez Penagos Eliézzer Dirosa Rosado

Yuliana Josefina Zarza Martínez María Del Carmen Cortés Quirroz Rodolfo Gustavo Ramírez Sánchez María Lilia Adriana Juárez López
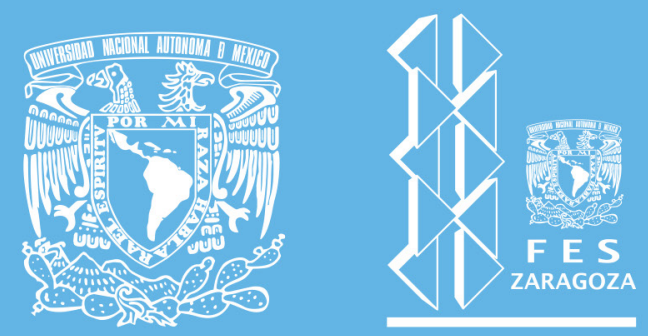


\section{Confiabilidad en la medición de caries dental}

Remedios Guadalupe Valdez Penagos Eliézer Erosa Rosado Yuliana Josefina Zarza Martínez María Del Carmen Cortés Quiroz Rodolfo Gustavo Ramírez Sánchez María Lilia Adriana Juárez López 


\section{Universidad Nacional Autónoma de México \\ Facultad de Estudios Superiores Zaragoza}

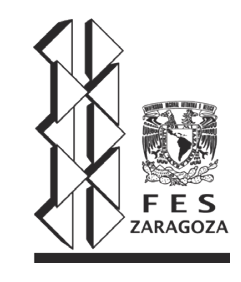

\section{Datos para catalogación bibliográfica}

Autores: Remedios Guadalupe Valdez Penagos, Eliézer Erosa Rosado, Yuliana Josefina Zarza Martínez, María Del Carmen Cortés Quiroz, Rodolfo Gustavo Ramírez Sánchez, María Lilia Adriana Juárez López

\section{Confiabilidad en la medición de caries dental}

UNAM, FES Zaragoza, enero de 2018.

Peso: $6 \mathrm{MB}$.

Diseño de portada: Carlos Raziel Leaños.

Diseño y formación de interiores: Claudia Ahumada Ballesteros.

ISBN: 978-607-30-0104-5.

\section{DERECHOS RESERVADOS}

Queda prohibida la reproducción o transmisión total o parcial del texto o las ilustraciones de la presente obra bajo cualesquiera formas, electrónicas o mecánicas, incluyendo fotocopiado, almacenamiento en algún sistema de recuperación de información, dispositivo de memoria digital o grabado sin el consentimiento previo y por escrito del editor.

\section{Confiabilidad en la medición de caries dental}

\section{D.R. () Universidad Nacional Autónoma de México}

Av. Universidad \# 3000, Col. Universidad Nacional Autónoma de México, C.U., Delegación Coyoacán, C.P. 04510, México, D.F.

\section{Facultad de Estudios Superiores Zaragoza}

Av. Guelatao \# 66, Col. Ejército de Oriente, Delegación Iztapalapa, C.P. 09230, México, D.F. 


\section{Contenido}

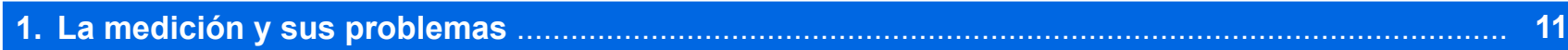

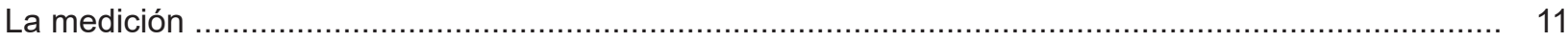

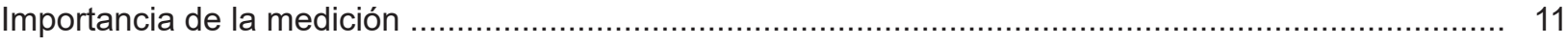

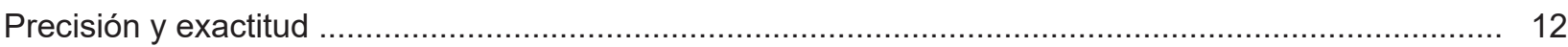

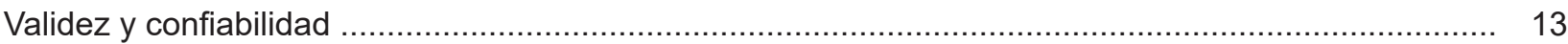

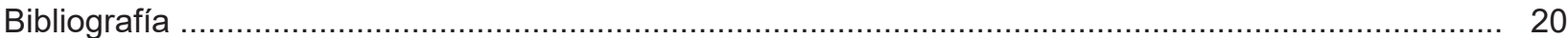

2. Confiabilidad en la medición epidemiológica del proceso caries .............................................. 21

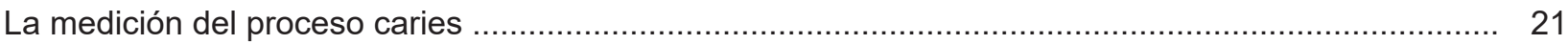

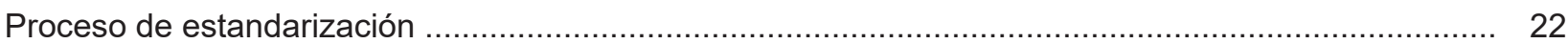

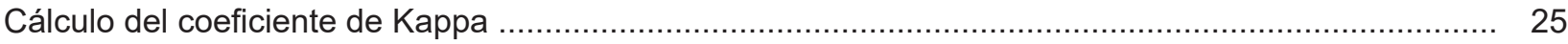

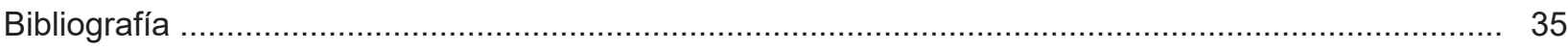

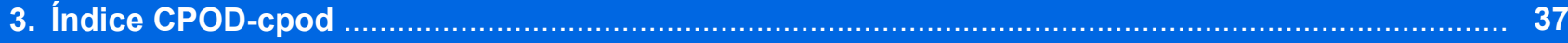

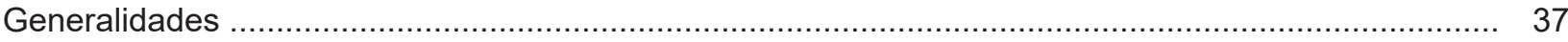

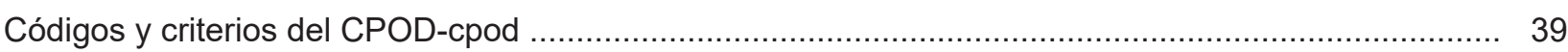

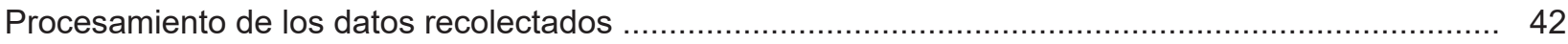

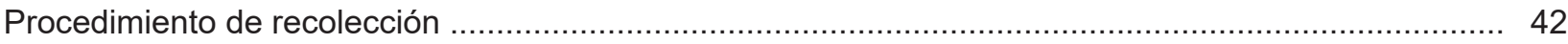

Recursos para el levantamiento epidemiológico .................................................................... 45

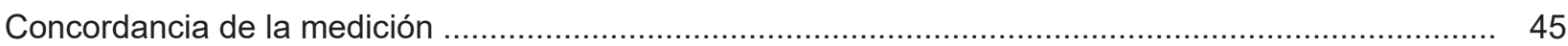

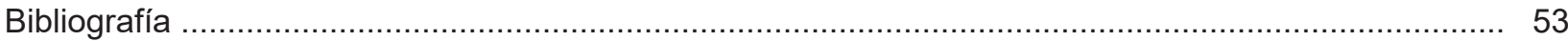

4. Índice para evaluar el estado de la dentición y tratamiento necesario ..................................... 55

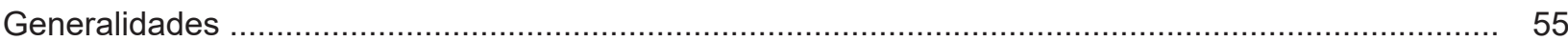

Códigos y criterios del índice para evaluar el estado de la dentición y tratamiento necesario................ 56

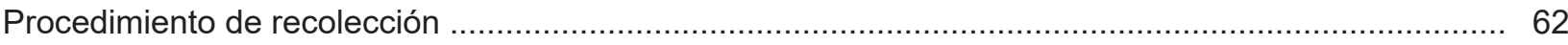

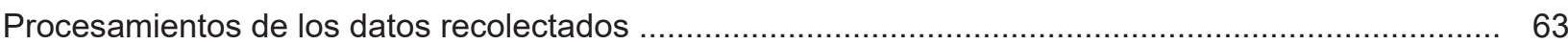

Recursos para el levantamiento epidemiológico ..................................................................... 66

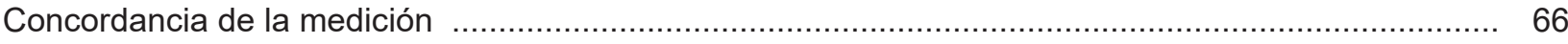

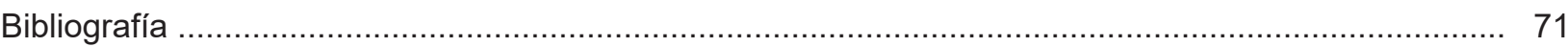




\section{Confiabilidad en la medición de caries dental}

\section{Sistema Internacional de Detección de Caries: ICDAS .................................................... 73}

Generalidades 73

Códigos y criterios del Sistema Internacional de Detección de Caries: ICDAS 74

Condición de caries radicular 76

Evaluación de restauraciones en la superficie dental 79

Procedimiento de recolección 82

Recursos para el levantamiento epidemiológico 84

Concordancia de la medición 85

Planeación del tratamiento considerando los criterios ICDAS 91

Bibliografía 93

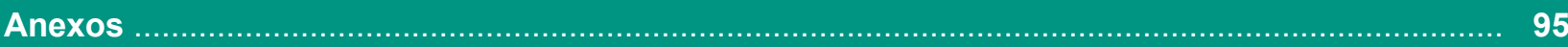

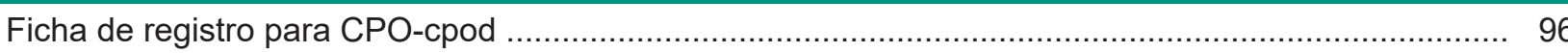

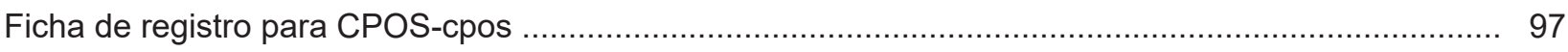

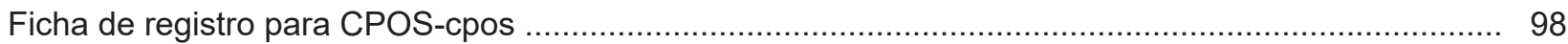

Ficha de registro del Estado de la Dentición y tratamiento necesario ............................................... 99

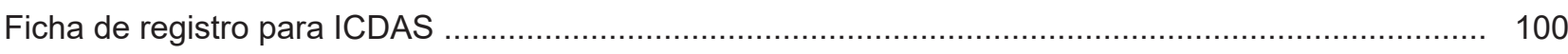




\section{Autores}

\section{REMEDIOS GUADALUPE VALDEZ PENAGOS}

Licenciatura en la Carrera de Cirujano Dentista, FES Zaragoza, UNAM.

Especialidad en Estomatología en Atención Primaria, FES Zaragoza. UNAM.

Maestría en Administración de Negocios, ULA.

Profesora de Carrera Tiempo Completo Asociado C en la Carrera de Cirujano Dentista, FES Zaragoza.

\section{ELIÉZER EROSA ROSADO}

Licenciatura en la Carrera de Psicología, ENEP Zaragoza, UNAM.

Profesor de Asignatura B Definitivo en la Carrera de Psicología, FES Zaragoza.

\section{YULIANA JOSEFINA ZARZA MARTÍNEZ}

Licenciatura en la Carrera de Cirujano Dentista, FES Zaragoza, UNAM.

Especialidad en Estomatología en Atención Primaria, FES Zaragoza, UNAM.

Profesora de Asignatura B Definitivo en la Carrera de Cirujano Dentista, FES Zaragoza.

\section{MARÍA DEL CARMEN CORTÉS QUIROZ}

Licenciatura en la Carrera de Cirujano Dentista, FES Zaragoza, UNAM.

Especialidad en Estomatología en Atención Primaria, FES Zaragoza, UNAM.

Profesora de Asignatura A Interina en la Carrera de Cirujano Dentista, FES Zaragoza.

\section{RODOLFO GUSTAVO RAMÍREZ SÁNCHEZ}

Pasante de la Carrera de Cirujano Dentista, FES Zaragoza, UNAM.

\section{MARÍA LILIA ADRIANA JUÁREZ LÓPEZ}

Licenciatura en la Carrera de Cirujano Dentista, Facultad de Odontología, UNAM.

Especialidad en Estomatología Pediatrica. Instituto Nacional de Pediatria.

Maestría en Odontología, Facultad de Odontología, UNAM.

Doctorado en Ciencias Odontológicas, Facultad de Odontología, UNAM.

Profesora de Carrera Tiempo Completo Titular C en la Carrera de Cirujano Dentista, FES Zaragoza.

Responsable de la línea de investigación en odontología clínica y epidemiológica., aprobada en el año 2002 y ratificada en 2014. 



\section{Agradecimientos}

A la Universidad Nacional Autónoma de México que a través de la Dirección General de Asuntos del Personal Académico (DGAPA) otorgó el apoyo de la edición del libro como producto del proyecto PE- 211915 del Programa de Apoyo a Proyectos para la Innovación y Mejoramiento de la Enseñanza (PAPIME).

A los pacientes y escolares que amablemente aceptaron ser fotografiados.

A los colegas Cirujanos Dentistas: Valdez-Penagos AG, Flores-Juárez A, y Pérez-lbarra E, por las fotografías compartidas. 



\section{Presentación}

El proceso caries dental es una alteración de salud bucal que ha alcanzado el nivel de pandemia, sin duda, requiere ser abordada a través de la participación de los diversos actores sociales: la población, el gremio estomatológico, el Sistema Nacional de Salud, la Secretaría de Educación Pública, las empresas productoras de alimentos y auxiliares de higiene bucal y por supuesto el gobierno a través de las Políticas Públicas.

El alumno de la Carrera de Cirujano Dentista tendrá presente que la frecuencia y magnitud de la caries dental es determinada por: el contexto político, la situación socioeconómica en la cual se encuentra el individuo, sus condiciones de vida, su comportamiento social, factores psicológicos y factores biológicos, así como el tipo de sistema de salud al cual tiene acceso el individuo.

Por lo tanto, la comprensión de esta problemática permitirá al futuro Cirujano Dentista planear y ejecutar programas preventivos y de rehabilitación, así como utilizar o crear materiales y tecnología innovadora para tener una práctica odontológica basada en la prevención, o bien, crear espacios alternativos en los cuales se integre a la población con la intención de resolver las necesidades que plantea cada escenario.

Para ello, es importante que el alumno de la Carrera de Cirujano Dentista reconozca que el primer paso en cualquier abordaje es realizar un diagnóstico de la población seleccionada, por lo tanto, se apoyará en indicadores cualitativos que le ayuden a explicar el por qué y cómo se producen algunas situaciones de salud y en indicadores cuantitativos que responden al qué, cuánto y cuándo respecto a la valoración de lesiones o experiencia de caries.

En relación a los indicadores epidemiológicos para valorar caries dental existe múltiples sistemas, sin embargo, en el presente libro se abordaran tres de los indicadores que forman parte del plan de estudios de la Carrera de Cirujano Dentista por ser los más utilizados y por generar información que da cuenta de la magnitud y severidad de caries en diversos grupos poblacionales.

El primero de ellos, es el CPOD que mide la experiencia de caries dental (diente cariado, diente perdido y diente obturado) en dentición permanente, el cpod que mide la experiencia de caries en dentición temporal y su variante CPOS y cpos que miden la experiencia de caries en dentición permanente y temporal según corresponde, cuya unidad de análisis es la superficie dental. Este indicador es uno de los más utilizados, por lo tanto, permite la comparación de los datos recolectados con los de otras investigaciones.

El segundo indicador descrito es el índice para la evaluación del estado de la dentición y tratamiento necesario, la utilización de este índice permite planear intervenciones de rehabilitación en la población. Un dato importante es que los criterios incluidos en este indicador permiten calcular el CPOD-cpod.

Finalmente se describe el Sistema Internacional de Detección de Caries (ICDAS) el cual por su sensibilidad en la medición de caries proporciona información relacionada con la caries dental desde que ésta muestra los primeros signos de cambio en el esmalte dental, por lo tanto, supone un gran avance en la detección de la enfermedad lo que permite al Cirujano Dentista actuar haciendo uso de métodos conservadores.

Los dos primeros indicadores tienen por objetivo identificar lesiones de caries cavitadas y son de gran ayuda en el diagnóstico comunitario y el tercero permite identificar los primeros cambios de coloración en la superficie dental. 


\section{Confiabilidad en la medición de caries dental}

Tanto el índice para la evaluación del estado de la dentición y tratamiento necesario como el ICDAS permiten la planeación de programas de intervención, los resultados que proporciona ICDAS permiten al Cirujano Dentista incluir medidas específicas de protección que ayudan a revertir los primeros efectos del proceso caries y dar seguimiento a estas lesiones.

Sin embargo, la medición es un proceso que requiere de un ejercicio previo de capacitación, que de respuesta a las siguientes interrogantes:

- ¿Qué instrumento debo utilizar?

- ¿Qué tan similares son mis mediciones entre si?

- ¿Qué tan similares son mis mediciones respecto a otros examinadores?

- ¿Dónde estoy cometiendo algún error?

- ¿Repercuten estos errores en los resultados obtenidos?

De tal manera, que el presente documento resalta la importancia de conocer el criterio diagnóstico de caries seleccionado y la consistencia en su aplicación a fin de contribuir en la producción de conocimiento válido y confiable, por lo que se ejemplifica el cálculo del coeficiente de kappa en cada uno de los índices mencionados, con el objetivo de que el alumno y cualquier profesional de la estomatología comprenda y aprenda la estrategia para medir la confiabilidad de la estandarización en los mencionados indicadores epidemiológicos para caries dental.

Por lo tanto esta información servirá como apoyo en el proceso enseñanza-aprendizaje a la formación epidemiológica de los Cirujanos Dentistas y los orientará en sus primeros acercamientos a uno de los objeto de estudio y trabajo cotidiano de su vida profesional.

REMEDIOS VALDEZ 


\title{
CAPÍtULLO I
}

\section{La medición y sus problemas}

\author{
ELIÉZZER EROSA ROSADO
}

\section{La medición}

Junto con la observación, el registro de la ocurrencia de un fenómeno es la actividad planeada que mejor describe la curiosidad de nuestra especie para explicarse el mundo que lo rodea de una manera ordenada y sistemática. ${ }^{1}$ Las marcas hechas en las rocas señalando la longitud y la postura de la sombra de un accidente del terreno a lo largo del año le permitieron a diferentes civilizaciones antiguas establecer que el sol "pasaba" regularmente por ciertas regiones del cielo, y que los intervalos entre ciertos puntos estaban asociados con las estaciones, y estas a su vez, con los cambios en el paisaje, como la floración, el deshielo, la crecida de los ríos, etc. y estos, con el cambio en el comportamiento de los animales (e.g., hibernación, cambio de pelaje, celo) y en el suyo propio. ${ }^{2}$

Las muescas y los agujeros practicados con una roca afilada en la corteza de un árbol o en un trozo de hueso, utilizadas una y otra vez sirvieron, por ejemplo, para reproducir patrones uniformes en los textiles, en los dibujos corporales, en la decoración de la cerámica, en el espaciamiento de los puntos de costura y en los recortes de piedras de sillares para la construcción de sus refugios.

El registro de los fenómenos y eventos durante la vida de una persona, y en algunos casos, de las vidas de más de una generación, permitieron eventualmente descubrir regularidades en estos casos. La aplicación práctica de los puntos de referencia señalados en su entorno y sus respectivas copias y símiles en objetos portátiles son los antecedentes rudimentarios de un proceso de descripción, reproducción y comunicación de regularidades que conocemos como medición. Es probable que los patrones de referencia en función del propio cuerpo o en función de ciertas actividades se haya desarrollado en esta etapa de la civilización, tal como aparece en estelas, petroglifos y pergaminos: "7 días de marcha", "8 lunas", "2 palmas", etcétera. El uso del concepto de cantidad, en forma de comparación con un objeto patrón está asociado a este nivel del desarrollo humano. ${ }^{3,4}$

Con el asentamiento de las civilizaciones y el desarrollo de obras relacionadas con la agricultura, como el riego, la división de los terrenos dedicados a cada tipo de plantío y el levantamiento de las ciudades, la medición evolucionó hacia la creación de patrones más uniformes, reproducidos una y otra vez, adoptados convencionalmente entre los grupos afines y tomados como unidad. Así, se sabe que los arquitectos constructores en Asiria, Babilonia y Egipto, utilizaban bastones y cuerdas de largos semejantes a los de los capataces y maestros de obra; los comerciantes usaban cuentas pulidas equilibradas en un platillo para fijar los pesos, y los granjeros y campesinos empleaban canastos y recipientes para medir volúmenes de granos y líquidos. Los bastones, las piedrecillas y los canastos eran igualados de una manera muy aproximada entre sí, a fin de que "midieran" cantidades semejantes. ${ }^{3,5}$ 


\section{Importancia de la medición}

Una máxima aristotélica reza: "Si algo existe, existe en alguna medida". Cuando quedó establecido que la medición era un proceso de asignación de números de unidades arbitrarias a ciertos objetos, que conformaba una comparación del objeto contra la escala de las unidades, y que los números se podían representar con símbolos, en lugar de manipular los propios objetos o usar analogías, la medición, o mejor dicho, el producto de la medición, se convirtió en un elemento clave en la abstracción de las propiedades de un objeto, hecho o evento. Si se le podía atribuir una medida a un objeto, a una idea, a un concepto, este se "sustancializaba", cobraba un valor de existencia, de realidad concreta.

La medición, o mejor, el proceso de medición, las reglas de correspondencia de valores y el sistema de números son isomórficos a la realidad. El conjunto de números debe corresponderse en algún sentido formal con el conjunto de objetos. Las reglas de asignación de valores a los objetos deben mostrar, racional y empíricamente, una clara correspondencia con la "realidad". ${ }^{6}$ Por lo tanto, una preocupación constante en la ciencia y la filosofía desde la Época Clásica griega, ha consistido precisamente en atribuir valores de medición a todos los fenómenos de su

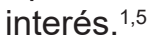

El problema de la medición a partir de entonces consistió en lograr dos cosas:

1. Mejores patrones de comparación, más uniformes, más consistentes, más útiles y menos variables entre sí; y

2. Mejores acuerdos sobre la precisión y la exactitud tanto de las mediciones, como de los instrumentos usados para medir.

El primer punto es una combinación de desarrollo científico, social, industrial, y de dominio político y económico. A lo largo de la historia, lentamente el intercambio entre pueblos conquistados y conquistadores, entre colonias y colonizadores, dio origen al reconocimiento y extensión del conocimiento, de sus tecnologías y también de las maneras de medir los fenómenos y acontecimientos, incluyendo la adopción de medidas.

El segundo punto es esencialmente una cuestión de desarrollo del pensamiento, de las capacidades científicas y tecnológicas para lograr mejores instrumentos y unidades de medición. Así, el metro pasó sucesivamente de ser una medida definida en base al cuadrante terrestre (en 1791), a un patrón definido por una barra de platino depositada en París (1799), a una barra de iridio-platino en el punto de fusión del hielo (1889), al número de marcas del espectro de un rayo de luz durante la transición del kriptón (1960), a la definición actual de la distancia recorrida por un rayo de luz en el vacío en $1 / 299792458$ partes de un segundo. ${ }^{7}$

\section{Precisión y exactitud}

\section{Precisión}

Aunque usualmente estos conceptos suelen ser empleados indistintamente en la vida cotidiana, tienen significados y consecuencias muy diferentes en los ámbitos de las ingenierías, la ciencia y la industria. La precisión es una limitación física o práctica del sistema o instrumento de medición; puede derivar de una consideración práctica de la medida; la exactitud es matemática y filosófica, ya que representa el límite al que podemos conocer el verdadero valor del objeto por conocer.

La precisión constituye el grado en que nos acercamos a la representación del verdadero valor del objeto que deseamos medir. La precisión es el valor que nos reporta nuestra observación o nuestro patrón de medida. Por ejemplo, el cálculo y los usos prácticos del número m (pi) varían con el propósito del usuario y el método de cálculo. 


\section{CAPÍTULO I La medición y sus problemas}

Para las posibilidades del trazo de un círculo con un compás con puntilla de lápiz, el valor de 3.14 es suficiente, pues el grueso de la puntilla se traslapará con el inicio del trazo, o bien, la distancia de separación será casi imperceptible para el ojo desnudo. En este caso, se dice que se trabaja con una precisión de 2 dígitos decimales significativos; un arquitecto, por otra parte, requerirá usar probablemente 3.1416 como valor de trabajo en los cálculos en que intervenga $\pi$. Estará trabajando con una precisión de 4 cifras decimales. ${ }^{8}$

La precisión está asociada con aspectos prácticos y convenientes del uso y necesidades de la medición. Por ejemplo, antes de iniciar un procedimiento de extracción, un estudiante registra la presión arterial del paciente con un esfigmomanómetro digital, cuya lectura es 117/93. En el expediente, sin embargo, el profesor supervisor encuentra el asiento como 120/90. Este redondeo a la decena más próxima refleja la convención de que los criterios para considerar anormalidades están basados en rangos cuyos valores frontera son cifras expresadas en decenas. Es decir, es suficiente considerar si el paciente está por arriba, por debajo o dentro de estos rangos de valores para declarar la posibilidad de daños vasculares, accidentes cerebrovasculares, insuficiencias cardíacas, etc., más que los valores puntuales. En otras palabras, la precisión de la medición sobre la tensión arterial se hace con aproximación a las decenas.

\section{Exactitud}

La exactitud, por otra parte, consiste en la capacidad de un instrumento para acercarse al verdadero valor de las dimensiones o propiedades del objeto. En cierto grado, la exactitud refleja la afectación de los errores sistemáticos sobre el cálculo del verdadero valor del objeto que reportamos. ${ }^{8}$ Es decir, para usar ejemplos de cálculo de $\pi$, quedando establecido que es un número irracional, las siguientes formas de calcularlo producen cada uno valores más cercanos al verdadero valor de $\pi$ :

1. Cálculo de Arquímedes: $3+10 / 71<\pi<3+1 / 7$, es decir $3.1407<\pi<3.1428$

2. Cálculo de Ptolomeo: $\pi \sim 3+8 / 60+30 / 3600 \sim 377 / 120 \sim 3.14166$

3. Cálculo de Liu Hui: $\pi \sim 3.14159$

En 2011 Shigeru Kondo produjo un programa para calcular el valor de $\pi$ con 10000000000000 (Diez billones) de dígitos. ${ }^{9}$ Es decir, produjo un cálculo sumaWmente exacto. Como nota curiosa, el cálculo de Kondo produjo un debate fuera del círculo académico sobre el grado de exactitud logrado, debido a los usos del lenguaje: en el inglés americano, se da el nombre de "billion" (billón) a la cantidad 1000000 000, y "trillion" (trillón) a la cifra 1000000 000 000, mientras que en inglés británico (como en español) son "Mil Millones" ("Millardo", término recomendado por la Real Academia de la Lengua española) y "Un billón" (un millón de millones), respectivamente. Así pues, había una diferencia por un factor de 1000 en la exactitud (i.e. el valor "verdadero") que entendían comunicadores británicos y americanos. ${ }^{10}$

Otro ejemplo para ilustrar el concepto de exactitud lo constituye la capacidad de resolución del microscopio. Las posibilidades de determinar el mínimo tamaño que se puede percibir con un microscopio depende de factores relacionados con la transparencia del material óptico, su espesor, su capacidad para introducir/compensar aberraciones cromáticas, el tallado y pulido y de factores mecánicos. Su exactitud global será, pues, una función de la exactitud individual de los elementos que intervienen en cada aspecto. ${ }^{8}$

En el campo de la Odontología podemos ilustrar ejemplos como el anterior, con el siguiente caso. Un artículo presentó los cálculos finales de las reacciones químicas de las sustancias activas de una resina para usos dentales como sigue: $1.52 \mathrm{ml}$ de solución solvente para $1.12 \mathrm{~g}$ de combinación de productos secos en polvo, para preparar un volumen de $0.7525 \mathrm{~cm}^{3}$ de resina, a la que hay que agregar $1 \%$ en volumen de catalizador $\left(0.007525 \mathrm{~cm}^{3}\right)$, para una polimerización total en 3:12 minutos a 20 grados centígrados. ${ }^{11}$ Naturalmente, aun contando con básculas y pipetas de laboratorio, que permitan medir cantidades tan pequeñas, el odontólogo general estará siempre trabajando invariablemente con cantidades aproximadas a las calculadas, tanto como se lo permitan discriminar sus cucharillas, espátulas y jeringas con las que se suele trabajar en campo. En el mejor de los casos usará las cantidades más cercanas a la cifra significativa mejor definida por sus instrumentos. 


\section{Validez y confiabilidad}

Dos conceptos centrales alrededor del problema de la medición los constituyen la validez y la confiabilidad. Ambos están relacionados con la adecuación y propiedad del instrumento, condiciones y métodos de medición al objeto por medir.

La validez es una medida de la efectividad de la medición. La validez responde a la cuestión de si se está midiendo en efecto el objeto de interés. En resumen, la definición de la validez de un instrumento de medición señala el grado en que mide o predice cualquier criterio de interés. Es una medida de la exactitud con que pueden hacerse medidas significativas y adecuadas con él, tal que midan realmente los rasgos que se pretenden medir. A primera vista esta idea puede sonar absurdamente obvia al estudiante, sobre todo en los casos relativos a las ciencias físicas, en que pareciera que los fenómenos que se estudian tienen propiedades inherentes evidentes, sustanciales y directamente reales. ${ }^{6}, 12$ Un examen más cuidadoso, inclusive en un área que parece tan sólida como lo es la Física, revela que esto no es así.

Por ejemplo, conceptos como la "Energía Potencial", la inercia o el "momentum" no son directamente observables, y antes de su reconocimiento como fenómenos "reales" y verdaderos, empezaron siendo constructos hipotéticos con representación como variables en una ecuación, o un sistema de ecuaciones. La "validez" de estos conceptos quedó afirmada en la medida que las observaciones, registros y mediciones por distintos investigadores confirmaron su adecuación para predecirlas en sí mismas o en sus efectos sobre las otras variables. Es decir, estos procedimientos le dieron certidumbre no sólo a los constructos, sino a los métodos de medición. ${ }^{6,13,14}$

La concordancia entre los resultados de las mediciones de observadores independientes bajo condiciones similares, ha permitido, por ejemplo, dar certeza a la relación causal entre la cantidad de azúcares y harinas presentes en la alimentación y la cantidad de cavidades dentarias, en lugar de atribuirlas exclusivamente a disposiciones genéticas, como alguna vez propuso Horowitz. ${ }^{15}$

De lo anterior se desprende inmediatamente la dificultad y la importancia que tiene determinar la validez de un concepto, de los métodos y técnicas y de los instrumentos en áreas de conocimiento con mayor incertidumbre o con más variables, como en las Ciencias Sociales y las Ciencias de la Salud. En estas áreas, en que la presencia de factores individuales introduce diferencias en la medición (formalmente llamadas "Error de muestreo"), hace imprescindible usar métodos estadísticos para establecer la validez. ${ }^{6,8,14,16}$

El otro concepto relacionado con el valor de la medición, no menos importante que la validez, es la confiabilidad. Una analogía útil, presentada por García Cueto, ${ }^{17}$ es concebirla en el mismo sentido que se le confiere en el terreno de la amistad. Un amigo "confiable" es aquel en quien se puede confiar en cada ocasión en que se le necesite, quien se comporta constantemente de la misma manera, que es predecible y, por lo tanto, no lo traiciona a uno. Imagine el lector que tiene una cinta métrica hecha de tela de un tejido muy abierto, y la tarea de medir una mesa. En su primera lectura, registra $1.20 \mathrm{~m}$; en una segunda lectura, $1.18 \mathrm{~m}$, en una tercera, $1.16 \mathrm{~m}$ ¿será que la mesa se ha encogido entre las mediciones? Seguramente no. Al constar la cinta métrica de un tejido abierto, se ha elongado y deformado, quedando las divisiones de un mayor tamaño que el del estándar. Es decir, esta cinta métrica en particular, no es instrumento confiable.

La confiabilidad es un indicador de la consistencia y regularidad de los resultados observados en un proceso de medición.

\section{Tipos de validez}

Como quedó dicho al principio de este apartado, el concepto de validez puede tener diferentes sentidos, dependiendo de los elementos que se utilicen para especificar y determinar las condiciones y propiedades del objeto por medir. Por lo tanto, estas consideraciones dan origen a distintas clasificaciones y especiaciones de la validez, de acuerdo a la utilidad percibida para ciertos propósitos o en cierto ámbito. 


\section{CAPÍTULO I La medición y sus problemas}

\section{Validez de constructo}

Cuando se realiza la medición de un objeto no se mide el objeto, estrictamente hablando. Se miden sus características, sus rasgos, sus propiedades o cualidades, a través de indicadores isomórficos de tales propiedades o características del objeto (e.g. el número de una escala o el color de una tira de papel tornasol). Mientras que algunos indicadores, sobre todo los de naturaleza física, pueden observarse directamente, otros son inferidos a partir de la observación indirecta de indicadores relacionados con tales efectos. Un odontólogo no observa directamente "la" caries: observa la presencia, tamaño, cantidad, densidad, profundidad, coloración, etc. de cavidades producto de la acción del metabolismo de las bacterias. ${ }^{6,12,14}$

Un "constructo hipotético" es una declaración de una variable o cualidades de una variable que se desea medir, a la cual se le atribuyen los efectos que se registran en la medición de los indicadores. ${ }^{6}$ El constructo llamado "magnetismo" se define, se manifiesta y se mide por los siguientes indicadores, entre otros: capacidad para atraer otros cuerpos metálicos de naturaleza férrea; inducir corrientes eléctricas al desplazarse entre o en las cercanías de una bobina de cobre.

Para que la verificación de la existencia de este constructo se lleve a cabo, debe desarrollarse un proceso que dilucide la evidencia en la cual basar la inferencia de que un rasgo real observado efectivamente en cada caso de estudio, tiene un correlato con un valor particular del instrumento usado para medirlo.6, 12 Por ejemplo, si se desarrolla el concepto de "celos de posición social" como una explicación causal de comportamientos destructivos contra los colaboradores, el instrumento que se desarrolle para su detección deberá mostrar valores altos para quienes presenten en la realidad estos comportamientos, valores medios para quienes los presenten en menor cantidad, y valores pequeños o nulos para quienes presenten los comportamientos en muy baja o ninguna proporción.

La validez de un constructo es central particularmente en los contextos teóricos.

Si un investigador declarase que la "percepción sociocultural" del odontólogo es un determinante de la disposición a la consulta y el apego al tratamiento, antes de decidir si es factible medir este rasgo, es imprescindible saber si "existe" objetivamente, en términos de acuerdos o concordancias entre los profesionales sobre su definición, de tal manera que se especifiquen los elementos objetivos observables directamente o mediante un instrumento isomórfico, que lo identifique unívoca e invariablamente, y que lo hagan un concepto útil para predecir la disposición a la consulta y el apego al tratamiento.

\section{Validez Convergente}

La validez convergente de un constructo se deriva de un procedimiento de multimedición. Se aplican simultáneamente varios instrumentos que se supone miden el mismo rasgo con métodos diferentes. Si las medidas son congruentes, es decir, si presentan altos valores en sus correlaciones, se "demuestra" que convergen, i.e. "coinciden" en el rasgo medido. Cuando se persigue el objetivo de desarrollar un nuevo método de detección o de medición de algún factor, es indispensable que éste demuestre validez convergente con los métodos previos. ${ }^{13,17}$

Un ejemplo de validez convergente es la correlación de signos y síntomas en la clínica, con los estudios de gabinete. La presencia de enrojecimiento gingival, inflamación, presencia de aftas o pústulas con líquido seroso, sensibilidad y dolor, son indicadores de una infección, lo mismo que los patógenos que podrían hallarse en un estudio microscópico del líquido de las pústulas o con el incremento en la cuenta de linfocitos en la sangre.

Validez Divergente (discriminativa).

La validez divergente también se valora sobre un proceso de multimedición, pero en este caso, se aplican instrumentos que con el mismo procedimiento miden rasgos o propiedades diferentes. Por lo tanto, no se espera que los valores de estos otros instrumentos correlacionen coherentemente con los valores de nuestro instrumento, sino más bien, que no correlacionen o lo hagan en muy baja medida. Es decir, se espera que se aparten entre sí, que sean independientes uno de otro, que sean "divergentes" respecto del rasgo de interés. Ello nos permite, entonces, diferenciar o "discriminar" los instrumentos en función de que no miden lo mismo, y que el instrumento de interés tiene entonces un "dominio" de valores sobre el rasgo o características de interés y no se ve interferido por los otros instrumentos o por los rasgos que estos miden. ${ }^{13,}{ }^{17}$ Los estudios de gabinete basados en pruebas de 


\section{Confiabilidad en la medición de caries dental}

reactivos suelen probarse bajo este tipo de validez, en que ciertas reacciones (por ejemplo, cambio de coloración) ocurren en presencia de un patógeno, pero no de otro. Quizás entre las más ilustrativas se cuenten las reacciones específicas cuando se presume envenenamiento por metales pesados, a fin de poder administrar un quelante adecuado al metal en cuestión.

\section{Validez Factorial}

Esta forma de valoración de la validez hace referencia a un procedimiento matemático llamado precisamente "Análisis Factorial". El análisis factorial tiene como objetivo explicar numéricamente las interrelaciones entre los rasgos con un número de variables más pequeño que con el que se comienza. A cada una de estas nuevas variables se le denomina "factor" y se considera compuesta por los elementos que miden el mismo elemento, dado que sus medidas se interrelacionan más cercanamente. ${ }^{6,13,17}$

Otra forma de decirlo es que un factor es una variable hipotética derivada matemáticamente cuyas puntuaciones influyen en una o varias variables registradas. Esta forma de definir la validez puede tomar formas en el sentido de "descubrir" estas agrupaciones de rasgos o de "confirmar" relaciones hipotetizadas u observadas previamente. ${ }^{17}$ No son pocos los estudios que en el último cuarto de siglo, particularmente, han identificado influencias de muy diverso tenor en el cuidado dentario, por ejemplo. Haciendo uso de estas técnicas, Moreno ${ }^{18}$ identificó las siguientes familias de condiciones que tienen alguna contribución en el cuidado dentario de adolescentes de 11 a 14 años: La condición de salud general (evaluando la limitación funcional, el dolor físico, el malestar psicológico, la incapacidad psicológica, la incapacidad física, incapacidad social y minusvalía), la condición Sociodemográfica (donde evaluó sexo, edad, nivel educativo, estrato socioeconómico y la autoercepción de la salud bucal (salud autopercibida, estado bucal autopercibido, satisfacción del estado bucal y la percepción del problemas bucales).

\section{VALIDEZ RELATIVA A CRITERIO}

Esta definición de validez opera en condiciones "a posteriori". Eventualmente, por ejemplo, en la inferencia de la valoración de la efectividad de una estrategia preventiva, el resultado no puede ser directamente medido por el instrumento de medición, dado que existe una proyección en el tiempo. En esta situación se trata de predecir el rendimiento futuro a partir de las puntuaciones presentes en la práctica de la estrategia de prevención. ${ }^{14,}$ 17, 19, 20

Las relaciones entre los puntajes del grupo se usan como predictores de otra variable (ajena -en realidad- externa al instrumento) con la cual se relaciona hipotéticamente: el "criterio". Este es cualquier rasgo o característica que se desee predecir a partir de las calificaciones en el instrumento. ${ }^{17}$

Los ejemplos regulares para calificar este tipo de validez son las calificaciones de los exámenes SAT, usados en los Estados Unidos de América, como predictores del éxito y nivel educativo probable por alcanzar, por un lado, y las tasas de presencia de una enfermedad a partir del conteo de anticuerpos específicos después de un intervalo de la administración de una o más dosis de vacuna.

Los criterios de calificación de la Validez por Criterio deben considerar, casi necesariamente, dos dimensiones que aseguren la utilidad y eficiencia de la predicción. El primer elemento, denominado Sensibilidad, es una medida de la capacidad de los instrumentos para detectar: A) la mínima cantidad del indicador presente bajo condiciones de observación dadas, y B) la mínima cantidad de cambio necesaria en el indicador para producir un efecto definido en el valor de la variable de predicción. El segundo elemento se denomina Especificidad, y se refiere a la capacidad de la variable criterio, para responder en un dominio específico de categorías de componentes en relación a los cambios del indicador en una dimensión. Por ejemplo, las características étnicas son buenos criterios de validez en relación a ciertos rasgos de la anatomía dental, por lo que se usan en la Antropología Forense para determinar el grupo étnico.

\section{Validez predictiva}

El término se usa precisamente para describir el caso en el que los valores registrados en una medición sirvan para pronosticar la variable criterio, en los mismos sujetos, después de un intervalo razonable. Usualmente se emplea un índice de correlación entre los valores de la(s) variable(s) de prueba tomadas antes de la introducción de la 


\section{CAPÍTULO I La medición y sus problemas}

variable independiente, y los valores de la(s) variable(s) criterio, después de transcurrido el lapso. Las pruebas del nivel de protección de las vacunas en el tiempo son un ejemplo práctico de la necesidad de la aplicación de la validez predictiva. ${ }^{6,12,17}$ También la fluoración del agua y la incidencia de caries en los años siguientes son un ejemplo de este tipo de validez.

\section{Validez concurrente}

Este tipo de valoración sobre la efectividad de una medición se estima cuando por razones del diseño del estudio o de las condiciones en que se lleva a cabo, o por la disposición de la muestra, etc. Se deben obtener las medidas tanto del criterio como de las puntuaciones del instrumento de manera simultánea o en tiempos inmediatamente contiguos. Este es el tipo de validez del que se habla cuando se estima la validez de un procedimiento comparando los resultados contra los de otro instrumento en el mismo sujeto o en sujetos equivalentes, que concurren simultáneamente o con un intervalo de tiempo despreciable entre ambas mediciones. ${ }^{6}{ }^{17}$ Por ejemplo, es el tipo de validez con el que queda establecida la utilidad y ventajas de los medidores portátiles de glucosa en sangre actuales, versus los métodos de detección de glucosa en orina que se usaban hace una veintena de años, que involucraban el manejo de un ácido y papel tornasol para su determinación en rangos de valores.

\section{Validez retrospectiva}

Una forma particular de la validez ocurre cuando se relacionan los puntajes de un procedimiento de medición con un criterio que fuera medido con anterioridad, incluso años antes. Esta es una situación que es común en las Ciencias de la Salud y del Comportamiento. Resulta obvio que en este caso el fin no está relacionado con la predicción (puesto que se observan los valores medidos en un momento presente), sino que se trata de dilucidar qué factor o factores del pasado pueden estar relacionados con un resultado actual, aquí y ahora. ${ }^{17} \mathrm{El}$ valor de las conclusiones de los estudios epidemiológicos de los factores de riesgo queda determinado por este tipo de validez. Las preguntas clínicas que se ocupan de preguntar a los pacientes que actualmente presentan Enfisema pulmonar sobre sus hábitos de tabaquismo, su ambiente de trabajo, su ocupación y relación con ciertas sustancias a lo largo de su vida pasada tienen el propósito de definir el valor de cada uno de estos elementos como factor causal o contribuyente a la presencia actual de la enfermedad, su pronóstico o diagnóstico por síntomas y signos tempranos.

\section{VALIDEZ DE CONTENIDO}

¿Se ha encontrado el lector en la situación de responder a cuestiones que piensa que tienen poca o ninguna relación con su consulta o padecimiento? ¿o preguntas de un examen que usted creyó que no se referían a los contenidos explícitos de su temario? Si es así, usted ha puesto en entredicho la validez de contenido de las cuestiones o del examen.

En efecto, esta valoración de la efectividad de un método, de un procedimiento o de un instrumento expresa la medida en que los componentes del mismo son una muestra del campo de interés del mismo. ${ }^{6,12,17}$ La validez de contenido se basa en cuidadosos análisis racionales de las diferentes partes del conjunto del instrumento o procedimiento (su "contenido"), examinando si, y en su caso, cómo, se han muestreado todos los aspectos relevantes característicos de la variable que se quiere someter a medida.

\section{Validez aparente}

Una forma particular de la Validez de contenido se refiere al grado de acuerdos existentes en que los componentes en particular y el procedimiento en general, miden efectivamente el elemento o rasgo para el cual se destinó el procedimiento o prueba. Por ejemplo, si un administrador del método, un operario y uno de los sujetos evaluados concordaran en que el procedimiento o prueba miden de hecho cierta variable, esto conformaría el nivel de Validez aparente del procedimiento, método o prueba. ${ }^{6,12}$

Dos tipos de validez de contenido, que no se describirán aquí por ser de interés casi exclusivo de los instrumentos tipo examen escolar, y por consiguiente, de interés institucional o pedagógico, lo constituyen la validez muestral referida a la consideración de la cantidad de elementos necesarios presentes (i.e. reactivos de un examen) sirven efectivamente para valorar suficientemente, por representatividad, a la mayor cantidad de elementos de la variable 


\section{Confiabilidad en la medición de caries dental}

o características que se pretenden medir y la validez curricular (que se contextualiza con respecto a un plan, un programa o un sistema de estudios).

\section{CONFIABILIDAD}

Como se estableció párrafos atrás, el concepto esencial de la confiabilidad es la estabilidad o constancia en la medida. Un instrumento o un método es confiable si cada vez que se emplea arroja los mismos resultados, es decir, si es consistente. Estadísticamente el concepto de confiabilidad se presenta como la correlación de las puntuaciones de un instrumento consigo mismas. ${ }^{6,13}$

Puesto que la confiabilidad es un requisito sustancial al desarrollo, propuesta y utilización de un instrumento, es indispensable que el investigador se preocupe por lograr (al menos por conocer) un alto grado de confiabilidad del/ los instrumento/s que emplea. Esta es una prioridad para el desarrollador de un instrumento o un procedimiento que aspira a convertirlo en una referencia global. En general, hay 4 métodos generales para valorar la confiabilidad: 1. El método de "test-retest" 2. El método de las Formas paralelas 3. El método de división en mitades. 4. Método de los observadores independientes. ${ }^{6,} 17$

\section{Confiabilidad por el método de "test-retest"}

Este es un procedimiento aplicable a variables que no sufrirán afectaciones por una variable independiente, es decir, que no estén sujetas a un procedimiento de intervención. No es apto para valorar rasgos que sufran efectos por factores como el aprendizaje o la maduración.

El procedimiento consiste en aplicar el instrumento a un grupo normativo en dos ocasiones diferentes y obtener el coeficiente de correlación entre ambos momentos. Una limitación práctica de este método lo constituye el hecho de que no es fácil tener a disposición a todos los participantes para una segunda aplicación, sobre todo tras periodos largos. ${ }^{17}$ Un ejemplo de aplicación práctica de la valoración de la confiabilidad de un procedimiento se encuentra en el trabajo de Córdova al valorar en ocasiones sucesivas el mantenimiento del aprendizaje de técnicas correctas de cepillado y la incidencia de diversos síntomas en personas con discapacidades intelectuales con concomitantes físicas. ${ }^{21}$

\section{Confiabilidad por el método de las formas paralelas}

En este caso se aplican 2 instrumentos o procedimientos equivalentes entre sí a un grupo normativo y se obtiene la correlación entre los puntajes de ambos. Este procedimiento no se ve influenciado por factores como el aprendizaje o la maduración o algún cambio del rasgo por el simple transcurso del tiempo. Sin embargo, introduce un problema mayor respecto a lo que significa "equivalencia". Con demasiada frecuencia existirán desacuerdos respecto de si en ambos casos se miden todos los factores del rasgo de la misma manera. ${ }^{6,12}$

\section{Confiabilidad por el método de división en mitades}

Si un instrumento o método está diseñado de manera efectiva para medir un rasgo particular a lo largo de todos sus componentes (e.g. preguntas), es posible aplicarlo una única ocasión a un grupo normativo, dividirlo aleatoriamente en dos mitades y obtener el coeficiente de correlación entre ambas mitades. Este procedimiento no se puede utilizar en instrumentos que están diseñados de manera acumulativa de manera que sus elementos miden eventualmente grados del rasgo; esto es, el instrumento o procedimiento bajo prueba se supone relativamente uniforme en su composición respecto a la variable que mide. Este procedimiento se suele aplicar en una gran cantidad de pruebas de carácter académico.

\section{Confiabilidad mediante observadores independientes}

Este es un procedimiento que valora el grado de acuerdo que hay entre observadores independientes que registran los resultados de un instrumento o procedimiento en el mismo momento o en aplicaciones diferentes, ya sea en tiempo o en ubicación. ${ }^{6}{ }^{17}$ Cuando los indicadores del procedimiento se refieren a variables no accesibles directamente o que constituyen un rasgo "emergente", o cuando la medición no incluye una escala objetiva, se suele emplear esta forma de valor la confiabilidad. Este método requiere un entrenamiento previo de los observadores, a fin de que haya un nivel inicial de concordancia respecto a los elementos que constituyen la variable por observar. ${ }^{6}$ Este procedimiento no es una medida directa de la confiabilidad del instrumento, sino de los observadores del 


\section{CAPÍTULO I La medición y sus problemas}

mismo. Si el rasgo es un constructo hipotético no observable o cuantificable directamente ${ }^{12}$, solamente se estará confiabilizando la subjetividad de los observadores. Un ejemplo extremo lo constituye el caso siguiente: Suponga que sus observadores concuerdan en un $90 \%$ que un rasgo particular de un dibujo revela rasgos inconscientes de desapego, frialdad y alejamiento emocional. Lo que usted tiene es la medida en que estos observadores creen que este rasgo está relacionado con ciertas emociones. No da ninguna medida de la "verdad" de esta asociación.

La confiabilidad entre observadores independientes tiene otras utilidades, como el establecimiento de elementos de sesgo y los correspondientes remedios, la detección de diferencias individuales (por ejemplo, teoría de detección de señales). Anecdóticamente, se remonta a la llamada "ecuación personal", que remite al episodio protagonizado en 1794 por el astrónomo Nevil Maskelyne, quinto astrónomo real de Inglaterra, y su asistente Kinnebroock, quienes trabajaban midiendo el tránsito de las estrellas a través del telescopio del observatorio de Greenwich. Siempre tenían diferencias de 0.1 segundo en sus observaciones. Cuando Kinnebrook intentó corregir sus diferencias, éstas empeoraron, lo que condujo a su despido. Posteriormente, el estudio del caso condujo a los psicólogos a establecer procedimientos de medición de tiempos de respuestas, latencia, y otros factores individuales, en sus estudios de procesos psicológicos básicos, y a considerar la importancia de estos factores psicológicos en otras ciencias, como la Física y la Química, al introducir variables personales del observador. ${ }^{22}$ 


\section{Bibliografia}

1. Bravo S. La ciencia, su método y su historia. México: UNAM; 1991.

2. Temple-Bell E. Historia de las Matemáticas. México: Fondo de Cultura Económica; 1985.

3. González Urbaneja PM. La historia de las matemáticas como recurso didáctico e instrumento para enriquecer culturalmente su enseñanza. SUMA [en línea]. 2004 febrero; [citado 15 julio 2015];45:[17-28]. Disponible en: http://www.fespm.es/sites/revistasuma.es/IMG/pdf/45/017-028.pdf.

4. $\quad$ Pickover C. Las computadoras y la imaginación. España: Almuzara; 1992.

5. Wussing H. Lecciones de Historia dSe las matemáticas. Barcelona: Siglo XXI; 1998.

6. Kerlinger FN, Lee HN. Investigación del comportamiento. México: McGraw-Hill; 2002.

7. Villena L. El metro. Investigación y ciencia. 1984;8(88):42-43.

8. Plutchik R. Fundamentos de la investigación científica. México: Harla;1975.

9. Kondo S, Yee A. 10 Trillion Digits of Pi: A case of summming Hypergeometric Series to high precicion on Multicore Systems. IDEALS [en línea].2011; [citado 24 septiembre 2015]; Disponible en: http://hdl.handle. net/2142/28348

10. Geoghegan T. Is trillion the new billion?. BBC News [en línea]. 2011 octubre; [citado 16 febrero 2016]; Disponible en: http://www.bbc.com/news/magazine-15478580

11. Rodríguez G, Douglas R, Pereira S, Natalie A. Evolución y tendencias actuales en resinas compuestas. Acta Odontológica Venezolana. 2008;43(3);381-392.

12. Hernández-Sampieri R, Fernández-Collado C, Baptista-Lucio M. Metodología de la Investigación. 5a. ed. Perú: McGraw-Hill; 2010.

13. Álvarez-Cáceres R. El Método Científico en las Ciencias de la Salud. Madrid: Díaz de Santos; 1996.

14. Polit DF, Hungler BP. Investigacion científica en ciencias de la salud: principios y métodos. México: McGrawHill; 2000.

15. Horowitz SL. Clinical aspects of genetic research in dentistry. J Dent Res. 1963; 42 Supl 6:S1330-1343.

16. Álvarez-Cáceres R. Estadística aplicada a las Ciencias de la Salud. Madrid: Díaz de Santos; 2007.

17. García-Cueto C. Introducción a la psicometría. Madrid: Siglo XXI; 1993.

18. Moreno RX, Vera AC, Cartes-Velásquez R. Impacto de la salud bucal en la calidad de vida de escolares de 11 a 14 años. Rev Clín Periodoncia Implantol Rehabil Oral. 2014;7(3):142-148.

19. Argimon-Pallas JM. Métodos de investigación: clínica y epidemiológica. Madrid: Harcourt; 2000.

20. Ramon-Torrell MJ, Cuenca-Sala E, Serra-Majem L, Subira-Pifarre C. Métodos de investigación en odontología: bases científicas y aplicaciones del diseño de la investigación clínica en las enfermedades dentales. Barcelona: Masson; 2000.

21. Córdova-Lagunes, M. Estudio del impacto de la enseñanza de técnicas de cepillado en personas con discapacidades intelectuales con distintos problemas dentogingivales. Informe de Profesor de T. C. al Consejo Técnico, Universidad Nacional Autónoma de México, Facultad de Odontología, México; 2001.

22. Arias-Gallegos W. La educación personal. XING [en línea]. 2010 abril; [citado 29 noviembre 2015]; Disponible en: https://www.xing.com: https://www.xing.com/communities/posts/la-ecuaci-n-personal-1003310648

\section{Consultar el video de apoyo del Capítulo 1: "La medición y sus problemas", en la pestaña del Módulo Estomatología Social II http://www.zaragoza.unam.mx/herramientas-para-el-aprendizaje/}




\title{
CAPít́tulo 2
}

\section{Confiabilidad en la medición epidemiológica de caries dental}

\author{
REMEDIOS GUADALUPE VALDEZ PENAGOS
}

\section{La medición de caries dental}

El desarrollo de la práctica profesional del estomatólogo depende del conocimiento y acercamiento que tenga con el método científico, ya que éste se convierte en una herramienta necesaria para comprender las condiciones en que se desarrolla el proceso salud-enfermedad; de acuerdo con Tamayo, este método se caracteriza por ser tentativo, verificable, de razonamiento riguroso y observación empírica. ${ }^{1}$

El método científico es el más utilizado al penetrar en el conocimiento de las ciencias de la salud ya que rechaza o elimina todo procedimiento que busque manipular la realidad en una forma caprichosa, tratando de imponer prejuicios, creencias o deseos que no se ajusten a una observación objetiva de la realidad y de los problemas que se investigan. ${ }^{1}$

La caries dental representa uno de los principales objetos de estudio en el campo de la estomatología debido a que es la alteración dental de mayor frecuencia, en México, el Sistema de Vigilancia Epidemiológica de Patologías Bucales (SIVEPAB) observó una prevalencia de caries de 96.4\% con una media de 13.41 dientes afectados en los usuarios del servicio de salud durante el año 2009, así mismo, a través la Encuesta Nacional de Caries Dental se observó que la población de 12 años presentan una prevalencia de caries dental de $58 \%$ con una media de 5.31 dientes afectados en habitantes del Distrito Federal, de tal manera que ha mayor edad incrementa la magnitud de esta afección..$^{2,3}$

Cabe señalar que variables geográficas y socioeconómicas como: el nivel de estudios, la ocupación y el ingreso económico influyen en la presencia de esta alteración, agravando la problemática de salud de la población lo cual repercute biológica y psicológicamente en el individuo. ${ }^{4-9}$

De tal manera que la investigación epidemiológica toma relevancia en el abordaje de esta alteración puesto que facilita la comprensión de su desarrollo en diversos grupos sociales, por lo tanto, sabemos que la experiencia de caries presente en cada individuo y colectivamente es el reflejo de la interacción de la biología humana con su entorno en un momento histórico definido. ${ }^{5,10}$

Así mismo, podemos observar como la identificación de los perfiles de caries permiten planear y evaluar programas de salud y políticas públicas, como la remineralización de dientes con caries incipientes a nivel individual o la fluoración del agua de forma colectiva. ${ }^{11-13}$

De ahí que es menester llevar a cabo la medición referente a la experiencia de caries buscando alcanzar validez y confiabilidad en los resultados obtenidos, con la finalidad de orientara las acciones pertinentes con base en evidencia de calidad. 


\section{Proceso de estandarización}

Como parte de la fase de planeación de toda investigación es deseable corroborar que se esta midiendo lo que en realidad se quiere medir, para ello es necesario la calibración y estandarización.

La calibración se dirige a los instrumentos, y consiste en ajustarlos con la mayor exactitud posible para que estos emitan la medida con los valores de la magnitud que han de medir. Tal es el caso de las básculas 0 esfignomanómetros por mencionar algunos. ${ }^{14}$

En el caso de utilizar instrumental como son: los espejos bucales o la sonda periodontal utilizada en el Índice Periodontal Comunitario (IPC), éstos deben contar con las mismas características (tamaño, modelo y marca) para garantizar la homogeneidad del instrumento de medición.

Es importante subrayar que el uso del explorador en la medición de caries no es recomendable debido a su potencial para fracturar el esmalte intacto, ${ }^{15}$ y por lo tanto la sonda IPC recomendada por la OMS (Figura 1) será el instrumento de elección para la medición de caries tanto en el CPOD-cpod, CPOS-cpos, el índice para evaluar el estado de la dentición y tratamiento necesario e ICDAS.

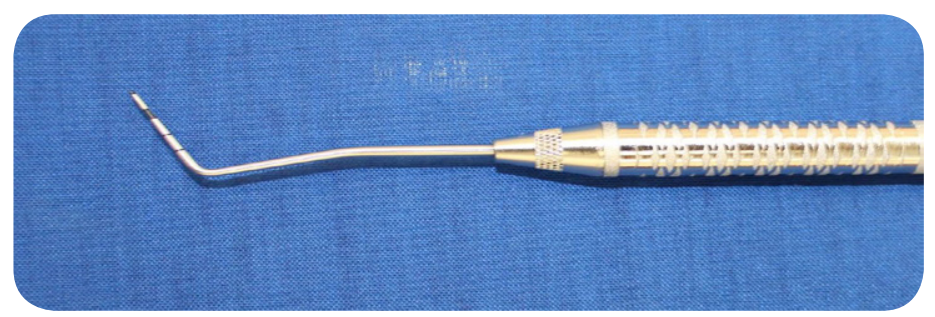

Figura 1. Sonda periodontal recomendada por la OMS. Su punta redonda de $0.5 \mathrm{~mm}$ se utiliza para detectar lesiones de caries cavitada.

La estandarización se orienta a los recursos humanos y en este caso consiste en establecer un acuerdo acerca de los criterios de diagnóstico utilizados en la medición de las alteraciones bucales, este ejercicio se llevará a cabo aún cuando se cuente con recursos humanos formados en el campo de la estomatología, ya que ésta condición no es suficiente para garantizar que los datos obtenidos referentes a la medición de lesiones de caries son validas y confiables. Sobre todo cuando la recolección de datos se lleva a cabo por más de un examinador.

La estandarización tiene por objetivo:

- Asegurar un diagnóstico confiable al registrar los criterios de identificación de las distintas enfermedades y afecciones a observar.

- Minimizar la variabilidad de criterio diagnóstico entre los observadores.

- Asegurar que cada examinador realiza a lo largo del estudio, un examen y registro consistente. ${ }^{16}$

Cuando el registro se lleva cabo, solo por un examinador, se realiza un ejercicio de estandarización para alcanzar la concordancia intraobservador la cual se refiere al grado de consistencia que tiene éste consigo mismo. Su evaluación requiere que un mismo examinador valore en dos ocasiones a los mismos sujetos. ${ }^{17}$

Si el registro se llevará a cabo por dos o más observadores primero se alcanzará la concordancia intraexaminador y posteriormente la concordancia interexaminador. 


\section{CAPÍTULO 2 Confiabilidad en la medición epidemiológica de caries dental}

La concordancia entre dos examinadores requiere que ambos valoren a un mismo grupo de personas de forma independiente y sus registros sean consistentes entre ellos. ${ }^{17,18}$

En algunas ocasiones se requiere de tres o más examinadores, en estos casos se puede tomar de referencia a un examinador estandarizado adecuadamente o capacitador experimentado como "explorador patrón" o "estándar de oro" para evaluar las observaciones del resto de los examinadores y no entre ellos. ${ }^{16}$

El ejercicio de estandarización se llevará a cabo recordando que:

a) Se realiza en población con características similares a la muestra del estudio en cuanto a: edad, sexo, variabilidad de la alteración o condición socioeconómica.

b) Desarrollarse en espacios físicos similares como pueden ser: sillón dental, mesa de exploración, salón o patio escolar.

c) Bajo las mismas condiciones: con los mismos formatos, instrumentos y tipo de iluminación (ya sea lámpara de luz blanca o luz natural).

Se sugiere que durante la estandarización se formen equipos de examinación integrados por un examinador y un anotador, Rubio propone llevar a cabo dos fases para la estandarización: ${ }^{16}$

\section{Primera fase: teórico-práctica}

Sesión teórica

Con ayuda de la literatura científica, fotografías, videos o aplicaciones electrónicas se estudiará el protocolo de recolección, modo de llenar la ficha, sistematización para realizar la exploración bucal y utilización del instrumental necesario.

Conocer el índice de medición es indispensable para lograr datos válidos y confiables, por un lado el examinador aplicará las condiciones, códigos y criterios del índice y por otro lado el anotador identificará la aplicación de los códigos utilizados.

- Condición. Es el estado o situación en que se halla el objeto a medir y del cual se pueden establecer categorías del objeto de medición; por ejemplo: cariado, perdido y obturado. En este sentido, antes de iniciar la recolección de datos el examinador deberá capacitarse en las categorías correspondientes al objeto de estudio y distinguir entre otras patologías, por ejemplo en la medición de caries diferenciar de manchas, hipoplasia y fluorosis.

- Código. Son signos otorgados a cada una de las condiciones de acuerdo al índice utilizado, éstos pueden ser numéricos o alfabéticos. Por ejemplo, en el índice CPOD-cpod la experiencia de caries se codifica a través de números, tal es el caso de la condición de cariado que se identifica con los números 1 para dientes permanentes y 6 para dientes temporales.

Por otro lado, el índice para evaluar el estado de la dentición y tratamiento necesario utiliza el número 1 para señalar la presencia de caries en dentición permanente y la letra B para hacerlo en dentición temporal.

- Criterio. Es la facultad del examinador de distinguir entre una condición y otra señalando la diferencia que hay entre ellas. Por ejemplo, en el CPO-cpo, el criterio para definir que un diente se encuentra cariado es la presencia de esmalte socavado, suelo o pared con reblandecimiento, así como la presencia de obturaciones temporales.

Puede ocurrir que aún después de la estandarización se presenten casos extraordinarios en los que el examinador no tenga certeza de la condición a diagnosticar, en estos casos se recomiendan registrar el menor grado de enfermedad. 


\section{Confiabilidad en la medición de caries dental}

\section{Sesión práctica}

Como un complemento de la sesión teórica, se buscará que todos los equipos de examinación revisen a seis individuos de cada uno de los grupos de edad incluidos en el examen. Durante esta sesión se discutirán las discrepancias en los hallazgos, en los criterios diagnósticos, utilizados de códigos, errores de registro en la ficha, entre otros que puedan surgir, con la finalidad de disminuir la variabilidad en las mediciones y por lo tanto alcanzar el mayor grado de acuerdo posible.

\section{Segunda fase: práctica}

Esta segunda fase propuesta por Rubio, corresponde al ejercicio de estandarización descrito por la OMS y corresponde a la comprobación de la confiabilidad del registro que tengan los observadores. ${ }^{16,19}$

\section{Estandarización intraexaminador}

Cuando sólo interviene un examinador y no se dispone de un examinador patrón, el examinador debe practicar primero el examen en un grupo de 10 sujetos que serán seleccionados que presenten las diferentes condiciones de caries según el indicador en el cual se este llevando a cabo la estandarización.

Posteriormente, el examinador determinará la confiabilidad con la que aplica los criterios de diagnóstico observando dos veces a un grupo de 20 individuos aproximadamente, entre cada una de las observaciones deberá existir un lapso de tiempo suficientemente corto para que la variable no cambie y suficientemente largo para que las personas no recuerden sus mediciones. La OMS recomienda que por lo menos exista un lapso de 30 minutos entre cada medición. ${ }^{19}$

\section{Estandarización interexaminador}

Cuando no se dispone de un instructor experimentado, y la observación se llevará a cabo por diferentes examinadores, cada examinador debe practicar la observación en un grupo de 10 sujetos.

Después cada examinador deberá observar independientemente un mismo grupo de por lo menos 20 sujetos y comparar sus resultados. Si los resultados tienen discrepancias importantes debe citarse de nuevo a los individuos para que los examinadores revisen las diferencias de los diagnósticos y las resuelvan en una retroalimentación de grupo.

Es importante destacar que la habilidad que tengan los profesionistas para estandarizarse con otros en la aplicación de un indicador epidemiológico, no es una medida de la aptitud clínica que puedan tener; por lo tanto, en caso de que alguno de los examinadores obtenga resultados notablemente distintos de los obtenidos por la mayoría y aun después de intentar corregir su forma de evaluar persistiera la discrepancia, debe ser excluido del equipo de examinadores. ${ }^{19}$

El grado de la concordancia intraexaminador e interexaminador se calcula a través del coeficiente de kappa, este cálculo se propuso originalmente para clasificar variables dicotómicas, en caso de que la variable a medir sea politómica una alternativa es calcular el coeficiente de kappa ponderado. ${ }^{17}$

El valor máximo del coeficiente de kappa es 1, que se produce cuando existe un acuerdo total entre ambos examinadores. El valor mínimo no es cero, sino que puede ser negativo. Si el valor es negativo esto significa que el porcentaje de datos observados es menor que el esperado por azar; vale la pena tomar en cuenta que entre más categorías tenga la variable, más disminuye la probabilidad de acuerdo. ${ }^{17,20}$

Al realizar la estandarización de examinadores, la OMS sugiere que se alcance un coeficiente de kappa $>85 \%{ }^{19}$

Sin embargo, los criterios establecidos por Landis y $\mathrm{Koch}^{21}$ consideran que una concordancia $\geq 0.81$ es casi perfecta (Cuadro 1), por lo que en el gremio científico es aceptable este valor como mínimo. 


\section{CAPÍTULO 2 Confiabilidad en la medición epidemiológica de caries dental}

Cuadro 1. Criterios de concordancia según Landis y Koch.

\begin{tabular}{|c|c|}
\hline Valor estadístico de kappa & Grado de concordancia \\
\hline$<0.00$ & Pobre \\
\hline $0.00-0.20$ & Leve \\
\hline $0.21-0.40$ & Mediana \\
\hline $0.41-0.60$ & Moderada \\
\hline $0.61-0.80$ & Sustancial \\
\hline $0.81-1.00$ & Casi perfecta \\
\hline Fuente: Landis y Koch & \\
\hline
\end{tabular}

\section{Cálculo del coeficiente de kappa. ${ }^{20}$}

Para calcular el grado de confiabilidad se utiliza una tabla de contingencia, el número de columnas y filas depende de las categorías de la variable que mida indicador, al medir la presencia y ausencia de caries se utiliza una tabla de contingencia de $2 \times 2$, como su nombre lo indica, esta tabla tiene dos columnas (verticales) y dos filas (horizontales). Cada una de las columnas y filas corresponde a una de las categorías de la variable que se esta evaluando, en este caso: presencia de caries $(+)$ y ausencia de caries o diente sano (-).

En el margen de las columnas se anota la sumatoria de la frecuencia registrada en la primera observación dicha cifra la llamaremos Total de Columna (TC), tanto de los datos positivos a caries como de los negativos, y en el margen de las filas se anotará la sumatoria de las frecuencias de los registros de los dientes con caries o sanos obtenidos en la segunda observación, a estas cifras las llamaremos Total de filas (TF), recuerde que ambas mediciones se realizan en los mismos individuos (Figura 2).

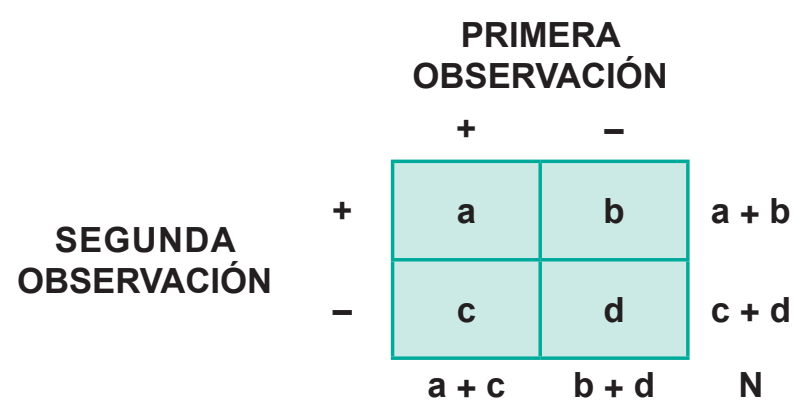

Figura 2. Tabla de contingencia $2 \times 2$.

La tabla de contingencia de 2x2 (Figura 2) se conforma por cuatro celdas (a, b, c, d), en las cuales se anotan las concordancias y discordancias de la siguiente manera:

$a=$ Concordancia de positivos entre observadores.

$b=$ Discordancia (donde en la primera observación se registró negativo y en la segunda observación se registró positivo). 


\section{Confiabilidad en la medición de caries dental}

$c=$ Discordancia (donde en la primera observación se registró positivo y en la segunda observación se registró negativo).

$d=$ Concordancia de negativos entre observaciones.

$\mathrm{N}=$ Total de observaciones.

La fórmula de kappa ${ }^{20}$ es la siguiente:

$$
k=\frac{P o-P e}{1-P e}
$$

En donde la Proporción de concordancias observadas (Po) se obtiene con la siguiente fórmula:

$$
\mathrm{Po}=\frac{\mathrm{N}-\text { discordancias }}{\mathrm{N}}
$$

Y la Proporción de concordancia esperada $(\mathrm{Pe})$ producida por el azar se calcula sumando los productos de la multiplicación del Total de Fila (TF) dividido entre el total de observaciones, por el Total de Columna (TC) dividido entre el total de observaciones de cada una de las categorías de la variable estudiada, con base en la siguiente fórmula:

$$
\mathrm{Pe}=\Sigma[\mathrm{TF} / \mathrm{N}][\mathrm{TC} / \mathrm{N}]
$$

\section{Ejemplo 1:}

Tenemos el caso de un observador que requiere valorar el grado de concordancia de sus mediciones de caries; por lo tanto, de acuerdo a lo sugerido por la OMS observó a 20 individuos, acumulando así un total de 580 dientes. Durante la primera medición registró 400 dientes con caries y 180 sanos.

En la segunda medición registró 395 dientes con caries y 185 sanos.

Al contrastar las mediciones, observó 380 concordancias de caries y 165 de dientes sanos.

Con los datos obtenidos es posible llenar las celdas de la tabla de contingencia (Figura 3), según las observaciones, de la siguiente manera:

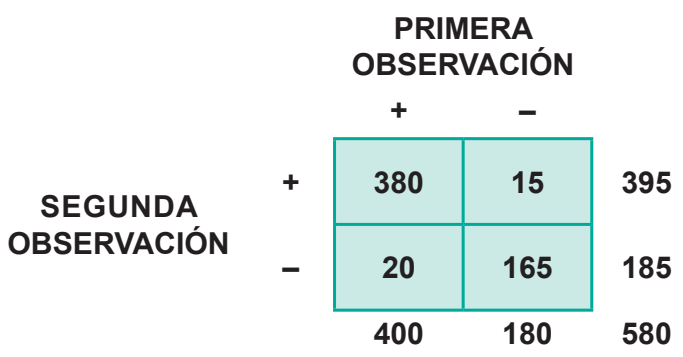

Figura 3. Tabla de contingencia del ejemplo 1.

El total de observaciones registradas se anotan en el margen de las filas y las columnas; la sumatoria de los totales tanto vertical como horizontalmente deben sumar el total de observaciones.

Las celdas a y d corresponden a las concordancias: positivas (celda a) y negativas (celda d); la frecuencia de las celdas b y c se obtienen restando al total correspondiente la concordancia observada. 


\section{CAPÍTULO 2 Confiabilidad en la medición epidemiológica de caries dental}

Una vez terminada la tabla de contingencia, se sustituyen los datos en la fórmula de Po, de la siguiente manera:

$$
\begin{gathered}
\mathrm{Po}=\frac{\mathrm{N}-\text { discordancias }}{\mathrm{N}} \\
\mathrm{Po}=\frac{580-35}{580}=\frac{545}{580}=\mathbf{0 . 9 3}
\end{gathered}
$$

Posteriormente, se calcula Pe con base en la siguiente fórmula:

$$
\mathrm{Pe}=\sum[\mathrm{TF} / \mathrm{N}][\mathrm{TC} / \mathrm{N}]
$$

\begin{tabular}{|c|c|c|c|c|c|}
\hline \multirow{6}{*}{ ¿zo } & \multicolumn{5}{|c|}{ PRIMERA OBSERVACIÓN } \\
\hline & Códigos & + & - & $\begin{array}{c}\text { Total de } \\
\text { Fila/N }\end{array}$ & $\begin{array}{l}\text { Cálculo } \\
\text { del TF/N }\end{array}$ \\
\hline & + & 380 & 15 & $395 / 580$ & 0.68 \\
\hline & - & 20 & 165 & $185 / 580$ & 0.31 \\
\hline & $\begin{array}{l}\text { Total de } \\
\text { Columna }\end{array}$ & $400 / 580$ & $180 / 580$ & $N=580$ & \\
\hline & $\begin{array}{l}\text { Cálculo } \\
\text { de TC/N }\end{array}$ & 0.68 & 0.31 & & \\
\hline
\end{tabular}

Para ello se obtiene primero el Total de Fila (TF) dividido entre el total de observaciones (N) y el Total de Columna (TC) dividido entre el total de observaciones (N) como lo muestra la Figura 4.

Figura 4. Cálculo del Total de Fila y Total de Columna.

Posteriormente se sustituye en la fórmula para obtener el resultado de Pe:

$$
\begin{array}{ll}
\mathrm{Pe}= & \sum[\mathrm{TF} / \mathrm{N}][\mathrm{TC} / \mathrm{N}] \\
\mathrm{Pe}= & {[395 / 580][400 / 580]+[185 / 580][180 / 580]} \\
\mathrm{Pe}= & {[0.68][0.68]+[0.31][0.31]} \\
\mathrm{Pe}= & 0.46+0.09 \\
\mathrm{Pe}=\mathbf{0 . 5 5} &
\end{array}
$$

Finalmente se sustituye en la fórmula de kappa:

$$
\begin{gathered}
k=\frac{\mathrm{Po}-\mathrm{Pe}}{1-\mathrm{Pe}} \\
k=\frac{0.93-0.55}{1-.055}=\frac{0.38}{0.45}=\mathbf{0 . 8 4}
\end{gathered}
$$

Interpretación: El coeficiente de kappa obtenido por el observador fue de 0.84 , que de acuerdo a los criterios de Landis y Koch equivale a una concordancia casi perfecta, por lo tanto, su consistencia en el criterio diagnóstico es confiable. 


\section{Cálculo del coeficiente de kappa a través de Excel}

Una herramienta que puede ser de utilidad para el cálculo del índice de kappa es la calculadora que proporciona la página fisterra.com disponible en la dirección: https://www.fisterra.com/mbe/investiga/kappa/kappa.asp $\mathbf{p}_{\mathbf{1}}$ en la opción >>Calculadora en Excel para calcular el índice Kappa<< que permitira descargar dos hojas de Excel una de ellas con una tabla de contingencia de $2 \times 2$ y otra de $5 \times 5 .{ }^{22}$

\section{Ejemplo 2:}

En el caso de valorar la confiabilidad interexaminador en la recolección del CPOD en 88 dientes se recurrirá a la página que contiene la tabla de contingencia de $5 \times 5$, realizará los siguientes pasos:

1. Descargar la calculadora y seleccionar la hoja $>>\operatorname{KAPPA}(\mathrm{C} \times \mathrm{C})<<$ aparecerá una hoja de cálculo con una tabla de contingencia de $5 \times 5$.

2. Escribir los códigos con los cuales se esta trabajando, en este caso: $1=$ caries, $2=$ perdido, $3=$ obturado, $4=$ sano y $0=$ no aplicable, tanto el la columna correspondiente al observador 1 como en la fila correspondiente al observador 2.

3. Escribir las frecuencias correspondientes en la tabla de contingencia. Por ejemplo en la figura 5 se observa que: - en la primer columna se registraron 18 concordancias entre los examinadores en el código 1 y 2 discordancias en las que el observador 1 registro el diente con el código 4 y el observador 2 con el código 1.

- en la segunda columna se registraron 7 concordancias entre los examinadores referentes al código 2.

- en la cuarta columna se observaron 3 discordancias entre los examinadores en las que el observador 1 registro el diente con el código 1 mientras que el examinador 2 lo hizo con el código 4.

- La tercera y quinta columna no presentaron registros.

4. Corroborar que los datos ingresados sean correctos ya que la obtención del índice de kappa se obtiene directamente.

La calculadora arroja cuatro resultados (Figura 5): el coeficiente del índice de kappa, el error estándar, el Intervalo de Confianza y la interpretación de la fuerza de concordancia con base en las categorías propuestas por Fleiss.

\begin{tabular}{|c|c|c|c|c|c|c|c|}
\hline \multicolumn{8}{|c|}{$\begin{array}{l}\text { Medidas de concordancia: el índice Kappa } \\
\text { (Tabla C x C) }\end{array}$} \\
\hline \multirow[b]{2}{*}{ Observador 1} & \multicolumn{6}{|c|}{ Observador 2} & \\
\hline & 1 & 2 & 3 & 4 & 0 & Marginal & \\
\hline 1 & 18 & 0 & 0 & 3 & 0 & 21 & \\
\hline 2 & 0 & 7 & 0 & 0 & 0 & 7 & \\
\hline 3 & 0 & 0 & 0 & 0 & 0 & & \\
\hline 4 & 2 & 0 & 0 & 58 & 0 & 60 & \\
\hline 0 & 0 & 0 & 0 & 0 & 0 & \multirow[b]{2}{*}{88} & \\
\hline Marginal & 20 & 7 & \multicolumn{3}{|c|}{61} & & \\
\hline \multirow{2}{*}{$\begin{array}{l}\text { ACUERDO OBSERVADO } \\
\text { ACUERDO ESPERADO }\end{array}$} & 0.94 & & & & & & \\
\hline & 0.53 & & & & & & \\
\hline ÍNDICE KAPPA & \multicolumn{3}{|c|}{ ERROR ESTÁNDAR } & & \multicolumn{2}{|c|}{ LC 95\% } & Fuerza de la concordancia \\
\hline \multirow[t]{2}{*}{0.676} & \multicolumn{3}{|c|}{0.053} & & $(0.7$ & $, 0.982)$ & Muy buena \\
\hline & \multicolumn{7}{|c|}{$\begin{array}{l}\text { Beatriz López Calviño } \\
\text { Salvador Pita Fernández } \\
\text { Teresa Seoane Pillado } \\
\text { Sonia Pértega Díaz } \\
\text { Unidad de epidemiología clínica y bioestadística } \\
\text { Complexo Hospitalario Universitario A Coruña }\end{array}$} \\
\hline
\end{tabular}

Figura 5. Ejemplo del cálculo del índice de kappa a través de la calculadora de excel. Calculadora. Disponible en: https://www.fisterra.com/mbe/investiga/kappa/kappa.asp 


\section{CAPÍTULO 2 Confiabilidad en la medición epidemiológica de caries dental}

El coeficiente de Kappa en este caso es interpretado con los Criterios de Fleiss (Cuadro 2).

Cuadro 2. Criterios de concordancia según Fleiss.

\begin{tabular}{|c|l|}
\hline Valor estadístico de kappa & \multicolumn{1}{c|}{ Grado de concordancia } \\
\hline$<0.00$ & Menos que la debida al azar \\
\hline $0.00-0.49$ & Inadecuada, puede ser debida al azar \\
\hline $0.50-0.74$ & $\begin{array}{l}\text { Buena, adecuada concordancia más grande que la } \\
\text { debida al azar }\end{array}$ \\
\hline $0.75-1.00$ & Muy buena concordancia, no debida al azar \\
\hline Fuente: Fleiss ${ }^{20}$ & \multicolumn{2}{|l}{} \\
\hline
\end{tabular}

En el ejemplo se muestra que el resultado del índice fue 0.87 , lo cual se interpreta como una muy buena concordancia. El error estándar mide el tipo de error causado por la variación aleatoria del muestreo al repetir una prueba en las mismas condiciones. Cuando se informa la media de una muestra, no se informa el promedio "verdadero" sino una estimación. La estadística muestral puede resultar levemente superior o inferior al valor verdadero desconocido. El error estándar de la media mide la diferencia que puede existir entre la media verdadera y la estadística que se informa. Los valores de error estándar bajos indican estimaciones más precisas de la media de la población.

Un mayor tamaño de la muestra dará como resultado un menor error estándar de la media y una estimación más precisa.

Debido a que el índice de kappa es una estimación con un solo punto o puntual, no proporciona suficiente información acerca de la precisión de dicha estimación, en este sentido el Intervalo de Confianza (IC) corresponde a un rango de valores, cuya distribución es "normal" y en el cual se encuentra, con alta probabilidad, el "valor real" de una determinada variable (en este caso, el coeficiente de kappa). Esta "alta probabilidad" se ha establecido por consenso en $95 \%$. Así, un intervalo de confianza de $95 \%$ nos indica que dentro del rango dado se encuentra el "valor real" de un parámetro con $95 \%$ de certeza. ${ }^{23,24}$

EI IC permite hacer inferencia estadística al excluir un valor crítico que indique la falta de asociación del intervalo, es decir, que los hallazgos son estadísticamente significativos porque el intervalo " no pasan por el 1", ya que un valor 1 indica que la frecuencia de un determinado evento fue igualmente presentado tanto en el grupo expuesto como en el que no, por lo que sería el "valor crítico" que debe excluirse para denotar significancia estadística, en la figura 5 podemos observar que en el ejemplo planteado se obtuvo un IC 95\% 0.775- 0.982, como el valor 1 está excluido del rango del intervalo, podemos decir que los hallazgos son estadísticamente significativos.

\section{Cálculo del coeficente de kappa con ayuda del programa IBM SPSS}

El programa SPSS (Statistical Product and Service Solutions) es un conjunto de herramientas de tratamiento de datos para el análisis estadístico útil para el cálculo del índice de kappa, su interfaz es similar a la del sistema operativo de Windows. ${ }^{25}$

\section{Ejemplo 3:}

Al iniciar sesión con el IBM SPSS Statistics 21 (Figura 6) se encontrará con un cuadro de diálogo que mostrará las opciones para trabajar con el programa, en éste seleccionará la opción >>introducir datos<< 


\section{Confiabilidad en la medición de caries dental}

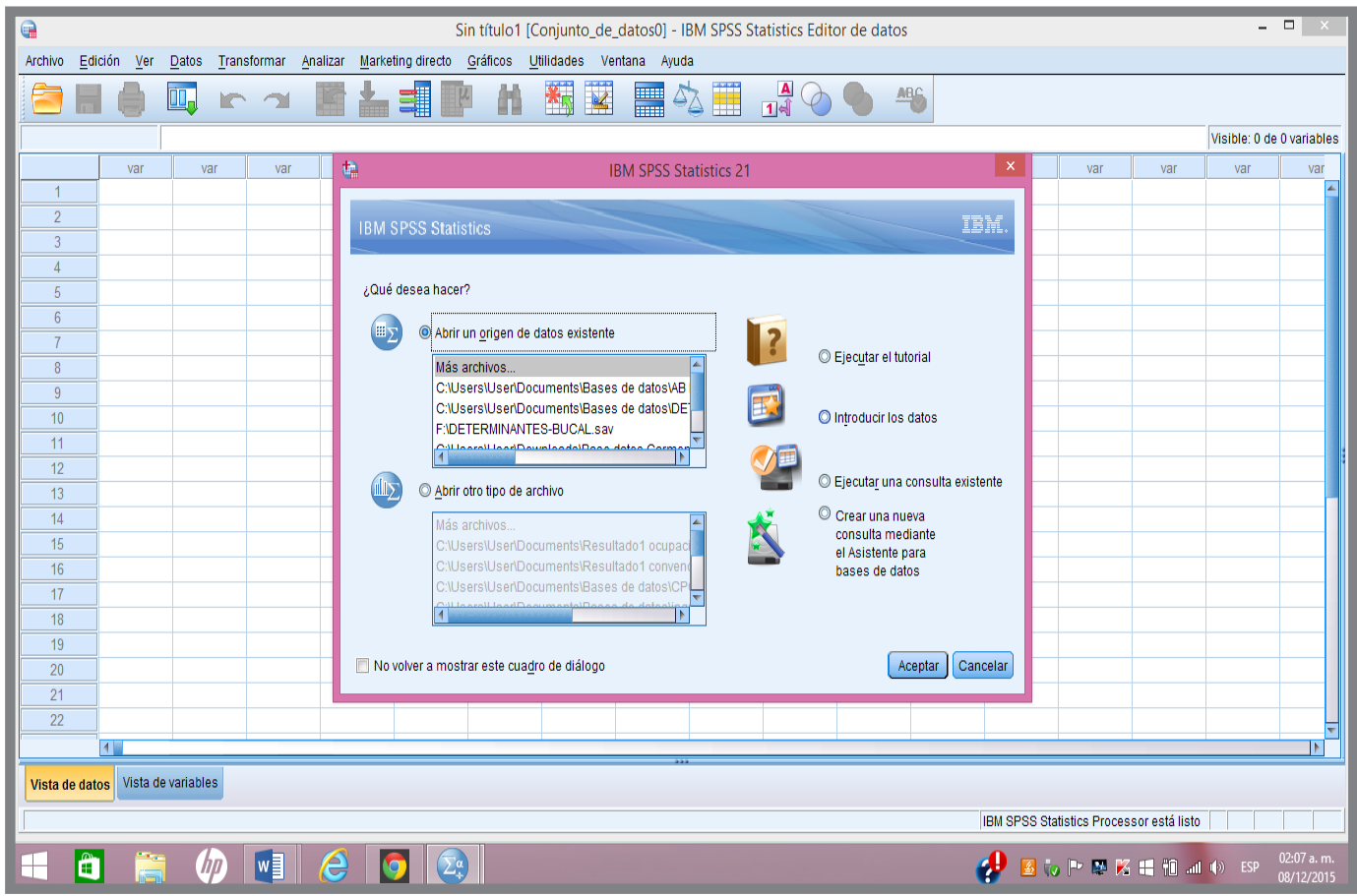

Figura 6. Página de inicio en una sesión con IBM SPSS Statistics 21.

Posteriormente seleccionará la pestaña correspondiente a >>vista de variables $<<$ en la cual creará dos variables, que corresponden al número de examinadores u observaciones según sea el tipo de ejercicio de estandarización.

1. Creación de variables .

a. Nombrar la variable. Escribir el nombre de las variables en las celdas que conforman la columna correspondiente al nombre de la variable, en el caso de realizar un ejercicio de estandarización interexaminador se crearán dos variables, una para cada examinador, por ejemplo: examinador 1 y examinador 2.

b. Fijar los valores de la variable. Ingresar a la opción valores para codificar las categorías de la variable que se esta midiendo.

En este ejemplo se utiliza el CPOD, por lo tanto, las categorías se etiquetan como: cariado, perdido, obturado, sano y no aplicable; a cada una de las categorías se le asigna un valor para elaborar la base de datos, en este caso: $1,2,3,4$ y 0 .

Al seleccionar la celda correspondiente a la variable en la que se fijarán los valores aparecerá un cuadro de diálogo de etiquetas de valor, escribir el valor correspondiente en su celda y en la etiqueta escribir la categoría, >>añadir $<<$ y >>aceptar<< la información (Figura 7). 


\section{CAPÍTULO 2 Confiabilidad en la medición epidemiológica de caries dental}

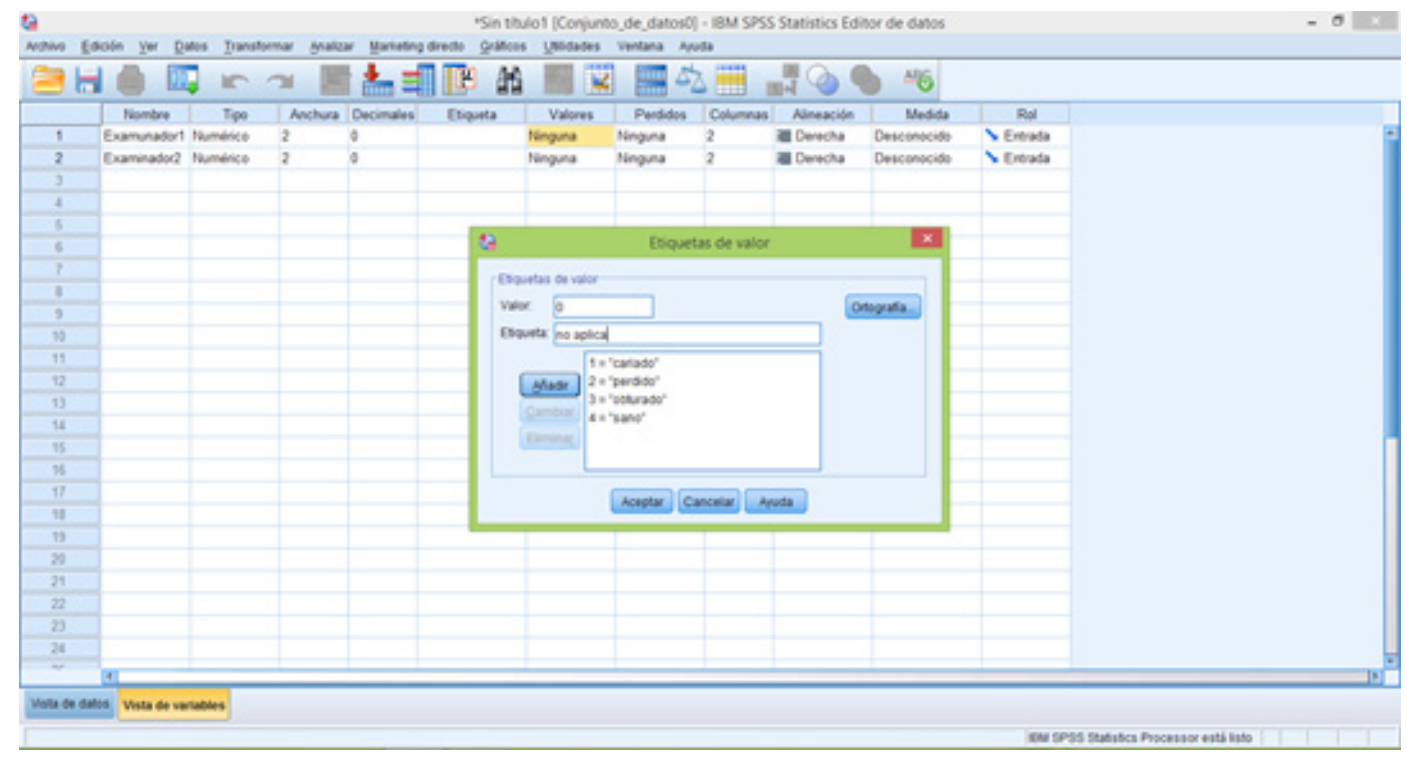

Figura 7. Elaboración de etiquetas de valor.

2. Capturar los datos.

La captura de los datos se lleva a cabo en la pestaña $>>$ vista de datos $<<$, en la cual anotará los códigos que fueron registrados por los observadores en la ficha epidemiológica de recolección.

Al seleccionar >>etiquetas de valor<< podrá observar en la pantalla como cambian los datos: de valor a etiqueta o de etiqueta a valor (Figura 8).

\begin{tabular}{|r|r|r|}
\hline & Examunador1 & Examinador2 \\
\hline 1 & cariado & cariado \\
\hline 2 & cariado & cariado \\
\hline 3 & cariado & cariado \\
\hline 4 & cariado & cariado \\
\hline 5 & cariado & cariado \\
\hline 6 & cariado & cariado \\
\hline 7 & cariado & cariado \\
\hline 8 & cariado & cariado \\
\hline 9 & cariado & cariado \\
\hline 10 & cariado & cariado \\
\hline 11 & sano & sano \\
\hline 12 & sano & sano \\
\hline 13 & sano & sano \\
\hline 14 & sano & sano \\
\hline 15 & cariado & sano \\
\hline 16 & obturado & obturado \\
\hline 17 & cariado & cariado \\
\hline 18 & obturado & obturado \\
\hline 19 & cariado & cariado \\
\hline 20 & sano & sano \\
\hline 21 & sano & sano \\
\hline 22 & sano & sano \\
\hline 23 & sano & sano \\
\hline
\end{tabular}

\begin{tabular}{|c|c|c|}
\hline & Examinador 1 & Examinador2 \\
\hline 1 & 1 & 1 \\
\hline 2 & 1 & 1 \\
\hline 3 & 1 & 1 \\
\hline 4 & 1 & 1 \\
\hline 5 & 1 & 1 \\
\hline 6 & 1 & 1 \\
\hline 7 & 1 & 1 \\
\hline 8 & 1 & 1 \\
\hline 9 & 1 & 1 \\
\hline 10 & 1 & 1 \\
\hline 11 & 4 & 4 \\
\hline 12 & 4 & 4 \\
\hline 13 & 4 & 4 \\
\hline 14 & 4 & 4 \\
\hline 15 & 1 & 4 \\
\hline 16 & 3 & 3 \\
\hline 17 & 1 & 1 \\
\hline 18 & 3 & 3 \\
\hline 19 & 1 & 1 \\
\hline 20 & 4 & 4 \\
\hline 21 & 4 & 4 \\
\hline 22 & 4 & 4 \\
\hline 23 & 4 & 4 \\
\hline
\end{tabular}

Figura 8. Cambio de etiquetas de valor. 


\section{Confiabilidad en la medición de caries dental}

\section{Cálculo del coeficente de kappa.}

En la barra de menú, desplegar la opción $>>$ Analizar $<<$, posteriormente seleccionar $>>$ Estadísticos descriptivos $<<$ y finalmente elegir $>>$ Tablas de contingencia $<<$ (Figura 9).

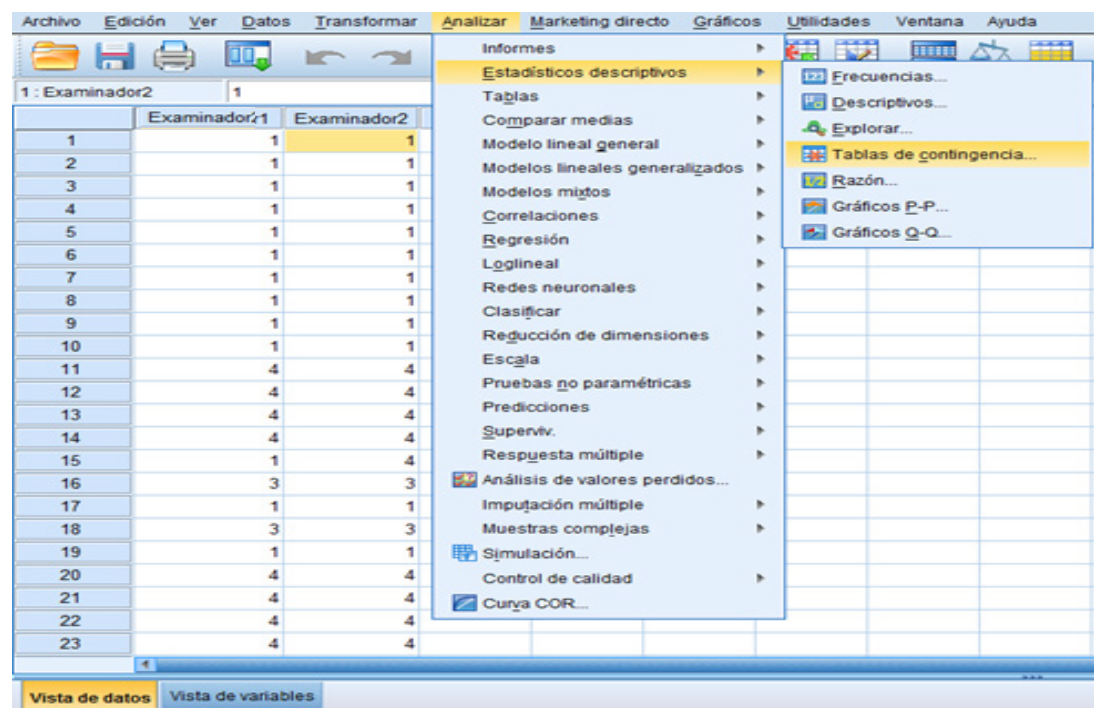

Figura 9. Ubicación de la opción >>tablas de contingencia<< para el cálculo del índice de kappa.

Se abrirá un cuadro de diálogo (Figura 10) en el cual encontrará una lista con los examinadores, el "examinador patrón" o también conocido como "estándar de oro" se colocará en la opción de columnas y en filas el examinador que será evaluado.

En el siguiente ejemplo fue seleccionado el examinador 1 como examinador patrón y el observador 2 como el examinador evaluado.

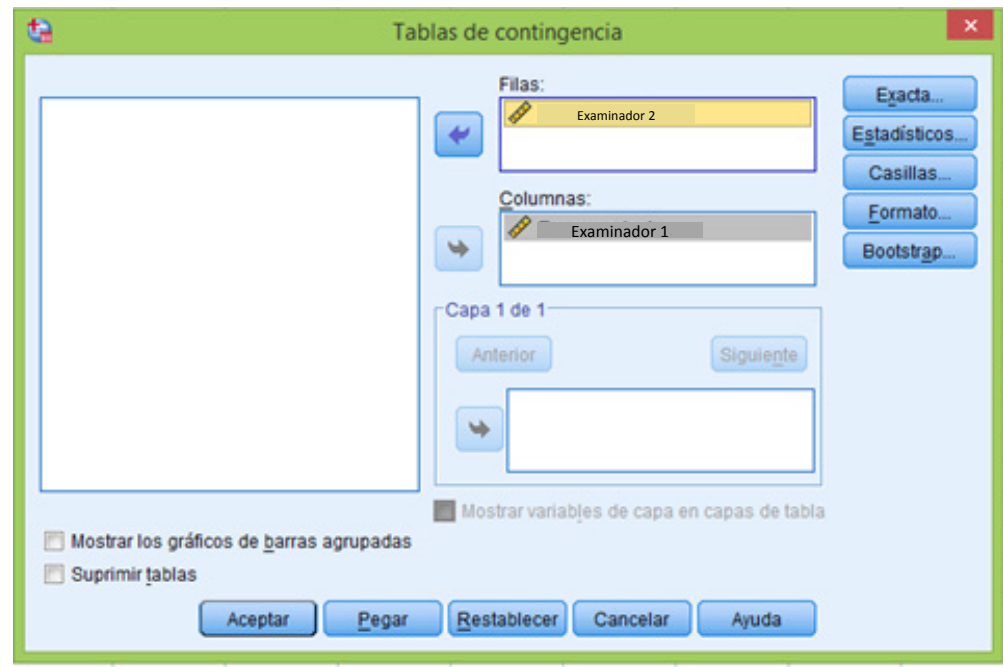

Figura 10. Selección de examinadores para la elaboración de la tabla de contingencia. 


\section{CAPÍ́TULO 2 Confiabilidad en la medición epidemiológica de caries dental}

A continuación seleccione el botón $>>$ Estadísticos...<< que desplegará un subcuadro de dialógo en el cual deberá seleccionar $>>$ Kappa $<<y ~>>$ Continuar $<<$ (Figura 11).

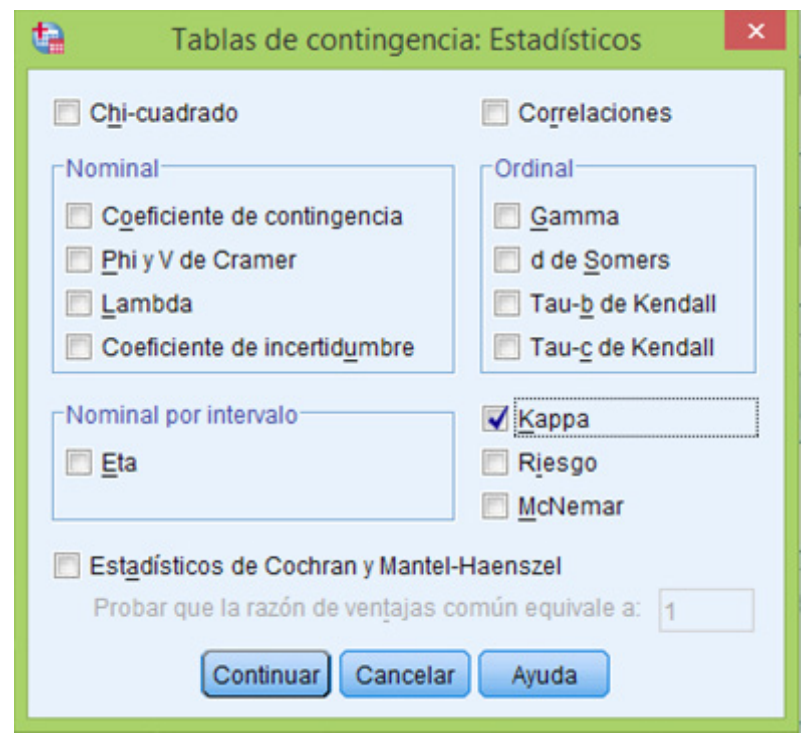

Figura 11. Selección de la prueba estadística.

Por último seleccione el botón $>>$ Casillas $<<$, se abrirá un subcuadro de diálogo con un amplio menú de opciones, es suficiente con elegir la opción de $>>$ Recuentos observados $<<$, seleccione el botón $>>$ Continuar $<<$ y $>>$ Aceptar $<<$ (Figura 12).

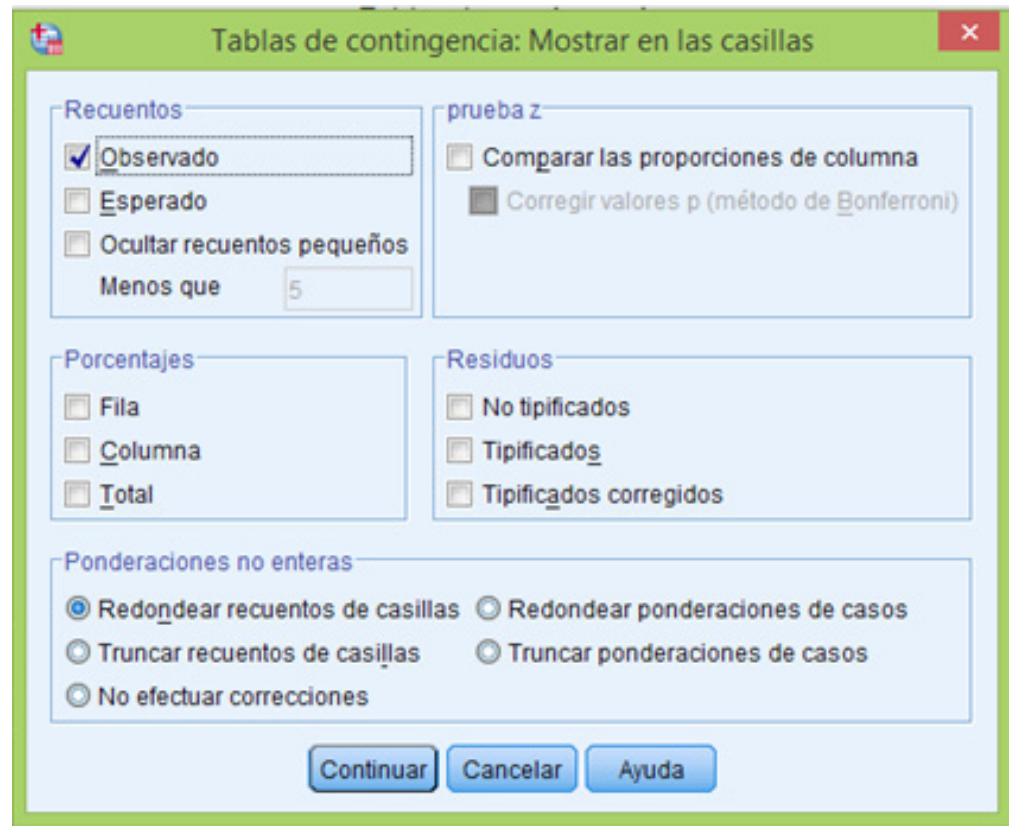

Figura 12. Selección de casillas en la tabla de contingencia. 


\section{Confiabilidad en la medición de caries dental}

Obtendrá una ventana de resultados (Figura 13) que incluirá:

- resumen del procesamiento de los casos,

- tabla de contingencia y

- medidas simétricas.

Tablas de contingencia

(Conjunto_de_datos0)

\begin{tabular}{|c|c|c|c|c|c|c|}
\hline \multicolumn{7}{|c|}{ Resumen del procesamiento de los casos } \\
\hline & \multicolumn{6}{|c|}{ Casos } \\
\hline & \multicolumn{2}{|c|}{ Válidos } & \multicolumn{2}{|c|}{ Perdidos } & \multicolumn{2}{|c|}{ Total } \\
\hline & $\mathbf{N}$ & Porcentaje & $\mathbf{N}$ & Porcentaje & $\mathbf{N}$ & Porcentaje \\
\hline $\begin{array}{l}\text { Examinador } 2^{*} \\
\text { Examinador } 1\end{array}$ & 32 & $100.0 \%$ & 0 & $0.0 \%$ & 32 & $100.0 \%$ \\
\hline
\end{tabular}

Recuento

Tabla de contingencia Examinador 2 Examinador *1

\begin{tabular}{|c|c|c|c|c|c|c|}
\hline \multirow{2}{*}{\multicolumn{2}{|c|}{ No aplica }} & \multicolumn{4}{|c|}{ Examinador 1} & \multirow[b]{2}{*}{ Total } \\
\hline & & no aplica & cariado & obturado & sano & \\
\hline \multirow[t]{4}{*}{ Examinador 2} & no aplica & 1 & 0 & 0 & 0 & 1 \\
\hline & cariado & 0 & 14 & 0 & 0 & 14 \\
\hline & obturado & 0 & 0 & 2 & 0 & 2 \\
\hline & sano & 0 & 1 & 0 & 14 & 15 \\
\hline Total & & 1 & 15 & 2 & 14 & 32 \\
\hline
\end{tabular}

\begin{tabular}{|l|r|r|r|r|}
\hline & & Medidas simétricas & \\
\hline & Valor & Error tip. asimnt. & T aproximada $^{\mathrm{b}}$ & Sig. aproximada $^{\circ}$ \\
\hline $\begin{array}{l}\text { Medida de acuerdo } \\
\text { N de casos validos }\end{array}$ & $\begin{array}{r}.947 \\
32\end{array}$ & .053 & 6.755 & .000 \\
\hline
\end{tabular}

b. Empleando el error típico asintótico basado en la hipótesis nula.

Figura 13. Resultados del cálculo del índice de kappa.

El resumen del procesamiento de los casos muestra el tamaño el total de datos analizados en este caso 88.

La tabla de contingencia muestra la frecuencia observada y esperada de las mediciones.

Y por último observaremos el valor de Kappa, en este caso de 0.947 lo que corresponde a una muy buena concordancia de acuerdo a los criterios de Landis y Koch.

A manera de conclusión podemos decir, que la investigación apegada al método científico proporciona información que permite comprender los objetos de estudio y orientar la práctica de los profesionistas. Por lo tanto, el proceso de estandarización es indispensable en la medición de caries, de ahí que examinadores y anotadores deben comprometerse en conocer el indicador que utilizarán y alcanzar un coeficiente de kappa $\geq 0.81$ con un IC que garantice una diferencia estadísticamente significativa antes de la recolección de información. 


\section{CAPÍTULO 2 Confiabilidad en la medición epidemiológica de caries dental}

\section{Bibliografia}

1. Tamayo TM. El proceso de la investigación científica. 4a. ed. México: LIMUSA; 2004.

2. SINAVE, DGE, SALUD. Perfil epidemiológico de la salud bucal en México 2010. [en línea]. 2011 [citado 5 diciembre 2015]; Disponible en: http://www.epidemiologia.salud.gob.mx/doctos/infoepid/publicaciones/2011/ monografias/P_EPI_DE_LA_SALUD_BUCAL_EN_MEXICO_2010.pdf.

3. Secretaría de Salud. Encuesta Nacional de caries dental. México: Centro Nacional de Vigilancia Epidemiológica y Control de enfermedades; 2001.

4. Duque-Naranjo C, Mora-Díaz II. La representación de la epidemiología de la caries en el mundo a través de mapas. Univ Odontol. 2012; 31(66):41-50.

5. Caudillo-Joya T, Adriano-Anaya MP, Gurrola-Martínez B, Caudillo-Adriano PA. Perfil epidemiológico de caries dental en ocho delegaciones políticas del Distrito Federal, México. Rev Costarr Salud Pública. 2010;19:81-87.

6. Del Socorro-Herrera M, Medina-Solís CE, Rosado-Vila G, Minaya-Sánchez AA, Casanova-Rosado JF. Prevalencia, severidad de caries y necesidades de tratamiento en preescolares de una comunidad suburbana de Campeche 2001. Bol Med Hosp Infant Mex. 2003;60:189-196.

7. Fuentes-Fernández R, Oporto VG, Silva MA, Soto PC, Prieto R, Sanhueza A, Cantín M. Impacto de la caries dental y enfermedad periodontal sobre la sexualidad de la mujer. Avances en odontoestomatología. 2015;31(4):273-258.

8. Gálvez-Cubas G, Céspedes-Martínez D, Gamero-Castillo F, Tomás-De la Cruz C, Díaz-Pizán M. Bullying escolar en niño como consecuencia de su estado de salud bucal; reporte de caso. Rev Estomatol Herediana. 2015;25(2):152.158.

9. Cereceda MM, Faleiros CS, Ormeño QA, Pinto MG, Tapia VR, Díaz SC, et al. Prevalencia de caries en alumnos de educación básica y su asociación con el estado nutricional. Rev. Chil Pedriatr. 2010;81(1):28-36.

10. León-Manco RA, Del Castillo-López CE. Capital social y experiencia de caries dental. Rev Estomatol Herediana. 2011;21(1):13-19.

11. Irigoyen ME, Zepeda MA, Sánchez L, Molina N. Prevalencia e incidencia de caries dental y hábitos de higiene bucal en un grupo de escolares del sur de la Ciudad de México: Estudio de seguimiento longitudinal. Rev ADM. 2001; 59(3):98-104.

12. Secretaría de Salud. Programa Sectorial de Salud. Programa de Acción específico para la prevención, detección y control de los problemas de salud bucal 2013-2018. [en línea]. [citado 24 junio 2015]; Disponible en: http:// cenaprece.salud.gob.mx/descargas/pdf/PAE_PrevencionDeteccionControlProblemasSaludBucal2013_2018. pdf

13. Juárez-López ML, Hernández-Palacios RD, Hernández-Guerrero JC, Jiménez-Farfán D, Moina-Ferchero N. Efecto preventivo y de remineralización de caries incipientes del fosfopéptido de caseína fosfato de calcio amorfo. Revista de Investigación Clinica. 2014;66(2):144-151.

14. Macchi RL. Introducción a la estadística en ciencias de la salud. 2a. ed. Buenos Aires: Médica Panamerica; 2014.

15. Lizmar D.V, Acevedo AM, Rojas SF. Métodos convencionales y no convencionales para la detección de la lesión inicial de caries. Revisión bibliográfica. Acta Odontológica Venezolana. [en línea]. 2011; [citado 3 septiembre 2015];49(2):[1-14]. Disponible en: http://actaodontologica.com/ediciones/2011/2/pdf/art21.pdf.

16. Rubio CJ, Robredo DT, Llodra CJ, Simón SF, Artazcoz OA, González AV, García-Camba J. Criterios mínimos de los estudios epidemiológicos de salud dental en escolares. Rev Esp Salud Pública. 1997; 71:231-242.

17. Argimon-Pallas JM, Jiménez J. Métodos de investigación, clínica y epidemiológica. 2a. ed. España: Harcourt; 2000.

18. Dawson B, Trapo R. Bioestadística médica. 3a. ed. México: El manual moderno; 2002.

19. World Health Organization. Oral Health Surveys. 5th. ed. Geneve: WHO; 2013.

20. Mendoza-Nuñez V, Sánchez-Rodriguez MA. Análisis y difusión de resultados científicos. México: Facultad de Estudios Superiores Zaragoza UNAM; 2001.

21. Landis JR, Koch GG. The measurement of observer agreement for categorical data. Biometrics. 1977; 33 (1): 159-174. 
22. López de Ullibarri-Galparsoro I, Pita-Fernández S. Medidas de concordancia: el índice Kappa. Cad Aten Primaria [en línea] 1999 [citado 5 diciembre 2015]; 6: 169-171. Disponible en: https://www.fisterra.com/mbe/ investiga/kappa/kappa.asp

23. Candia BR, Caiozzi AG. Intervalos de Confianza. Rev Méd Chile. 2005;133 (9):1111-1115.

24. Murrieta-Pruneda JF, Marques-Dos Santos MJ, Romo-Pinales MR. Fundamentos de estadística para odontología. México: FES Zaragoza; 2006.

25. Bausela-Herreras E. SPSS: Un instrumento de análisis de datos cuantitativos. Revista de Informática Educativa y Medios Audiovisuales. 2005; 2(4):62-69.

Consultar el video de apoyo del Capítulo 2: "Confiabilidad en la medición epidemiológica de caries dental", en la pestaña del Módulo Estomatología Social II http://www.zaragoza.unam.mx/herramientas-para-el-aprendizaje/ 


\title{
CAPÍ́TULO 3
}

\section{Índice CPOID - cpod}

\author{
YULIANA JOSEFINA ZARZA MAR'TÍNEZ \\ REMEDIOS GUADALUPE VALDEZ PENAGOS
}

\section{Generalidades}

EI CPOD es uno de los índices para la medición de caries frecuentemente utilizado en el ambiente epidemiológico ya que por su sencillez y alta posibilidad de reproducción ha facilitado la comparación de diferentes poblaciones, o de la misma a través del tiempo, así como la evaluación de algunas medidas preventivas. 1, 2, 3,4,5

La primera referencia del CPOD fue presentada por Henry Klein y Carroll E. Palmer en diciembre de 1937 en el artículo "Dental Caries in American Indian Children" (Figura14) dentro del Public Health Bolletin en donde los autores mencionan: ${ }^{6}$

...”a fin de obtener información específica en cuanto al ataque de la caries, los datos se expresan en términos del número total de dientes permanentes cariados, perdidos y obturados (CPO)".

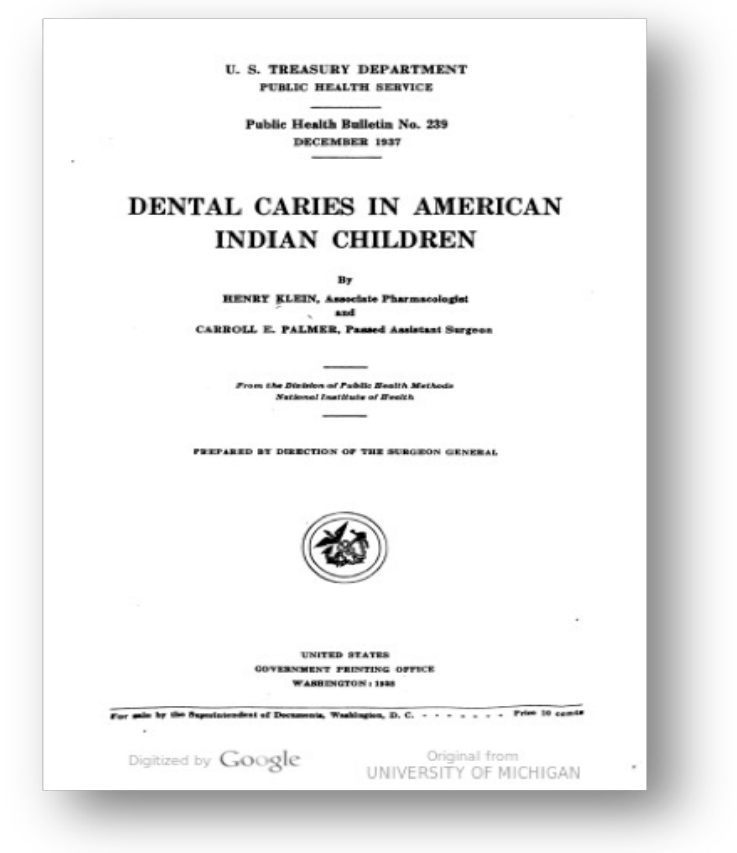

Figura 14. Portada original del artículo de Klein y Palmer.

Fuente: http://babel.hathitrust.org/cgi/pt?id= mdp.39015006457702;view=1up;seq=24;skin=mobile 


\section{Confiabilidad en la medición de caries dental}

Posteriormente, en el artículo "Studies on Dental Caries: I. Dental Status and Dental Needs of Elementary School Children" publicado en el año de 1938 en Public Health Reports; los autores: Klein, Palmer y Knutson ${ }^{7}$ hacen algunas especificaciones importantes:

..."la caries dental es una enfermedad acumulativa. Una descripción precisa del estado de la enfermedad en un grupo de población exige, por lo tanto, una evaluación cuantitativa y completa de la experiencia de la caries". ${ }^{7}$

..."La evaluación completa requiere la consideración de lo que puede llamarse caries pasada y presente". ${ }^{7}$

- CARIES PASADA: término utilizado para referirse a los dientes obturados y a los que han sido extraídos por consecuencia de una lesión cariosa.

- CARIES PRESENTE: se considerada a la perdida de la continuidad del esmalte a consecuencia de caries dental.

..."Con los propósitos de precisión y brevedad, se introdujo el término CPO (Cariado, Perdido, Obturado) o por sus siglas en inglés DMF (Decalled, Missing or Filled)".7

El objetivo del CPO es cuantificar la experiencia de caries en dentición permanente a través de la sumatoria de los dientes cariados, perdidos por caries y obturados. ${ }^{7}$

Es a partir de estas líneas que surge el indicador CPO, el cual ha sido adoptado por el gremio odontológico como una unidad de medida básica para describir la situación epidemiológica de las poblaciones. ${ }^{8,9}$

En el año de 1944, Gruebbel realiza una modificación de este índice e introduce el ceod, adaptándolo para la medición de experiencia de caries en dentición temporal, la medición a través de este indicador no consideraba el registro de dientes temporales perdidos por caries debido a que se tomaba en cuenta que el proceso de intercambio dental dificulta la identificación de la causa de la pérdida del diente, y en muchos casos el niño no puede proporcionar información que ayude a determinar si el diente no se encuentra presente por exfoliación o porque fue extraído por caries. ${ }^{10,11,12}$

El objetivo del índice ceod es cuantificar la experiencia de caries en dentición temporal a través de la sumatoria de los dientes cariados, con extracción indicada y obturados, por lo tanto por mucho tiempo se utilizó la combinación del CPOD con el ceod para realizar la medición de experiencia de caries en dentición mixta.

Sin embago, en el año 2013 la OMS toma los criterios que propusieron en su momento Klein y Palmer, tanto para la dentición temporal como para la dentición permanente y elimina la identificación de la condición de extracción indicada, incluyendo éstos dientes en la condición de caries. Por lo tanto la nomenclarura para identitifar la experiencia de caries en dentición temporal cambia de ceo a cpod, de ahí que en el presente documento nos referiremos al indicador como cpod cuando se trate de dentición temporal. ${ }^{13}$

Esta adecuación permite la medición de experiencia de caries en dentición mixta, aplicando ambos índices en población infantil refiriéndose como: CPOD-cpod.

El resultado obtenido a través de la utilización de este indicador se presenta a través de un promedio, en cuyo caso se puede categorizar el grado de afección de la enfermedad en dentición temporal o permanente siguiendo los criterios de la OMS (Cuadro 3 ). ${ }^{13}$ 


\section{CAPÍTULO 3 CPOD - cpod}

Cuadro 3. Categorización de la experiencia de caries en dentición permanente.

\begin{tabular}{|l|c|c|}
\hline \multicolumn{1}{|c|}{ Categoría } & $\begin{array}{c}\text { Niños de 12 años } \\
\text { de edad }\end{array}$ & $\begin{array}{c}\text { Adultos de 35-44 años } \\
\text { de edad }\end{array}$ \\
\hline Muy bajo & $<1.2$ & $<5.0$ \\
\hline Bajo & $1.2-2.6$ & $5.0-8.9$ \\
\hline Moderado & $2.7-4.4$ & $9.0-13.9$ \\
\hline Alto & $4.5-6.5$ & $>13.9$ \\
\hline Muy alto & $>6.5$ & S.D. ${ }^{*}$ \\
\hline *S.D. = Sin Dato Fuente: MMS $^{13}$ & \\
\hline
\end{tabular}

La utilización del indicador CPOD, del cpod, o su aplicación conjunta CPOD-cpod se puede llevar a cabo utilizando como unidad de medición el diente o las superficies dentales; por lo tanto se realiza la especificación al final de las siglas conocidas escribiendo una " $\mathrm{D}$ " cuando se trata de medición por diente y una "S" en caso de realizar la medición por superficies, por ejemplo: CPOD y CPOS. ${ }^{5}$

Es importante recordar que Klein y colaboradores en 1938 mencionan:

..."La extensión de la caries en cualquier diente se mide en términos de superficie”.

De tal manera que la medición de caries a través de CPOS y cpos permite obtener información relacionada con el diente por superficie. ${ }^{14}$

\section{Códligos y criterios del CPOD-cpod}

El registro del indicador se lleva a cabo en fichas previamente elaboradas (Anexo 1, 2 y 3 ) a través de la escritura de códigos correspondientes a cada una de las condiciones, como ya se mencionó es fácil encontrarnos con literatura científica que aún conserva la descripción de sus códigos y criterios para identificar la experiencia de caries, incluyendo la condición de extracción indicada como se muestra en el cuadros 4. ${ }^{10,11,15}$

Los códigos y condiciones que se han manejado de forma tradicional de acuerdo a Mena ${ }^{10}$, Adriano $^{11}$ y Murrieta $^{15}$, se presentan tal como se ve en el cuadro siguiente:

Cuadro 4. Códigos y condición de experiencia de caries de acuerdo al indicador CPO-ceo.

\begin{tabular}{|c|c|c|}
\hline $\begin{array}{c}\text { Códigos para dientes } \\
\text { permanentes (CPO) }\end{array}$ & $\begin{array}{c}\text { Condición de experiencia de } \\
\text { caries }\end{array}$ & $\begin{array}{c}\text { Códigos para dientes } \\
\text { temporales (ceo) }\end{array}$ \\
\hline 1 & CARIADO & 6 \\
\hline 2 & OBTURADO & 7 \\
\hline 3 & PERDIDO POR CARIES & - \\
\hline 4 & EXTRACCIÓN INDICADA & 9 \\
\hline 5 & SANO & 0 \\
\hline 0 & NO APLICABLE & \\
\hline Fuente: Mena GA, ${ }^{10}$ Adriano AM, ${ }^{11}$ Murrieta PJ. ${ }^{15}$ & \\
\hline
\end{tabular}




\section{Confiabilidad en la medición de caries dental}

La OMS actualmente considera dos indicadores en la medición de caries, uno es el índice para evaluar el estado de dentición y tratamiento necesario, y el otro es el CPOD- cpod. ${ }^{13}$

Es así que los cambios propuestos en este material están apoyados en lo planteado por la OMS ${ }^{13}$, en donde se señala que las condiciones y criterios para el CPOD-cpod son tomados a partir del índice para evaluar el estado de la dentición y tratamiento necesario. Cabe resaltar que la OMS no señala o asigna códigos para los índices CPOD-cpod, por tal motivo en este material se propone una reorganización de los códigos que facilite y simplifique su utilización en el momento del levantamiento epidemiológico como se observa a continuación (cuadro 5). Así mismo más adelante se podrán encontrar a detalle los criterios a considerar en la evaluación de las condiciones de la experiencia de caries (cuadro 6).

El lector debe tomar en cuenta que los códigos no identifican grado o severidad de la lesión, estos se utilizan solo para identificar la condición del diente y así llevar a cabo el registro y procesamiento estadístico de la información recolectada. Es importante destacar que el criterio que se tomaba en cuenta para identificar la condición de extracción indicada queda incluido en la condición de diente con caries.

\section{Consideraciones especiales: ${ }^{10,15}$}

- Un diente con erupción incompleta es posible considerarlo para el examen, cuando cualquier porción de su superficie estuviese expuesta en la cavidad bucal y pudiese ser tocada por la sonda.

- Un diente es considerado presente, aun y cuando su corona este totalmente destruida, incluso cuando lo único visible sean sus raíces.

- Los dientes supernumerarios no son considerados para este índice.

- Si un diente temporal no ha sido exfoliado y su sucesor permanente está presente, se registra solamente el permanente.

- Cuando existe duda entre si el diente presente es un primer premolar, o un segundo premolar, se registrará siempre como si fuera el primer premolar.

- Cuando se tiene duda en la condición que presenta el diente, siempre se registrará el menor grado, ejemplo: entre sano y cariado se registra sano, entre cariado y obturado se registra como obturado, entre cariado y extracción indicada se registra como cariado.

- El paciente que presente aparatología de ortodoncia queda excluido del estudio epidemiológico.

Cuadro 5. Códigos y condición de experiencia de caries de acuerdo al indicador CPOD-cpod.

\begin{tabular}{|c|c|c|}
\hline $\begin{array}{c}\text { CPOD } \\
\text { Dentición adulta }\end{array}$ & CÓDIGOS Y CRITERIOS & $\begin{array}{c}\text { cpod } \\
\text { Dentición infantil }\end{array}$ \\
\hline 1 & CARIADO & 5 \\
\hline 2 & PERDIDO & 6 \\
\hline 3 & OBTURADO & 7 \\
\hline 4 & SANO & 8 \\
\hline 0 & NO APLICABLE & 0 \\
\hline
\end{tabular}




\section{CAPÍTULO 3 CPOD - cpod}

Cuadro 6. Criterios para identificar la condición de experiencia de caries.

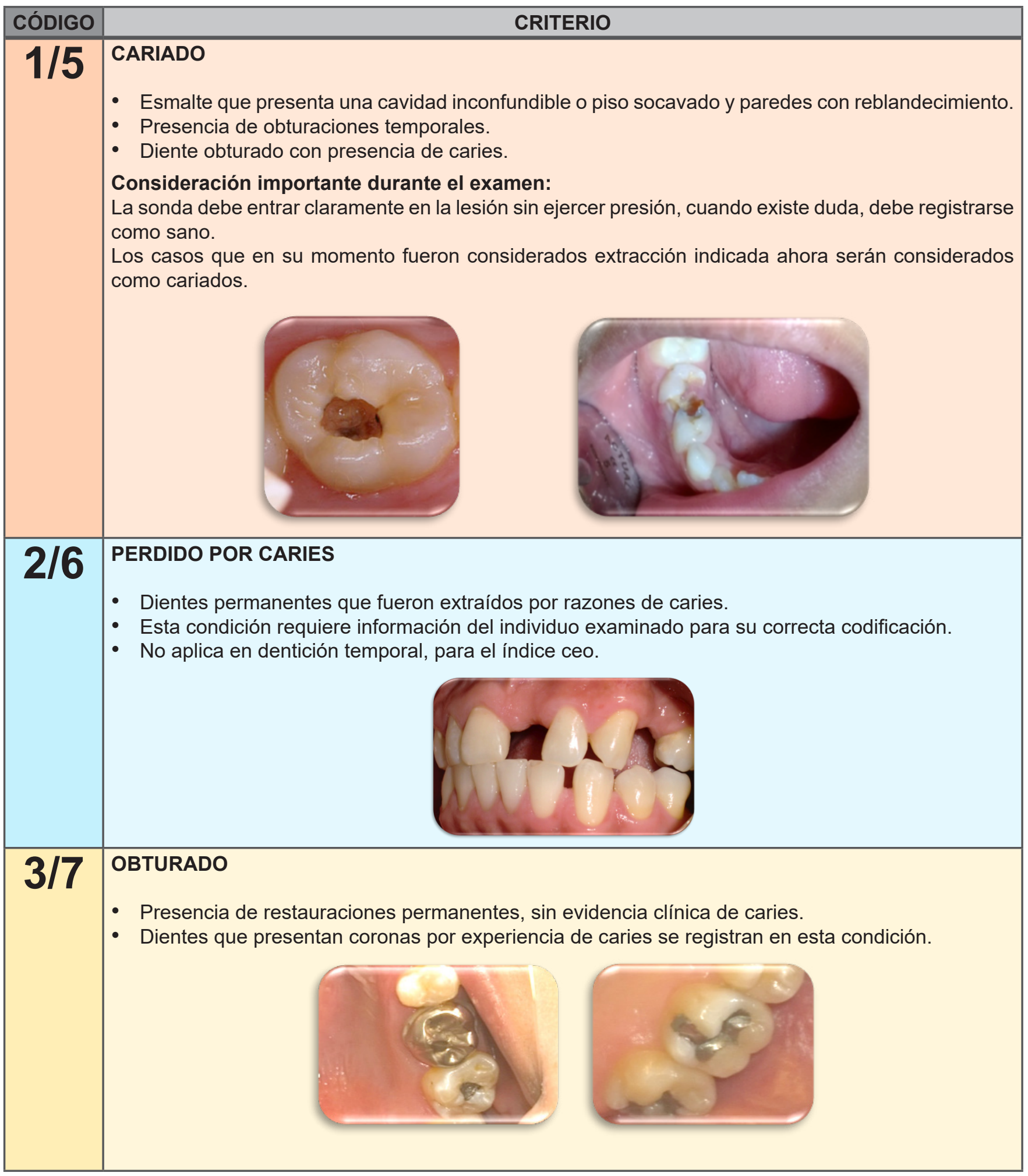




\section{Confiabilidad en la medición de caries dental}

\begin{tabular}{|c|c|}
\hline CÓDIGO & CRITERIO \\
\hline $4 / 8$ & $\begin{array}{l}\text { NO APLICABLE } \\
\text { - Dientes con presencia de coronas por otro motivo diferente a caries, ejemplo de ello el soporte de } \\
\text { una prótesis fija. } \\
\text { - Dientes que presentan obturación de fisura con sellador u otro tipo de material. } \\
\text { - Diente perdido por otra razón diferente a caries, ejemplo de ello es el tratamiento de ortodoncia. } \\
\text { - Se encuentra retenido y la persona examinada lo refiere. } \\
\text { - Dientes que no se pueden observar por presencia de bandas de ortondoncia. } \\
\text { - Dientes fracturados. }\end{array}$ \\
\hline & \\
\hline
\end{tabular}

\section{Procedimiento de recolección}

Se coloca una mesa de trabajo y cerca de ésta otra para el material utilizado (Figura 15) con una bolsa de plástico para los desechos.

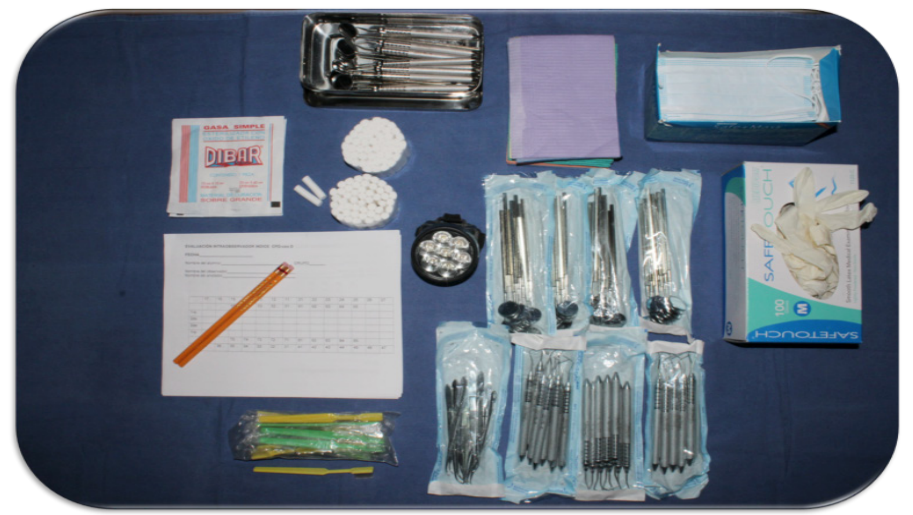

Figura 15. Material requerido para la medición de caries a través del CPOD-cpod. 


\section{CAPÍTULO 3 CPOD - cpod}

Es conveniente que el individuo que será revisado, primero lave sus dientes, en caso de no solicitarlo, se recomienda incluir cepillos de dientes desechables en el material básico de exploración, para remover adecuadamente la comida de las superficies dentales, en caso de ser necesario.

El paciente debe encontrarse recostado, por lo tanto, se tendrá especial cuidado con proteger la privacidad de las participantes con campos de tela; si no se cuenta con una mesa se solicita al individuo que sentado en una silla coloque la cabeza lo más atrás posible.

El observador se coloca a las 12 de acuerdo a las manecillas del reloj y el anotador a una distancia que le permita escuchar claramente los códigos (Figura 16). ${ }^{15}$

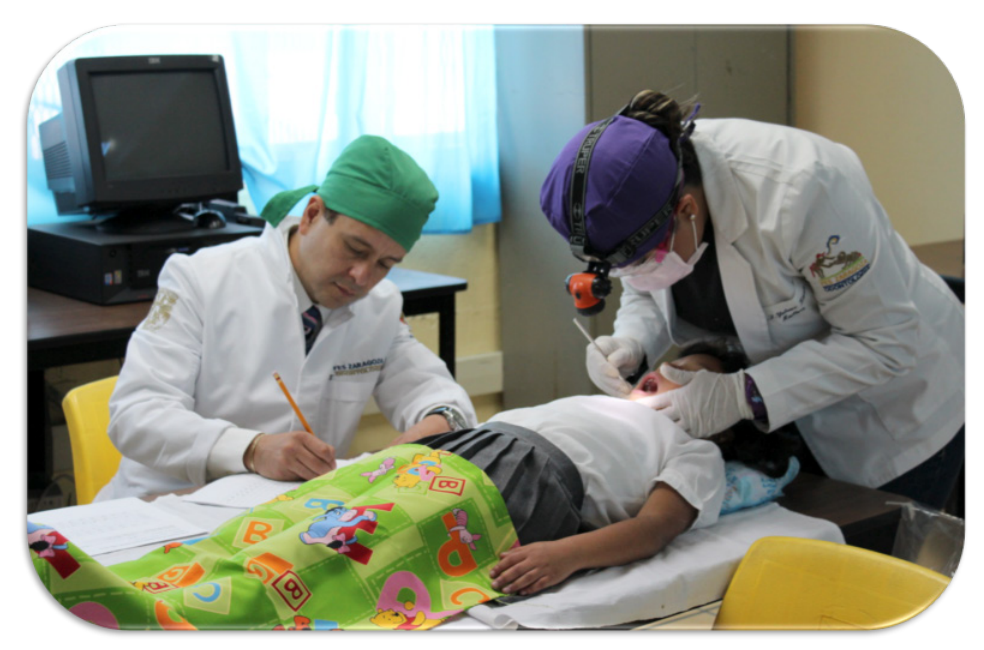

Figura 16. Posición del observador y anotador.

La boca del individuo se orienta hacia la luz natural; en caso de contar con lámpara de luz, en el espectro de blanca a azul, la boca se orienta en sentido opuesto a la luz natural para que ésta no interfiera con la luz de la lámpara. ${ }^{16}$

EI CPOD considera los 32 dientes permanentes y el cpod los 20 dientes temporales; en población de 5 a 15 años es recomendable utilizar el CPOD-cpod por lo tanto la ficha de recolección (Anexo 1-3) incluye la nomenclatura de la dentición mixta, sin embargo, solo se registra un código por cada diente, debemos recordar que cuando se encuentran presentes tanto el diente temporal como el permanente, se registra solo el permanente. $5,10,13,15,17$

Por lo tanto, es recomendable agregar a la ficha de registro del índice un espacio de observaciones en el cual se puede incluir una nota en caso de observarse algún hallazgo que sea necesario tratar con la finalidad de remitir al individuo a tratamiento oportuno, como es el caso de estos dientes temporales que deben ser extraídos para que no interfieran en la posición de los dientes o el caso de abscesos periapicales. ${ }^{17}$

Durante el proceso de estandarización, el observador y anotador deberán conocer la ficha de recolección antes de iniciar con el examen y seguir siempre el mismo orden para el llenado de la misma, la observación se realiza de 18 a 28 y de 48 a 38, por lo tanto el llenado de la ficha se realiza de izquierda a derecha. ${ }^{13}$

Todas las superficies de los dientes deben ser examinadas, se recomienda iniciar con la superficie oclusal, continuar con la superficie mesial del diente y seguir la observación alrededor del diente de acuerdo a las manecillas del reloj, terminando siempre en la cara palatina o lingual (Figura 17). ${ }^{15}$ 


\begin{tabular}{|c|}
\hline $\begin{array}{c}\text { Cuadrantes } \\
\text { I y II }\end{array}$ \\
\hline Oclusal \\
\hline Mesial \\
\hline Vestibular \\
\hline Distal \\
\hline $\begin{array}{c}\text { Palatino o } \\
\text { lingual }\end{array}$ \\
\hline
\end{tabular}

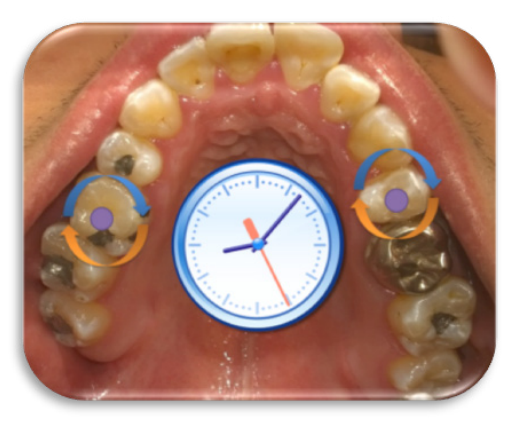

\begin{tabular}{|c|}
\hline $\begin{array}{c}\text { Cuadrantes } \\
\text { III y IV }\end{array}$ \\
\hline Oclusal \\
\hline Mesial \\
\hline Vestibular \\
\hline Distal \\
\hline $\begin{array}{c}\text { Palatino o } \\
\text { lingual }\end{array}$ \\
\hline
\end{tabular}

Figura 17. Secuencia del examen dental.

Esta manera de observar facilita y agiliza el registro sobre todo en el caso de la realización del CPO-S y cpo-s, puesto que el observador solo debe emitir los códigos correspondientes (sin mencionar el diente) y el anotador registra en la ficha siguiendo este orden.

Si la intención del estudio es identificar la extensión de la caries, se utiliza como unidad de medición la "superficie" del diente, de ahí que la nomenclatura del índice es CPO-S y cpo-s. En este caso se incluyen cinco superficies por cada diente posterior y cuatro superficies por cada diente anterior registrando un código para cada una de ellas, obteniendo así un máximo de 148 superficies para dentición de adulto y 88 para dentición infantil.

Cuando se lleva a cabo una encuesta, por ejemplo, para la evaluación de un programa de prevención de la enfermedad, los planificadores podría registrar el estado de la dentición por superficie esto es a través del CPOS. ${ }^{12}$ En el caso de utilizarse como unidad de análisis el "Diente" la nomenclatura corresponde a CPOD-cpod en este caso solo se registra un código que represente la condición del diente observado.

Inicialmente se utilizaba un explorador de punta fina para la detección de las lesiones, ${ }^{6}$ sin embargo, debido a que se ha demostrado que el explorador tiene gran potencial para producir fracturas del esmalte intacto o convertir en irreversibles lesiones que pudieron ser remineralizadas, actualmente se realiza con la sonda periodontal diseñada por la OMS utilizada en el Índice Periodontal Comunitario (IPC) diseñada por la OMS, la cual presenta una esfera de $0.5 \mathrm{~mm}$ en la punta. ${ }^{13,18}$

La utilización de la sonda por lo tanto se traduce en la protección del diente y por otro lado ayuda al examinador a identificar solamente dientes cavitados, siendo ésta la característica de medición del CPOD.

Sin embargo, la utilización del explorador dental en la detección de caries en los diagnósticos epidemiológicos es común pese a sus consecuencias. ${ }^{19,20}$

\section{Procesamiento de los datos recolectados}

- El CPOD, cpod o CPOD-cpod individual se calcula sumando el número de dientes registrados con las condiciones: Cariado, perdido y obturado. ${ }^{13,15}$

- El valor del CPOD y cpod grupal corresponde al promedio del total de dientes con experiencia de caries del grupo examinado. ${ }^{10}$ 


\section{CAPÍTULO 3 CPOD - cpod}

\section{Recursos para el levantamiento epidemiológico}

Físicos

Lugar dentro de la comunidad designado para realizar la actividad, como un aula dentro de una escuela o una sala o auditorio de usos múltiples. El lugar seleccionado deberá estar alejado de distractores para los observadores y anotadores.

\section{Materiales}

- Relación de individuos que serán revisados.

- Mesas y sillas.

- Toallas húmedas desinfectantes.

- Campos para las mesas y para cubrir las piernas.

- Almohadas pequeñas.

- Jabón antibacterial y toallas desechables.

- Barreras de protección (bata, gorros, cubrebocas, guantes).

- Lámparas tipo minero de luz blanca.

- Espejos planos del número 5.

- Sondas periodontal utilizada en el IPC diseñada por la OMS..$^{13}$

- Cajas para esterilización del instrumental.

- Fichas de registro del índice (Anexo 1-3).

- Lápices y gomas.

- Cepillos dentales.

- Gasas.

\section{Humanos}

- Observadores.

- Anotadores.

- Apoyo para organizar la actividad.

\section{Concordancia de la medición}

Antes de la recolección de datos es necesario realizar un ejercicio de estandarización intraexaminador, en caso de que los datos se recolecten por más de un observador también se realizará un ejercicio interexaminador. ${ }^{21}$

El ejercicio consiste en la revisión de un grupo de individuos en dos ocasiones diferentes, separadas por un intervalo de tiempo de 30 minutos. $^{13}$

El observador se limitará a la revisión de lesiones de caries tratando de interactuar lo menos posible con los individuos revisados con la intención de que su segunda observación no se vea afectada por la memoria que pueda tener de la primera observación.

\section{Ejemplo 4.}

En la figura 18, se muestran los registros de experiencia de caries de un examinador a través del CPOS obtenidos de la revisión a un mismo individuo bajo las mismas condiciones después de 30 minutos. 


\section{Confiabilidad en la medición de caries dental}

PRIMERA OBSERVACIÓN -ARCADA SUPERIOR-

\begin{tabular}{|c|c|c|c|c|c|c|c|c|c|c|c|c|c|c|c|c|}
\hline & & & & \multirow[b]{2}{*}{15} & \multirow{2}{*}{\begin{tabular}{|l|}
54 \\
14
\end{tabular}} & \multirow{2}{*}{\begin{tabular}{|l|}
53 \\
13
\end{tabular}} & \multirow{2}{*}{\begin{tabular}{|l|}
52 \\
12
\end{tabular}} & \multirow{2}{*}{\begin{tabular}{|l|}
51 \\
11
\end{tabular}} & \multirow{2}{*}{$\begin{array}{l}61 \\
21\end{array}$} & \multirow{2}{*}{\begin{tabular}{l|l}
62 & \\
22 &
\end{tabular}} & \multirow{2}{*}{\begin{tabular}{l|}
63 \\
23
\end{tabular}} & \multirow{2}{*}{\begin{tabular}{l|}
64 \\
24
\end{tabular}} & \multirow{2}{*}{\begin{tabular}{l|}
65 \\
25
\end{tabular}} & \multirow[b]{2}{*}{26} & \multirow[b]{2}{*}{27} & \multirow[b]{2}{*}{28} \\
\hline & 18 & 17 & 16 & & & & & & & & & & & & & \\
\hline Oclusal & 1 & 1 & 4 & 1 & 3 & - & - & - & - & - & - & 3 & 3 & 1 & 3 & 4 \\
\hline Mesial & 1 & 4 & 4 & 4 & 3 & 4 & 4 & 4 & 1 & 1 & 4 & 4 & 4 & 1 & 4 & 4 \\
\hline Vestibular & 4 & 4 & 1 & 4 & 4 & 4 & 4 & 4 & 4 & 4 & 4 & 4 & 4 & 4 & 4 & 4 \\
\hline Distal & 4 & 1 & 4 & 4 & 4 & 4 & 4 & 4 & 4 & 4 & 4 & 3 & 3 & 4 & 4 & 4 \\
\hline Palatina & 4 & 4 & 1 & 4 & 4 & 4 & 1 & 3 & 4 & 4 & 4 & 4 & 4 & 4 & 4 & 4 \\
\hline
\end{tabular}

SEGUNDA OBSERVACIÓN -ARCADA SUPERIOR-

\begin{tabular}{|c|c|c|c|c|c|c|c|c|c|c|c|c|c|c|c|c|}
\cline { 3 - 15 } \multicolumn{1}{c|}{} & 18 & 17 & 16 & 15 & 14 & 13 & 12 & 11 & 21 & 22 & 23 & 24 & 25 & 26 & 27 & 28 \\
\hline Oclusal & 1 & 1 & 1 & 1 & 3 & - & - & - & - & - & - & 3 & 3 & 1 & 3 & 4 \\
\hline Mesial & 1 & 4 & 4 & 4 & 3 & 4 & 4 & 4 & 1 & 1 & 1 & 1 & 1 & 1 & 1 & 4 \\
\hline Vestibular & 4 & 4 & 1 & 4 & 1 & 4 & 4 & 4 & 4 & 4 & 1 & 1 & 1 & 4 & 4 & 4 \\
\hline Distal & 4 & 1 & 4 & 4 & 4 & 4 & 4 & 4 & 4 & 4 & 1 & 3 & 3 & 1 & 1 & 4 \\
\hline Palatina & 4 & 4 & 1 & 4 & 4 & 4 & 4 & 4 & 4 & 4 & 4 & 4 & 1 & 1 & 4 & 1 \\
\hline
\end{tabular}

PRIMERA OBSERVACIÓN -ARCADA INFERIOR-

\begin{tabular}{|c|c|c|c|c|c|c|c|c|c|c|c|c|c|c|c|c|}
\hline & & & & \multirow[b]{2}{*}{8} & \multirow{3}{*}{84} & \multirow{3}{*}{\begin{tabular}{|l|}
83 \\
43
\end{tabular}} & \multirow{3}{*}{$\begin{array}{l}82 \\
42\end{array}$} & \multirow{3}{*}{$\begin{array}{l}81 \\
41\end{array}$} & \multirow{3}{*}{\begin{tabular}{|l|}
71 \\
31 \\
\end{tabular}} & \multirow{3}{*}{\begin{tabular}{|l|}
72 \\
32
\end{tabular}} & \multirow{3}{*}{$\begin{array}{l}73 \\
33\end{array}$} & \multirow{3}{*}{$\begin{array}{l}74 \\
34\end{array}$} & \multirow{3}{*}{$\begin{array}{l}75 \\
35\end{array}$} & & \multirow[b]{3}{*}{38} \\
\hline & & & & & & & & & & & & & & & & \\
\hline & 48 & 47 & 46 & 45 & & & & & & & & & & 36 & 37 & \\
\hline Oclusal & 1 & 1 & 1 & 1 & 3 & - & - & - & - & - & - & 3 & 3 & 1 & 3 & 4 \\
\hline Mesial & 1 & 4 & 1 & 1 & 4 & 4 & 4 & 4 & 4 & 4 & 4 & 4 & 4 & 1 & 4 & 1 \\
\hline Vestibular & 4 & 4 & 1 & 4 & 4 & 4 & 4 & 4 & 4 & 4 & 4 & 4 & 4 & 1 & 1 & 4 \\
\hline Distal & 1 & 4 & 4 & 4 & 4 & 4 & 4 & 4 & 4 & 4 & 4 & 4 & 4 & 1 & 4 & 1 \\
\hline Lingual & 4 & 4 & 1 & 4 & 4 & 4 & 4 & 4 & 4 & 4 & 4 & 4 & 4 & 4 & 4 & 4 \\
\hline
\end{tabular}

SEGUNDA OBSERVACIÓN -ARCADA INFERIOR-

\begin{tabular}{|c|c|c|c|c|c|c|c|c|c|c|c|c|c|c|c|c|}
\hline & & & & 85 & 84 & 83 & 82 & 81 & 71 & 72 & 73 & 74 & 75 & & & \\
\hline & 48 & 47 & 46 & 45 & 44 & 43 & 42 & 41 & 31 & 32 & 33 & 34 & 35 & 36 & 37 & 38 \\
\hline Oclusal & 4 & 1 & 1 & 1 & 3 & - & - & - & - & - & - & 3 & 3 & 3 & 3 & 1 \\
\hline Mesial & 4 & 4 & 1 & 3 & 4 & 4 & 4 & 4 & 4 & 4 & 4 & 1 & 4 & 1 & 4 & 1 \\
\hline Vestibular & 4 & 4 & 1 & 4 & 4 & 4 & 4 & 4 & 4 & 4 & 4 & 4 & 4 & 1 & 1 & 4 \\
\hline Distal & 4 & 4 & 4 & 4 & 4 & 4 & 4 & 4 & 4 & 4 & 4 & 4 & 4 & 1 & 4 & 1 \\
\hline Lingual & 4 & 4 & 1 & 4 & 4 & 4 & 4 & 4 & 4 & 4 & 4 & 4 & 4 & 1 & 4 & 4 \\
\hline
\end{tabular}

Figura 18. Registro de experiencia de caries CPOS del ejemplo 4.

Con la intensión de identificar la concordancia entre sus mediciones se realiza el cálculo del coeficiente de kappa. ${ }^{21}$ Primero se elabora la tabla de contingencia de $5 \times 5$ ya que se incluye una columna y una fila por cada condición del indicador (Figura 19).

Se consideran concordancias los registros que coinciden entre las dos mediciones de una misma superficie, por ejemplo, en el diente 16 tanto en el primer registro, como en el segundo el observador identificó con caries (código 1) las superficies vestibular y palatina, e identificó como sanas (código 4) las superficies mesial y distal.

Así mismo, se observó una discordancia, puesto que la superficie oclusal primero se registró como sana (código 4) y en la segunda observación se registró con caries (código 1).

En las celdas de la tabla de contingencia se escriben las frecuencias correspondientes a los registros de las concordancias y discordancias.

Las filas corresponden a los registros de la primera observación, las columnas a los registros de la segunda observación, de tal manera que en la primera celda se anota una frecuencia de 24 concordancias 1-1, en las cuales tanto en la primera como en la segunda observación se registró el código 1 para la misma superficie.

De la misma manera se pueden identificar 11 concordancias 3-3 y 88 concordancias 4-4.

En la celda que hace intersección la fila 1 y la columna 3 se anotó una frecuencia de 2, ya que es el número de veces en las cuales primero se registró el código 1 y en la segunda medición se registró el código 3 , estas discordancias se observan en superficies mesial del diente 45 y oclusal del diente 36. 


\section{CAPÍTULO 3 CPOD - cpod}

También se observaron 4 discordancias en donde primero se registró el código 1 y en la segunda observación se registro el código 4, las cuales corresponden a superficies: palatina del diente 12 y oclusal, mesial y distal del diente 48.

Se anotaron 18 discordancias en la cual en la primera observación se registró el código 4 y en la segunda observación el código 1.

Finalmente, 1 discordancia más donde primero se registró 3 y en la segunda observación se registró 4 .

SEGUNDA OBSERVACIÓN

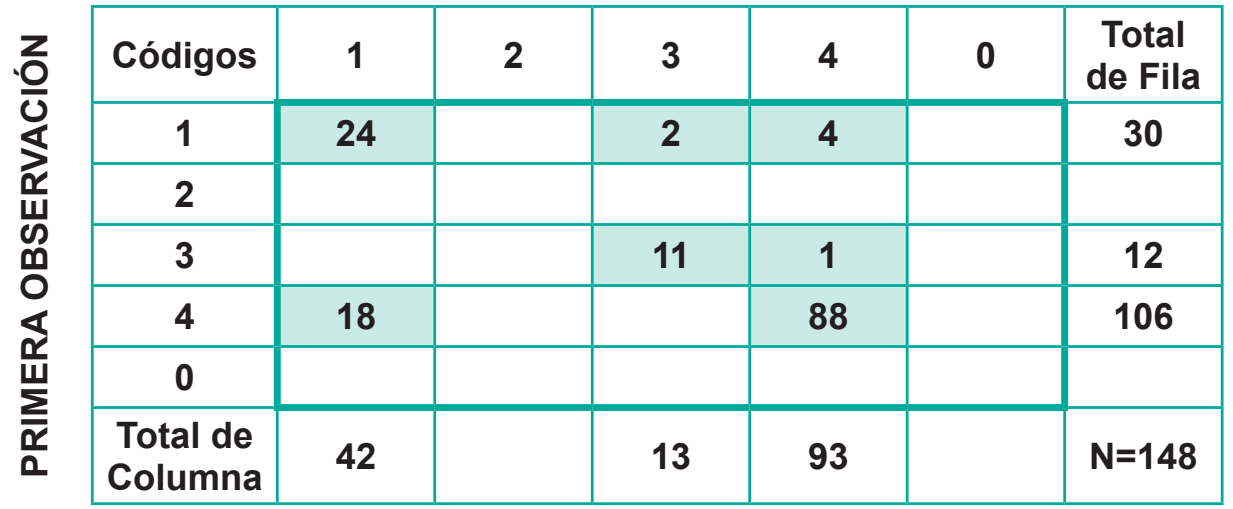

Figura 19. Tabla de contingencia del ejemplo 4 - CPOS.

$$
k=\frac{P o-P e}{1-P e}
$$

Una vez identificadas todas las concordancias y discordancias en la tabla de contingencia se obtiene el Total de Fila (TF) y Total de Columna (TC) sumando la frecuencia por cada fila y columnas, anotando la cifra en el margen correspondiente. Con la intención de corroborar que se han incluido todos los datos, la sumatoria de los márgenes debe corresponder al total de datos.

Recordemos que la fórmula de la prueba de kappa es:

Donde:

Po $=$ Proporción observada .

$\mathrm{Pe}=$ Proporción esperada.

$$
\mathrm{Po}=\frac{\mathrm{N}-\text { discordancias }}{\mathrm{N}}
$$

La fórmula para calcular la proporción observada es:

$$
\mathrm{Po}=\frac{148-25}{148}=\frac{123}{148}=\mathbf{0 . 8 3}
$$

Posteriormente, se calcula la Proporción esperada, con la siguiente fórmula: 


$$
\mathrm{Pe}=\sum[\mathrm{TF} / \mathrm{N}][\mathrm{TC} / \mathrm{N}]
$$

Para ello se utiliza la tabla de contingencia, como se muestra en la Figura 20:

PRIMERA OBSERVACIÓN

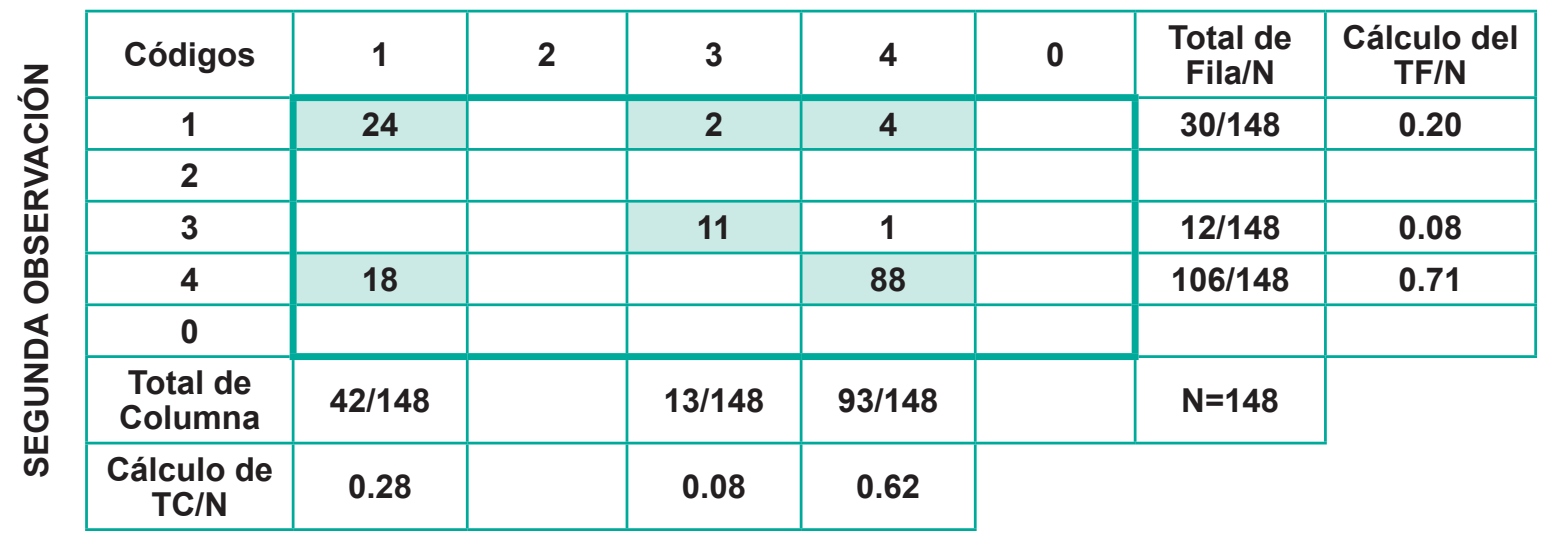

Figura 20. Cálculo del total de fila y columna del ejemplo 4-CPOS.

De tal manera que el cálculo de Pe es:

$$
\begin{aligned}
& \mathrm{Pe}=\sum[\mathrm{TF} / \mathrm{N}][\mathrm{TC} / \mathrm{N}] \\
& \mathrm{Pe}=[30 / 148][42 / 148]+[12 / 148][13 / 148]+[106 / 148][93 / 148] \\
& \mathrm{Pe}=[0.20][0.28]+[0.08][0.08]+[0.71][0.62] \\
& \mathrm{Pe}=0.05+0.00+0.44 \\
& \mathrm{Pe}=\mathbf{0 . 4 9}
\end{aligned}
$$

Por lo tanto, al despejar en:

$$
k=\frac{P o-P e}{1-P e}=\frac{0.83-0.49}{1-0.49}=\frac{0.34}{0.51}=\mathbf{0 . 6 6}
$$

Interpretación: El observador obtuvo un índice de kappa de 0.66 , por lo tanto, tienen una condición sustancial de acuerdo a los criterios de Landis y Koch.

En este caso, es importante que el examinador pueda comparar sus registros con la condición de las superficies y discutir con un observador experto los casos en los cuales obtuvo dsiscordancias para tomar una decisión de diagnóstico. Una vez llevado a cabo este ejercicio repetir su ejercicio intraexaminador hasta alcanzar una concordancia $\geq 0.81$ de acuerdo a los criterios de Landis y Koch.

\section{Ejemplo 5.}

En la Figura 21, se muestran los registros de experiencia de caries de dos examinadores a través del índice cpos obtenidos de la revisión a un mismo individuo bajo las mismas condiciones. 
EXAMINADOR 1 - ARCADA SUPERIOR-

\begin{tabular}{|l|c|c|c|c|c|c|c|c|c|c|}
\hline & 55 & 54 & 53 & 52 & 51 & 61 & 62 & 63 & 64 & 65 \\
\hline Oclusal & 7 & 7 & - & - & - & - & - & - & 5 & 0 \\
\hline Mesial & 7 & 8 & 8 & 8 & 5 & 5 & 8 & 8 & 5 & 0 \\
\hline Vestibular & 7 & 8 & 8 & 8 & 8 & 8 & 8 & 8 & 8 & 0 \\
\hline Distal & 7 & 8 & 8 & 8 & 8 & 8 & 8 & 8 & 8 & 0 \\
\hline Palatina & 7 & 8 & 8 & 8 & 8 & 8 & 8 & 8 & 8 & 0 \\
\hline
\end{tabular}

EXAMINADOR 2 - ARCADA SUPERIOR-

\begin{tabular}{|l|c|c|c|c|c|c|c|c|c|c|}
\hline & 55 & 54 & 53 & 52 & 51 & 61 & 62 & 63 & 64 & 65 \\
\hline Oclusal & 7 & 7 & - & - & - & - & - & - & 5 & 0 \\
\hline Mesial & 7 & 8 & 8 & 8 & 8 & 8 & 8 & 8 & 5 & 0 \\
\hline Vestibular & 7 & 5 & 8 & 8 & 8 & 8 & 8 & 8 & 5 & 0 \\
\hline Distal & 7 & 8 & 8 & 8 & 8 & 8 & 8 & 8 & 5 & 0 \\
\hline Palatina & 7 & 8 & 8 & 8 & 8 & 8 & 8 & 8 & 8 & 0 \\
\hline
\end{tabular}

EXAMINADOR 1 - ARCADA INFERIOR-

\begin{tabular}{|l|c|c|c|c|c|c|c|c|c|c|}
\hline & 85 & 84 & 83 & 82 & 81 & 71 & 72 & 73 & 74 & 75 \\
\hline Oclusal & 7 & 7 & - & - & - & - & - & - & 5 & 0 \\
\hline Mesial & 8 & 8 & 8 & 8 & 8 & 8 & 8 & 8 & 5 & 0 \\
\hline Vestibular & 8 & 8 & 8 & 8 & 8 & 8 & 8 & 8 & 8 & 0 \\
\hline Distal & 8 & 8 & 8 & 8 & 8 & 8 & 8 & 8 & 8 & 0 \\
\hline Palatina & 8 & 8 & 8 & 8 & 8 & 8 & 8 & 8 & 8 & 0 \\
\hline
\end{tabular}

EXAMINADOR 2 - ARCADA INFERIOR-

\begin{tabular}{|l|c|c|c|c|c|c|c|c|c|c|}
\hline & 85 & 84 & 83 & 82 & 81 & 71 & 72 & 73 & 74 & 75 \\
\hline Oclusal & 7 & 7 & - & - & - & - & - & - & 5 & 0 \\
\hline Mesial & 8 & 8 & 8 & 8 & 8 & 8 & 8 & 8 & 5 & 0 \\
\hline Vestibular & 8 & 8 & 8 & 8 & 8 & 8 & 8 & 8 & 8 & 0 \\
\hline Distal & 8 & 8 & 8 & 8 & 8 & 8 & 8 & 8 & 8 & 0 \\
\hline Palatina & 8 & 8 & 8 & 8 & 8 & 8 & 8 & 8 & 5 & 0 \\
\hline
\end{tabular}

Figura 21. Registro de experiencia de caries cpos del ejemplo 5.

Se elabora la tabla de contingencia de $5 \times 5$ con base en los códigos de cpos, en la cual se anotan las frecuencias de las concordancias y discordancias (Figura 22).

EXAMINADOR 2

\begin{tabular}{|c|c|c|c|c|c|c|}
\hline Códigos & 5 & 6 & 7 & 8 & 0 & $\begin{array}{c}\text { Total de } \\
\text { Fila }\end{array}$ \\
\hline 5 & 4 & & & 2 & & 6 \\
\hline 6 & & & & & & \\
\hline 7 & & & 8 & & & 8 \\
\hline 8 & 4 & & & 60 & & 64 \\
\hline 0 & & & & & 10 & 10 \\
\hline $\begin{array}{l}\text { Total de } \\
\text { Columna }\end{array}$ & 8 & & 8 & 62 & 10 & $N=88$ \\
\hline
\end{tabular}

Figura 22. Tabla de contingencia del ejemplo 5 -ceos. 


\section{Confiabilidad en la medición de caries dental}

Una vez identificadas las discordancias es posible sustituir en la fórmula para obtener Po:

$$
\begin{gathered}
\mathrm{Po}=\frac{\mathrm{N}-\text { discordancias }}{\mathrm{N}} \\
\mathrm{Po}_{\mathrm{O}}=\frac{88-6}{88}=\frac{82}{88}=\mathbf{0 . 9 3}
\end{gathered}
$$

El cálculo de Pe requiere la obtención del total de fila y total de columna (Figura 23).

EXAMINADOR 2

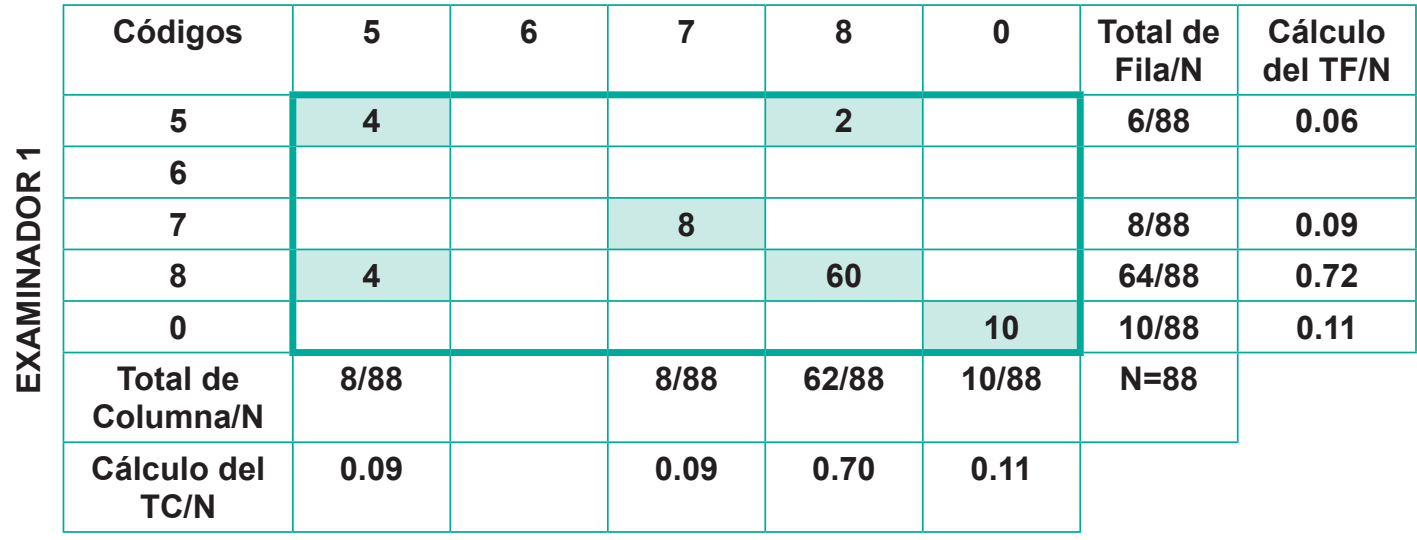

Figura 23. Cálculo del total de fila y columna del ejemplo 5-ceos.

$\mathrm{Pe}=\sum[\mathrm{TF} / \mathrm{N}][\mathrm{TC} / \mathrm{N}]$

$\mathrm{Pe}=[6 / 88][8 / 88]+[8 / 88][8 / 88]+[64 / 88][62 / 88]+[10 / 88][10 / 88]$

$\mathrm{Pe}=[0.06][0.09]+[0.09][0.09]+[0.72][0.70]+[0.11][0.11]$

$\mathrm{Pe}=0.00+0.00+0.50+0.01$

$\mathrm{Pe}=\mathbf{0 . 5 1}$

$$
k=\frac{P o-P e}{1-P e}=\frac{0.93-0.51}{1-0.51}=\frac{0.42}{0.49}=0.85
$$

Interpretación: Los examinadores obtuvieron un coeficiente de kappa de 0.85 , por lo tanto, tienen una concordancia casi perfecta de acuerdo a los criterios de Landis y Koch.

\section{Ejemplo 6.}

Se presentan los registros de experiencia de caries de dos examinadores (Figura 24) obtenidos a través del CPODcpod después de la revisión al mismo individuo bajo las mismas condiciones. 


\section{EXAMINADOR 1}

\begin{tabular}{|c|c|c|c|c|c|c|c|c|c|c|c|c|c|c|c|}
\hline & 55 & 54 & 53 & 52 & 51 & 61 & 62 & 63 & 64 & 65 & & & \\
\hline 18 & 17 & 16 & 15 & 14 & 13 & 12 & 11 & 21 & 22 & 23 & 24 & 25 & 26 & 27 & 28 \\
\hline 0 & 4 & 1 & 4 & 4 & 8 & 4 & 4 & 4 & 4 & 5 & 4 & 4 & 1 & 4 & 0 \\
\hline 0 & 4 & 4 & 4 & 4 & 4 & 4 & 4 & 4 & 4 & 5 & 4 & 4 & 1 & 4 & 0 \\
\hline 48 & 47 & 46 & 45 & 44 & 43 & 42 & 41 & 31 & 32 & 33 & 34 & 35 & 36 & 37 & 38 \\
\hline & & & 85 & 84 & 83 & 82 & 81 & 71 & 72 & 73 & 74 & 75 & & & \\
\hline
\end{tabular}

\section{EXAMINADOR 2}

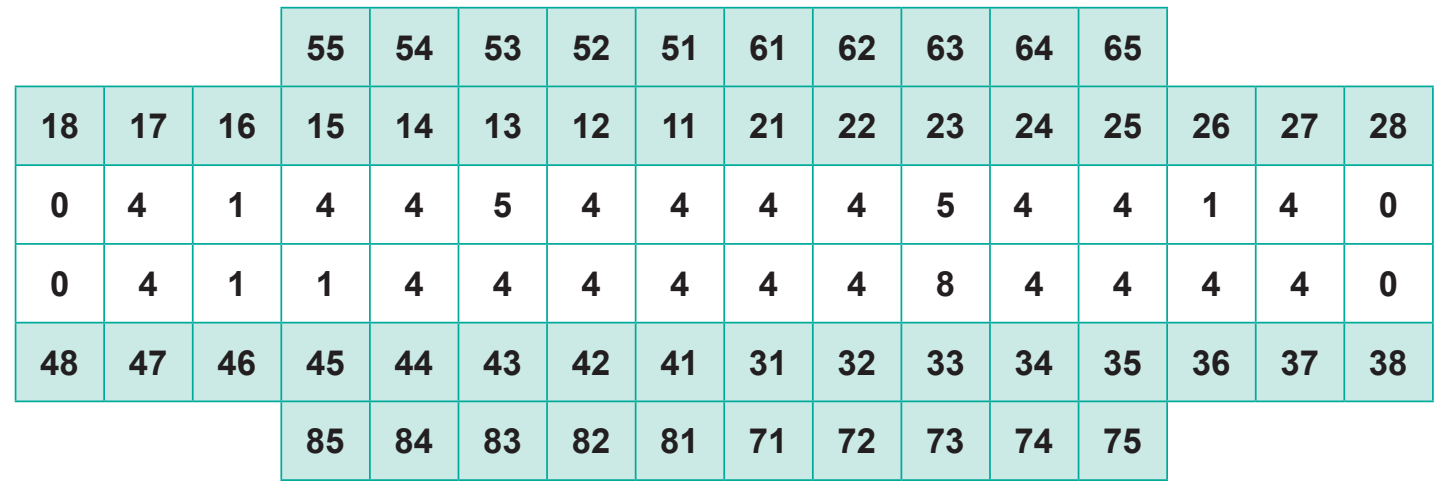

Figura 24. Registro de experiencia de caries CPOD-cpod del ejemplo 6.

Se inicia con la elaboración de la tabla de contingencia, en este caso incluyendo los códigos para los dientes temporales y permanentes (Figura 25).

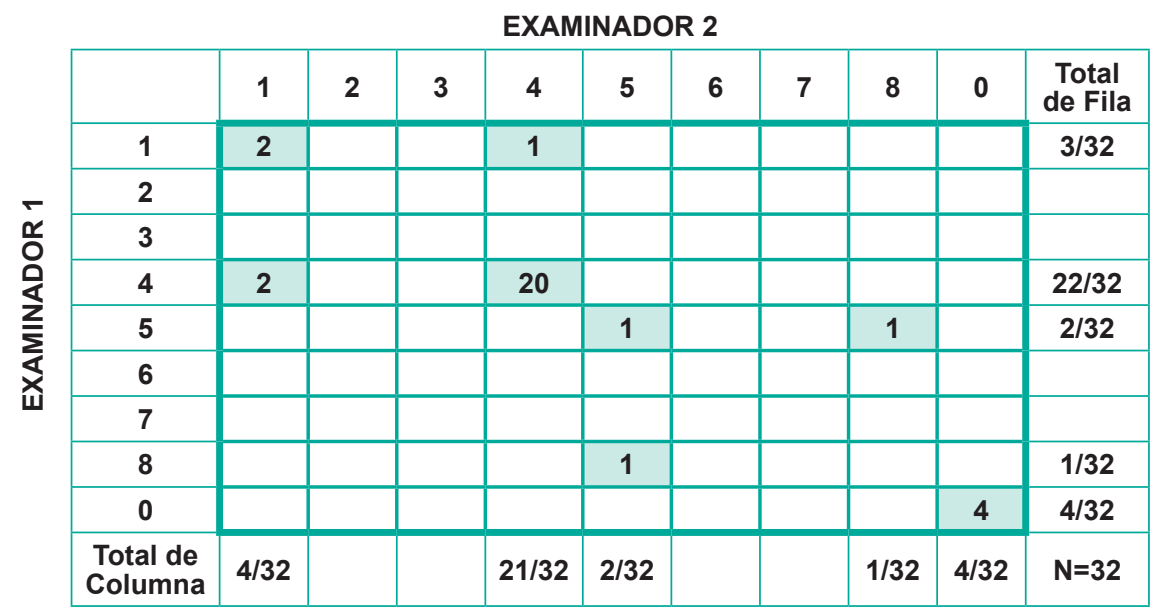

Figura 25. Tabla de contingencia del ejemplo 6 - CPOD-ceod. 


\section{Confiabilidad en la medición de caries dental}

Se sustituye en la fórmula de Po:

$$
\begin{gathered}
P o=\frac{N-\text { discordancias }}{N} \\
P o=\frac{32-5}{32}=\frac{27}{32}=0.84
\end{gathered}
$$

\begin{tabular}{|c|c|c|c|c|c|c|c|c|c|c|c|}
\hline \multicolumn{12}{|c|}{ EXAMINADOR 2} \\
\hline & 1 & 2 & 3 & 4 & 5 & 6 & 7 & 8 & 0 & $\begin{array}{c}\text { Total de } \\
\text { Fila/N }\end{array}$ & $\begin{array}{l}\text { Cálculo } \\
\text { del TF/N }\end{array}$ \\
\hline 1 & 2 & & & 1 & & & & & & $3 / 32$ & 0.09 \\
\hline 2 & & & & & & & & & & & \\
\hline 3 & & & & & & & & & & & \\
\hline 4 & 2 & & & 20 & & & & & & $22 / 32$ & 0.68 \\
\hline 5 & & & & & 1 & & & 1 & & $2 / 32$ & 0.06 \\
\hline 6 & & & & & & & & & & & \\
\hline 7 & & & & & & & & & & & \\
\hline 8 & & & & & 1 & & & & & $1 / 32$ & 0.03 \\
\hline 0 & & & & & & & & & 4 & $4 / 32$ & 0.12 \\
\hline $\begin{array}{c}\text { Total de } \\
\text { Columna/N }\end{array}$ & $4 / 32$ & & & $21 / 32$ & $2 / 32$ & & & $1 / 32$ & $4 / 32$ & $\mathrm{~N}=32$ & \\
\hline $\begin{array}{c}\text { Cálculo del } \\
\text { TC/N }\end{array}$ & 0.12 & & & 0.65 & 0.06 & & & 0.03 & 0.12 & & \\
\hline
\end{tabular}

Posteriormente se obtendrá Pe, para ello es necesario calcular el margen de columna y fila (Figura 26).

Figura 26. Cálculo del total de fila y columna del ejemplo 6 - CPOD-cpod.

Los datos obtenidos se sustituyen en la formula:

$\mathrm{Pe}=\sum[\mathrm{TF} / \mathrm{N}][\mathrm{TC} / \mathrm{N}]$

$\mathrm{Pe}=[3 / 32][4 / 32]+[22 / 32][21 / 32]+[2 / 32][2 / 32]+[1 / 32][1 / 32]+[4 / 32][4 / 32]$

$\mathrm{Pe}=[0.09][0.12]+[0.68][0.65]+[0.06][0.06]+[0.03][0.03]+[0.12][0.12]$

$\mathrm{Pe}=0.01+0.44+0.0+0.00+0.01$

$\mathrm{Pe}=\mathbf{0 . 4 6}$

Finalmente, se obtiene el coeficiente de kappa a partir de la fórmula:

$$
k=\frac{P o-P e}{1-P e}=\frac{0.84-0.46}{1-0.46}=\frac{0.38}{0.54}=\mathbf{0 . 7 0}
$$

Interpretación: Los examinadores obtuvieron un coeficiente de kappa de 0.70, por lo tanto, tienen una concordancia casi sustancial de acuerdo a los criterios de Landis y Koch.

Este valor indica que no existe concordancia entre las mediciones de los examinadores al valorar la condición de caries y diente sano, por lo tanto vale la pena observar nuevamente los cados de discordancia y discutir los criterios que llevaron a tal resultado. Posteriormente el ejercicio de observación debe ser repetido en otro grupo de individuos para lograr la estandarización entre los examinadores implicados. 


\section{Bibliografia}

1. Alves FP, Ventura SR, Vianna VM. Fatores associados a cárie dental e doença periodontal em indígenas na América Latina: revisão sistemática. Rev Panam Salud Publica. 2014;35(1):67-77.

2. Padilla SB, Llodra CJ, Belío RI, García JR, Osuna RI, Ramírez AM, Loyola RJ. Predicción de riesgo de caries en escolares del noroeste de México: estudio longitudinal. Revista de Investigación Clínica. 2013; 65(1): 24-29.

3. Sanín GB, Aránzazu J, Angarita JA, Rodríguez MJ, Flórez LT. Estimación del riesgo de caries dental mediante el uso del Cariograma en estudiantes de odontología: análisis preliminar. Ustasalud. 2011; 10: 83-90.

4. Sánchez HY, Sence CR. Ensayo comunitario de intervención: incidencia de caries en preescolares de un programa educativo preventivo en salud bucal. Rev Estomatol Herediana. 2012; 22(1): 3-15.

5. Malmö University, WHO. Caries Prevalence: DMFT and DMFS.Oral Health Country/AreaProfile Project [en línea].2011 [citado 1 diciembre 2015];Disponible en: https:// www.mah.se/CAPP/Methods-and-Indices/forCaries-prevalence/.

6. Klein H, Palmer CE. Dental caries in American e Indian childrens. Public HealtBoletin. 1937. [citado 5 agosto 2015]; Disponible en: http://babel.hathitrust.org/cgi/pt?id=mdp.39015006457702;view=1up;seq=24;skin=mobile.

7. Klein H, Palmer CE, Knutson JW. Studies on dental caries: I. Dental Status and Dental Needs of Elementary school children. Public Health Reports. 1938;53(19):751-765.

8. Secretaría de Salud. Encuesta Nacional de Caries Dental 2001. México: Centro Nacional de Vigilancia Epidemiológica y Control de Enfermedades; 2001.

9. Ministerio de Salud. Encuesta Nacional de caries Ministerio de Salud. Prevalencia Nacional de caries dental, fluorosis del esmalte y urgencias de tratamiento en escolares de 6 a 8, 10, 12 y 15 años, Perú. 2001-2002. Oficina General de Epidemiología y Dirección General de Salud de las Personas. Lima 2005. Serie Informes Técnicos de Investigación epidemiológica No. 05/050. [citado 5 agosto 2015]; Disponible en: http://www.dge. gobpe/publi9caciones/pub_caries/.

10. Mena GA, Rivera L. Epidemiología bucal, conceptos básicos. Venezuela: OFEDO/DUAL; 1991.

11. Adriano AM, Caudillo JT, Gómez CA. Epidemiología estomatológica, situación actual y perspectiva. 2a. ed. México: FES Zaragoza; 2001.

12. Higashida BY. Odontología preventiva. 2a. ed. México: McGraw Hill; 2009.

13. World Health Organization. Oral Health Surveys. Basic Methods. 5th ed. Geneve: WHO; 2013.

14. Klein H, Palmer CE. Studies on dental caries: V. Familial resemblance in the caries experience of siblings. Public Health Reports. 1938:53(31):1353-1364.

15. Murrieta PJ, López RY, Juárez LL. Índices epidemiológicos de morbilidad bucal. México: Ed. Ideograma; 2006.

16. Organización Panamericana de la Salud. Encuesta Nacional de Salud Oral, calibración de examinadores. República de El Salvador: Unidad de Salud Oral del Ministerio de Salud y Asistencia Social; 2008. [citado 15 agosto 2015]; Disponible en: http://www2.paho.org/hq/dmdocuments/2009/OH_ELS_EncSaludOralCalexam2008.pdf.

17. Organización Mundial de la Salud. Encuesta de salud bucodental, Métodos Básicos. 4a. ed. OMS: Ginebra; 1997.

18. Lizmar DV, Acevedo AM, Rojas SF. Métodos convencionales y no convencionales para la detección de la lesión inicial de caries. Revisión bibliográfica. Acta Odontológica Venezolana. [en línea]. 2011 [citado 15 agosto 2015];49(2):1-14. Disponible en: http://actaodontologica.com/ediciones/2011/2/ pdf/art21.pdf.

19. Ministerio de Salud de la Nación. Indicadores epidemiológicos para la caries dental. Buenos Aires: 2013 [citado 1 diciembre 2015]. Disponible en: http://www.msal.gob.ar/images/stories/bes/graficos/0000000236cntprotocolo-indice-cpod.pdf.

20. Zambrano JG, Urbina BH, Esis VI, Acevedo AM. Patrón de caries dental en indígenas residentes en Corozal, Maniapure, Estado de Bolivar, Venezuela. Acta odontológica Vanezolana [en línea]. 2014 [citado 1 diciembre 2015]; 5(1): Disponible en: http://actaodontologica.com/ediciones/2014/1/art13.asp.

21. Cerda LJ, Villaroel del PL. Evaluación de la concordancia inter-observador en investigación pediátrica: Coeficiente de Kappa. Rev Chil Pediatr. 2008;79(1):54-58.

\section{Consultar el video de apoyo del Capítulo 3: "Índice CPOD-cpod", en la pestaña del Módulo Estomatología Social II http://www.zaragoza.unam.mx/herramientas-para-el-aprendizaje/}





\title{
CAPít́tulo 4
}

\section{Índice para evaluar el estado de la dentición y tratamiento necesario}

\author{
MARÍA DEL CARMEN COR'TÉS QUIROZ \\ RODOLFO GUSTAVO RAMÍREZ SÁ YCHEZ
}

\section{Generalidades}

Los indicadores epidemiológicos para medir la caries dental dan cuenta de diferentes momentos de la historia natural de esta alteración, de acuerdo con Piovano ${ }^{1}$ y Bordoni, ${ }^{2}$ se pueden mencionar algunos índices que responden a diferentes necesidades de los estudios, por ejemplo:

a) Cuando se desea conocer la experiencia de caries (CPOD, cpod). ${ }^{3}$

b) Para identificar los factores de riesgo (Cariograma). ${ }^{4}$

c) Con la intención de identificar las necesidades de tratamiento realcionadas con experiencia de caries de una población (Índice de Necesidad de Tratamiento para Caries dental). ${ }^{1}$

d) Para el estudio detallado del desarrollo de la caries dental (índice de Nyvad e ICDAS). ${ }^{5}$

Existen por lo tanto, una gran variación en los criterios de diagnóstico epidemiológico para identificar el proceso de caries dental, uno de ellos es el que ha desarrollado la $\mathrm{OMS}^{5,6}$ con el nombre de índice del estado de la dentición y tratamiento necesario, el cual no solo incluye la valoración del diente a través de los criterios del CPOD-cpod, sino que toma en consideración otros estados del diente que no están relacionados con la experiencia de caries con la intención de acercar al investigador a las necesidades de tratamiento dental de la población.

El índice del estado de la dentición y tratamiento necesario por lo tanto, se encuentra estructurado por dos componentes: $:^{7,8}$

1) El estado de la dentición, que permite obtener la experiencia de caries CPOD y cpod y otras condiciones dentales.

2) El tratamiento necesario, por lo tanto, a través de éste se puede planear la intervención clínica.

El índice del estado de la dentición y tratamiento necesario tiene como unidad de medición el diente y establece un esquema que permite comparar fácilmente la condición de salud bucal entre diferentes grupos, además de identificar las necesidades de tratamiento odontológico de un paciente o de un grupo a partir de su estado de salud bucal actual, características que lo convierten en el indicador adecuado en el diagnóstico epidemiológico que servirá como base para la elaboración de programas de intervención o rehabilitación clínica. 5,6

Una característica importante de este indicador, es que además de llevar a cabo la observación de la corona dental, también se incluye la evaluación de la condición de la raíz; ${ }^{4,5}$ situación que favorece la identificación de las necesidades de tratamiento en población adulta, como lo muestra Ángel y colaboradores, al aplicar el indicador en población adulta de la Isla Huapi (Chile). ${ }^{9}$ 


\section{Confiabilidad en la medición de caries dental}

La utilización de este indicador se ha realizado con mayor frecuencia para identificar las necesidades de tratamiento de tipo curativo, que en la población mexicana estudiada son altas ya que van de $83 \%$ a $97 \%$. $^{10-13}$

Vale la pena mencionar que al utilizar este indicador se puede destacar la necesidad de tratamiento preventivo como lo han descrito algunos autores ${ }^{15-18}$ al identificar las necesidades de barniz de fluoruro o selladores.

Así mismo, estas necesidades de tratamiento pueden organizarse de forma específica, como lo han hecho Piovano y Bordoni, ${ }^{1} 19$ quienes para su utilización en programas dirigidos a niños y adolescentes dividen a la población en tres grupos:

- Grupo 1, población que presenta boca sana y que se encuentra en un plan preventivo. Por lo tanto se considera sin necesidades de tratamiento.

- Grupo 2, población que presenta boca sana y que no tiene un plan preventivo. Por lo tanto la necesidad de tratamiento es incluirlos en un plan preventivo.

- Grupo 3, población que presenta alguna necesidad de tratamiento dental y se complementa con el plan preventivo.

De tal manera que este indicador provee datos epidemiológicos que pueden guiar las acciones administrativas en la planeación de servicios de salud bucal.

\section{Códigos y criterios del índice para evaluar el estado de la dentición y tratamiento necesario}

En la ficha de registro (Anexo 4) se anotan tres códigos para cada diente: dos de ellos corresponden a la condición de la corona y raíz respectivamente, y el tercero al tratamiento necesario. El registro de la condición de la corona y raíz se llevan a cabo con base en los códigos presentados en la cuadro 7 siguiendo los criterios descritos en la cuadro 8.

Cuadro 7. Códigos y condición del estado del diente.

\begin{tabular}{|c|c|c|c|}
\hline $\begin{array}{c}\text { Códigos para } \\
\text { dientes temporales }\end{array}$ & \multirow[t]{2}{*}{ Estado de la dentición } & \multicolumn{2}{|c|}{$\begin{array}{l}\text { Códigos para dientes } \\
\text { permanentes }\end{array}$} \\
\hline Corona & & Corona & Raíz \\
\hline A & SATISFACTORIO & 0 & 0 \\
\hline $\mathrm{B}$ & CARIADO & 1 & 1 \\
\hline C & OBTURADO, CON CARIES & 2 & 2 \\
\hline $\mathrm{D}$ & OBTURADO SIN CARIES & 3 & 3 \\
\hline$E$ & PERDIDO COMO RESULTADO DE CARIES & 4 & ----- \\
\hline----- & PERDIDO POR CUALQUIER OTRO MOTIVO & 5 & ----- \\
\hline $\mathrm{F}$ & FISURA OBTURADA & 6 & ----- \\
\hline G & $\begin{array}{c}\text { SOPORTE DE PUENTE, CORONA ESPECIAL O } \\
\text { FUNDA/IMPLANTE }\end{array}$ & 7 & 7 \\
\hline----- & DIENTE SI BROTAR (CORONA) O RAÍZ CUBIERTA & 8 & 8 \\
\hline $\mathrm{T}$ & TRAUMATISMO (FRACTURA) & $\mathrm{T}$ & ----- \\
\hline & NO REGISTRADO & 9 & 9 \\
\hline
\end{tabular}




\section{CAPÍTULO 4 Índice para evaluar el estado de la dentición y tratamiento necesario}

Cuadro 8. Criterios para identificar el estado de la dentición.

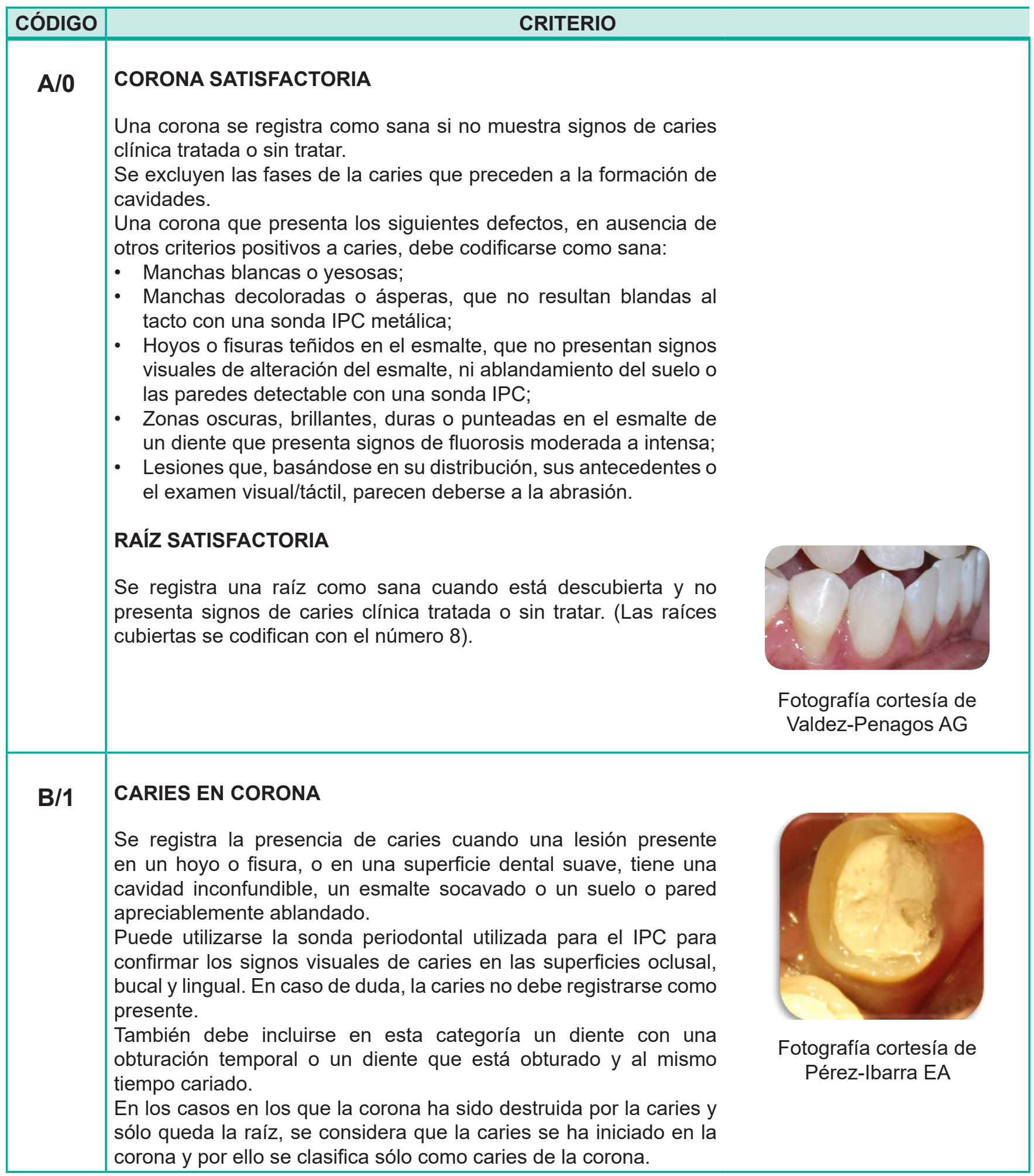




\begin{tabular}{|c|c|}
\hline CÓDIGO & CRITERIO \\
\hline$B / 1$ & $\begin{array}{l}\text { CARIES EN RAÍZ } \\
\text { Se registra la presencia de caries cuando una lesión resulta blanda } \\
\text { o correosa al explorarla con la sonda periodontal utilizada para el } \\
\text { IPC. } \\
\text { Si la caries de la raíz es distinta de la presente en la corona y } \\
\text { requiriera un tratamiento separado, debe registrarse como caries } \\
\text { de la raíz. } \\
\text { En el caso de las lesiones de caries únicas que afectan tanto a } \\
\text { la corona como a la raíz, el origen probable de la lesión debe } \\
\text { registrarse como cariado. Si no es posible determinar el origen se } \\
\text { registrarán como cariadas tanto la corona como la raíz. }\end{array}$ \\
\hline $\mathrm{C} / 2$ & $\begin{array}{l}\text { OBTURACIÓN CON CARIES EN CORONA } \\
\text { Se considera que una corona está obturada con caries cuando tiene } \\
\text { una o más restauraciones permanentes y una o más zonas están } \\
\text { cariadas. No debe diferenciarse la caries primaria de la secundaria } \\
\text { (esto es, se aplica la misma clave con independencia de que las } \\
\text { lesiones de caries estén físicamente asociadas a restauraciones). } \\
\text { EN RAÍz } \\
\text { Se considera que una raíz está obturada, con caries, cuanto tiene } \\
\text { una o más restauraciones permanentes y una o más zonas que } \\
\text { están cariadas. No se diferencia la caries primaria de la secundaria. } \\
\text { En el caso de obturaciones que comprenden tanto la corona } \\
\text { como la raíz, es más difícil determinar la localización del origen. } \\
\text { En cualquier restauración que comprenda tanto la corona como } \\
\text { la raíz, con caries secundaria, se registra como obturada, con } \\
\text { caries, la localización más probable de la caries primaria. Cuando } \\
\text { es imposible decidir el origen de la caries primaria, se registran la } \\
\text { corona y la raíz como obturadas, con caries. }\end{array}$ \\
\hline$D / 3$ & $\begin{array}{l}\text { OBTURACIÓN SIN CARIES EN CORONA } \\
\text { Se considera que una corona está obturada, sin caries, cuando se } \\
\text { hallan una más restauraciones permanentes y no existe ninguna } \\
\text { caries en la corona. } \\
\text { Se incluye en esta categoría un diente con una corona colocada } \\
\text { debido a una caries anterior (Se aplica la clave } 7 \text { (G) a un diente } \\
\text { que presenta una corona por cualquier motivo distinto de la caries, } \\
\text { por ejemplo el soporte de un puente). }\end{array}$ \\
\hline
\end{tabular}




\section{CAPÍTULO 4 Índice para evaluar el estado de la dentición y tratamiento necesario}

\begin{tabular}{|c|c|}
\hline CÓDIGO & CRITERIO \\
\hline$D / 3$ & $\begin{array}{l}\text { OBTURACIÓN SIN CARIES EN RAÍZ } \\
\text { Se considera que una raíz está obturada, sin caries, cuando se hallan } \\
\text { una o más restauraciones permanentes y no hay caries en ninguna } \\
\text { parte de la raíz. En el caso de obturaciones que comprenden tanto } \\
\text { la corona como la raíz, es más difícil determinar la localización del } \\
\text { origen. En cualquier restauración que comprenda tanto la corona } \\
\text { como la raíz, se registra como obturada la localización más probable } \\
\text { de la caries primaria. Cuando es imposible decidir el origen, se } \\
\text { registran la corona y la raíz como obturadas. }\end{array}$ \\
\hline$E / 4$ & $\begin{array}{l}\text { DIENTE PERDIDO COMO RESULTADO DE CARIES } \\
\text { Se utiliza esta clave para los dientes permanentes o primarios que } \\
\text { han sido extraídos debido a la presencia de caries, incluyendo el } \\
\text { registro en el estado de la corona. } \\
\text { Para los dientes primarios perdidos, este grado debe emplearse } \\
\text { sólo si el sujeto presenta una edad en la que la exfoliación normal } \\
\text { no sería explicación suficiente de la ausencia. En algunos grupos de } \\
\text { edad puede ser difícil diferenciar entre los dientes sin brotar (clave } \\
\text { 8) y los dientes perdidos (claves } 4 \text { ó 5). Los conocimientos básicos } \\
\text { sobre los tipos de erupción de los dientes, el aspecto del borde } \\
\text { alveolar en el espacio dental en cuestión y el estado de caries de } \\
\text { otros dientes pueden proporcionar datos útiles para establecer un } \\
\text { diagnóstico diferencial entre dientes sin brotar y extraídos. } \\
\text { No debe utilizarse la clave } 4 \text { para los dientes que se consideran } \\
\text { perdidos por algún motivo distinto a la caries. En los arcos totalmente } \\
\text { desdentados, por comodidad se inscribe un solo « } 4 \text { en las casillas, } \\
\text { según corresponda, uniendo los respectivos pares de números con } \\
\text { líneas rectas. } \\
\text { RAíz DE DIENTE PERDIDo como RESULTADO DE CARIES } \\
\text { Nota: El estado de la raíz de un diente que ha sido clasificado como } \\
\text { perdido por causa de caries debe codificarse «7» o «9». }\end{array}$ \\
\hline 5 & $\begin{array}{l}\text { DIENTE PERMANENTE PERDIDO POR CUALQUIER OTRO } \\
\text { MOTIVO } \\
\text { Esta clave se utiliza para los dientes permanentes que se consideran } \\
\text { ausentes de modo congénito o que se han extraído por motivos } \\
\text { ortodónticos (como es el caso del segundo premolar superior de la } \\
\text { fotografía) o por periodontopatías, traumatismos, etc. Igual que en } \\
\text { la clave } 4 \text {, dos inscripciones de la clave } 5 \text { pueden unirse por una } \\
\text { línea en los casos de arcos totalmente desdentados. } \\
\text { Nota: El estado de la raíz de un diente clasificado } 5 \text { debe codificarse } \\
\text { « } 7 » 0 \text { «9». }\end{array}$ \\
\hline
\end{tabular}




\begin{tabular}{|c|c|}
\hline CÓDIGO & CRITERIO \\
\hline$F / 6$ & $\begin{array}{l}\text { OBTURACIÓN DE FISURA } \\
\text { Se utiliza esta clave para los dientes en los que se ha colocado una } \\
\text { obturación de fisura en la superficie oclusal o para los dientes en los } \\
\text { que la fisura oclusal se ha ensanchado con una fresa redondeada o } \\
\text { «en forma de llama» colocando un material compuesto. Si el diente } \\
\text { obturado tiene caries, debe codificarse como } 1 \text { o B. }\end{array}$ \\
\hline $\mathrm{G} / 7$ & $\begin{array}{l}\text { SOPORTE DE PUENTE, CORONA ESPECIAL O FUNDA } \\
\text { Se incluye esta clave en el estado de la corona para indicar que un } \\
\text { diente forma parte de un puente fijo, esto es un soporte de puente. } \\
\text { Esta clave puede también emplearse para coronas colocadas por } \\
\text { motivos distintos de la caries y para fundas o láminas que cubren } \\
\text { la superficie labial de un diente en el que no hay signos de caries o } \\
\text { de restauración } \\
\text { Nota: Los dientes perdidos sustituidos por pónticos de puente se } \\
\text { codifican } 4 \text { ó } 5 \text { en el estado de la corona, mientras que la situación } \\
\text { de la raíz se clasifica como } 9 . \\
\text { RAÍz } \\
\text { Implante. Se utiliza esta clave en el estado de la raíz para indicar } \\
\text { que se ha colocado un implante como soporte. }\end{array}$ \\
\hline & $\begin{array}{l}\text { CORONA SIN BROTAR } \\
\text { Esta condición está limitada a los dientes permanentes y se utiliza } \\
\text { sólo para un espacio dental en el que hay un diente permanente sin } \\
\text { brotar, pero en ausencia de diente primario. } \\
\text { Los dientes clasificados como no erupcionados quedan excluidos } \\
\text { de todos los cálculos relativos a la caries dental. Esta categoría } \\
\text { no incluye los dientes ausentes congénitamente, perdidos por } \\
\text { traumatismos, etc. consulte la clave } 5 \text { para el diagnóstico diferencial } \\
\text { entre dientes perdidos y sin brotar. } \\
\text { RAíz } \\
\text { El código } 8 \text { indica que la superficie de la raíz está cubierta, esto es, } \\
\text { no hay recesión gingival más allá de la unión cemento- esmalte. }\end{array}$ \\
\hline
\end{tabular}




\section{CAPÍTULO 4 Índice para evaluar el estado de la dentición y tratamiento necesario}

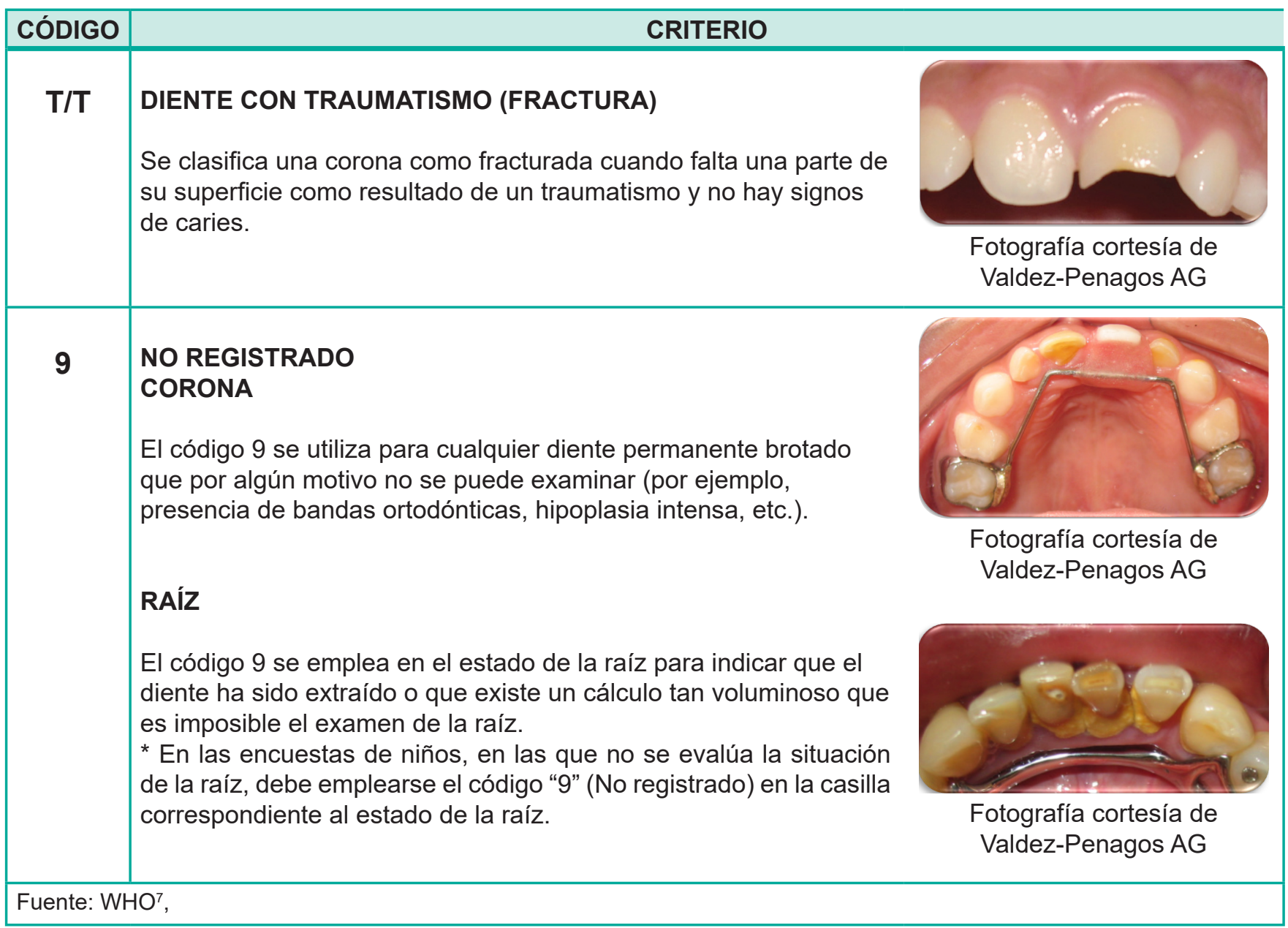

La necesidad de tratamiento se evalúa tomando en cuenta la totalidad del diente, incluyendo el estado de la corona y de la raíz, los códigos correspondientes a las necesidades de tratamiento se muestran en la cuadro 9.

El criterio para tomar una decisión de necesidad de tratamiento queda sujeta completamente a los recursos del examinador.

Cuadro 9. Códigos y criterios del tratamiento necesario.

\begin{tabular}{|c|l|l|}
\hline CÓDIGO & TRATAMIENTO NECESARIO & CRITERIO \\
\hline $\mathbf{0}$ & Ningún tratamiento & \\
\hline $\mathbf{P}$ & $\begin{array}{l}\text { Preventivo, cuidados de } \\
\text { detención de la caries }\end{array}$ & \\
\hline $\mathbf{F}$ & Obturación de fisura & \\
\hline $\mathbf{1}$ & Una obturación superficial & $\bullet$ Tratar caries inicial. \\
\hline
\end{tabular}




\section{Confiabilidad en la medición de caries dental}

\begin{tabular}{|c|c|c|}
\hline CÓDIGO & TRATAMIENTO NECESARIO & CRITERIO \\
\hline 2 & $\begin{array}{l}\text { Dos o más obturaciones } \\
\text { superficiales }\end{array}$ & $\begin{array}{l}\text { - Tratar caries primaria o secundaria. } \\
\text { - Decoloración del diente o un defecto de desarrollo. } \\
\text { - Lesiones producidas por traumatismos, erosión o abrasión. } \\
\text { - Sustituir obturaciones o selladores insatisfactorios en caso de que } \\
\text { se presente: margen deficiente, margen colgante, fractura de una } \\
\text { restauración existente o decoloración. }\end{array}$ \\
\hline 3 & Corona por cualquier motivo & \\
\hline 4 & Funda o lámina & - Puede recomendarse por motivos estéticos. \\
\hline 5 & $\begin{array}{l}\text { Cuidados de la pulpa y } \\
\text { restauración }\end{array}$ & $\begin{array}{l}\text { - Se utiliza en presencia de una caries profunda y amplia, o a la } \\
\text { mutilación o traumatismo del diente. } \\
\text { - Nota: Nunca debe introducirse una sonda en la profundidad de una } \\
\text { cavidad para confirmar la presencia de la exposición sospechosa } \\
\text { de la pulpa. }\end{array}$ \\
\hline 6 & Extracción & $\begin{array}{l}\text { - Cuando la caries ha destruido tanto el diente que no se puede } \\
\text { restaurar. } \\
\text { - En presencia de enfermedad periodontal avanzada hasta el punto } \\
\text { de que el diente tiene movilidad, causa dolor o está afuncional, lo } \\
\text { que según a juicio clínico del examinador, no se puede restaurar } \\
\text { hasta una situación funcional. } \\
\text { - Un diente necesita extraerse a fin de dejar lugar para una prótesis. } \\
\text { - Por motivos ortodónticos o cosméticos, o debido a la inclusión del } \\
\text { diente. }\end{array}$ \\
\hline $7 / 8$ & Necesidad de otra asistencia & $\begin{array}{l}\text { El examinador debe especificar los tipos de asistencia utilizando } \\
\text { las claves } 7 \text { y } 8 \text {. El empleo de estas dos claves debe reducirse al } \\
\text { mínimo. }\end{array}$ \\
\hline 9 & No registrado & \\
\hline
\end{tabular}

\section{Procedimiento de recolección}

Los examinadores deben adoptar un procedimiento sistemático para evaluar el estado de la dentición y las necesidades de tratamiento.

El examen debe efectuarse de forma ordenada pasando de un diente o espacio dental al diente o espacio dental adyacente, se inicia con la medición del diente 18 a 28 y de 48 a 38, la medición incluye los 32 dientes permanentes y los 20 dientes temporales según la edad del individuo revisado.

El estado del diente se determina visualmente, considerando como diente presente cualquier parte visible sin la necesidad de retraer la encía. Si un diente permanente y otro primario ocupan el mismo espacio dental, debe registrarse el estado del diente permanente.

Aunque este índice tiene por unidad de medición el diente, es recomendable apegarse a la secuencia de examen por superficie para observar todo el diente antes de emitir algún juicio del estado del diente.

El registro del estado de los dientes temporales solo incluye la corona y se hace a través de un registro alfabético, por lo tanto, debe emplearse la clave «9» (No registrado) en la casilla correspondiente al estado de la raíz en la ficha de registro (Anexo 4). 


\section{CAPÍTULO 4 Índice para evaluar el estado de la dentición y tratamiento necesario}

Por otro lado, el estado de la dentición permanente incluye un registro para la corona y otro para la raíz dental y se lleva a cabo a través de números. En ambos casos debe agregarse el registro del tratamiento necesario para cada diente conforme el diagnóstico y criterio clínico del examinador.,

Tal y como se describió en el CPOD, se coloca una mesa con todo el material requerido atrás del examinador (Figura 15 y 16 del capítulo 3).

El examen debe realizarse con un espejo bucal plano del No. 5. y sonda periodoentoal utilizada para el IPC, es importante recordar que el uso del explorador debe eliminarse por su potencial para fracturar el esmalte..$^{5,6,22}$

No se recomienda el uso de radiografías, por que no es factible utilizar el equipo radiográfico en todas las situaciones. ${ }^{6}$

En cada diente debe indicarse el estado de la corona, la raíz y el tratamiento necesario antes de continuar con el registro de otro diente, en la figura 27 se muestra el registro del estado del diente y tratamiento necesario de un individuo adulto en el cual se observa:

1. Diente 48: Caries en corona y raíz cuyo tratamiento corresponde a exodoncia.

2. Diente 47: Corona con caries y raíz cubierta por encía, de acuerdo con el criterio del examinador el tratamiento correspondiente es una obturación.

3. Diente 46: Corona obturada con presencia de caries que afecta la raíz, dicha condición lleva al examinador a sugerir cuidado de la pulpa y restauración.

4. Diente 45, 43 y 42: Corona sana con raíz cubierta por encía, por lo tanto no se sugiere tratamiento.

5. Diente 44: Corona con caries y raíz expuesta sin caries, por lo tanto el tratamiento sugerido corresponde a una obturación.

Vale la pena destacar que el código 0 en raíz nos indica que debido a recesión gingival se puede observar la raíz sin evidencia de caries, a diferencia del código 8 en el cual la raíz se encuentra cubierta por la encía.

\begin{tabular}{|c|c|c|c|c|c|c|c|c|}
\hline & & & & 85 & 84 & 83 & 82 & 81 \\
\hline & 48 & 47 & 46 & 45 & 44 & 43 & 42 & 41 \\
\hline Estado de la corona & 1 & 1 & 2 & 0 & 1 & 0 & 0 & 9 \\
\hline Estado de la raíz & 1 & 8 & 1 & 8 & 0 & 8 & 8 & 9 \\
\hline Necesidad de tratamiento & 6 & 2 & 5 & 0 & 2 & 0 & 0 & 9 \\
\hline
\end{tabular}

Figura 27. Registro del índice para evaluar el estado de la dentición y tratamiento necesario.

Como se puede observar, la necesidad de tratamiento se determina de acuerdo al juicio del examinador, esto dependerá de las condiciones y recursos bajo las cuales se realizará la atención. ${ }^{6,7}$

\section{Procesamiento de los datos recolectados}

El componente sobre el estado del diente permite obtener el valor de la experiencia de caries en dentición permanente por unidad de diente (CPOD); se calcula realizando la sumatoria de los códigos: 1, 2, 3, y 4, registrados en la observación de la corona dental. 


\section{Confiabilidad en la medición de caries dental}

En la figura 28 se observa que la frecuencia de dientes con experiencia de caries es la siguiente:

\begin{tabular}{|c|c|}
\hline Código & Frecuencia \\
\hline 1 & 7 \\
\hline 2 & 1 \\
\hline 3 & 1 \\
\hline 4 & 2 \\
\hline Sumatoria & 11 \\
\hline
\end{tabular}

Por lo tanto podemos observar que el CPOD del individuo revisado es de 11 dientes con experiencia de caries.

\begin{tabular}{|l|c|c|c|c|c|c|c|c|c|c|c|c|c|c|c|c|}
\cline { 2 - 16 } & 18 & 17 & 16 & 15 & 14 & 13 & 12 & 11 & 21 & 22 & 23 & 24 & 25 & 26 & 27 & 28 \\
\hline Estado de la corona & 9 & 1 & 2 & 3 & 0 & 0 & 7 & 1 & 0 & 0 & 0 & 0 & 0 & 1 & 1 & 9 \\
\hline Estado de la raíz & 9 & 1 & 8 & 8 & 8 & 8 & 7 & 8 & 8 & 8 & 8 & 8 & 8 & 8 & 0 & 9 \\
\hline
\end{tabular}

Figura 28. Registro del estado del diente en dentición permanente.

Debido a que la evaluación es por diente, se contabilizarán los códigos correspondientes al CPOD después de valorar tanto la corona como la raíz, por ejemplo en el caso del diente 17 que fue registrado con código 1 tanto en corona como en raíz, se cuantifica como un diente con experiencia de caries.

De la misma forma, se puede calcular la experiencia de caries en dentición temporal (cpod) a través de la sumatoria de los códigos: B, C, D y E.

En la figura 29 se observa la siguiente frecuencia de experiencia de caries:

\begin{tabular}{|c|c|}
\hline Código & Frecuencia \\
\hline B & 7 \\
\hline C & 1 \\
\hline D & 1 \\
\hline E & 1 \\
\hline Sumatoria & 11 \\
\hline
\end{tabular}




\section{CAPÍTULO 4 Índice para evaluar el estado de la dentición y tratamiento necesario}

\begin{tabular}{|c|c|c|c|c|c|c|c|c|c|c|}
\hline \multicolumn{1}{|c|}{} & 55 & 54 & 53 & 52 & 51 & 61 & 62 & 63 & 64 & 65 \\
\hline \multirow{2}{*}{ Estado de la corona } & D & B & C & A & A & A & A & B & B & A \\
\cline { 2 - 10 } & B & B & A & A & A & B & B & A & A & E \\
\hline & 85 & 84 & 83 & 82 & 81 & 71 & 72 & 73 & 74 & 75 \\
\hline
\end{tabular}

Figura 29. Registro del estado del diente en dentición temporal.

Después de la revisión podemos decir que el niño observado presentó 11 dientes con experiencia de caries.

Los datos registrados permiten identificar las Necesidades de Tratamiento (NT) relacionadas con experiencia de caries a través del cálculo de una proporción siguiendo la fórmula: ${ }^{13,14,20}$

$$
\mathrm{NT}=\frac{\text { promedio de dientes cariados }}{\text { promedio de dientes cariados }+ \text { promedio de dientes obturados }} \times 100
$$

De tal manera que primero se obtiene el promedio de dientes afectados en cada categoría quedando de la siguiente manera, en el caso de 10 individuos:

\begin{tabular}{c|cc} 
FOLIO & $\begin{array}{r}\text { CARIADO } \\
(\mathrm{fx})\end{array}$ & $\begin{array}{c}\text { OBTURADO } \\
(\mathrm{fx})\end{array}$ \\
\hline 01 & 5 & 3 \\
02 & 5 & 4 \\
03 & 5 & 3 \\
04 & 3 & 3 \\
05 & 5 & 3 \\
06 & 7 & 3 \\
07 & 6 & 4 \\
08 & 5 & 3 \\
09 & 5 & 2 \\
10 & 4 & 2 \\
\hline Promedio & 5 & 3
\end{tabular}

Sustituyendo en la fórmula:

$$
\mathrm{NT}=\frac{5}{5+3} \times 100=62.5 \%
$$

De tal manera que podemos afirmar que el $62.5 \%$ de los dientes con experiencia de caries presentan alguna necesidad de tratamiento. 


\section{Recursos para el levantamiento epidemiológico}

\section{Físicos}

Lugar dentro de la comunidad designado para realizar la actividad, como un aula dentro de una escuela o una sala o auditorio de usos múltiples. El lugar seleccionado deberá estar alejado de distractores para los examinadores y anotadores.

\section{Materiales}

- Relación de individuos que serán revisados.

- Mesas y sillas.

- Toallas húmedas desinfectantes .

- Campos para las mesas y para cubrir las piernas.

- Almohadas pequeñas.

- Jabón de manos antibacterial.

- Toallas de papel desechable.

- Barreras de protección (bata, gorros, cubrebocas, guantes).

- Lámparas tipo minero de luz blanca.

- Espejos planos del número 5.

- Sonda periodontal utilizada para el IPC. ${ }^{7}$

- Cajas para esterilización del instrumental.

- Fichas de registro del índice (Anexo 4).

- Lápices y gomas.

- Cepillos dentales.

- Gasas.

\section{Humanos}

- Examinadores.

- Anotadores.

- Apoyo para organizar la actividad.

\section{Concordancia de la medición}

Se ha hecho énfasis en la necesidad de la estandarización de criterios que es requisito para recolectar datos en cualquier estudio epidemiológico, ${ }^{23}$ en este caso el procedimiento corresponde solo al componente del estado de la dentición de la corona y raíz, dejando el tratamiento totalmente a juicio del examinador.

\section{Ejemplo 7.}

Se muestran los registros (Figura 30) de dos examinadores a través del índice para evaluar el estado de la dentición y tratamiento necesario después de la revisión a un sujeto en dos ocasiones, separadas por un lapso de 30 minutos. $^{1}$

El cálculo del coeficiente de kappa requiere la elaboración de una tabla de contingencia, en el ejemplo podemos observar la concordancia en el registro de los códigos 0-0, 1-1 y 2-2, también podemos observar las discordancias en 0-1 y 1-0 (Figura 31).

Este índice considera 11 estados de la dentición; en poblaciones que no asisten al servicio dental podremos observar con frecuencia tablas de contingencia como la obtenida en este ejercicio puesto que la principal afección encontrada es la experiencia de caries. 
CAPÍTULO 4 Índice para evaluar el estado de la dentición y tratamiento necesario

\section{Examinador 1}

\begin{tabular}{|l|l|l|l|l|l|l|l|l|l|l|l|l|l|l|l|l|}
\hline \multicolumn{1}{|c|}{} & 18 & 17 & 16 & 15 & 14 & 13 & 12 & 11 & 21 & 22 & 23 & 24 & 25 & 26 & 27 & 28 \\
\hline Estado de la corona & 9 & 1 & 1 & 0 & 0 & 0 & 0 & 0 & 0 & 0 & 0 & 1 & 0 & 1 & 1 & 9 \\
\hline Estado de la raíz & 9 & 0 & 0 & 0 & 0 & 0 & 0 & 0 & 0 & 0 & 0 & 0 & 0 & 0 & 0 & 9 \\
\hline
\end{tabular}

\begin{tabular}{|l|c|c|c|c|c|c|c|c|c|c|c|c|c|c|c|c|}
\cline { 2 - 11 } & 48 & 47 & 46 & 45 & 44 & 43 & 42 & 41 & 31 & 32 & 33 & 34 & 35 & 36 & 37 & 38 \\
\hline Estado de la corona & 9 & 1 & 0 & 2 & 0 & 0 & 0 & 0 & 0 & 0 & 0 & 0 & 1 & 2 & 1 & 9 \\
\hline Estado de la raíz & 9 & 0 & 0 & 0 & 0 & 0 & 0 & 0 & 0 & 0 & 0 & 0 & 0 & 1 & 0 & 9 \\
\hline
\end{tabular}

\section{Examinador 2}

\begin{tabular}{|l|l|l|l|l|l|l|l|l|l|l|l|l|l|l|l|l|}
\cline { 2 - 15 } \multicolumn{1}{l|}{} & 18 & 17 & 16 & 15 & 14 & 13 & 12 & 11 & 21 & 22 & 23 & 24 & 25 & 26 & 27 & 28 \\
\hline Estado de la corona & 9 & 1 & 1 & 0 & 0 & 0 & 0 & 1 & 0 & 0 & 0 & 1 & 0 & 1 & 1 & 9 \\
\hline Estado de la raíz & 9 & 0 & 0 & 0 & 0 & 0 & 0 & 0 & 0 & 0 & 0 & 0 & 0 & 0 & 0 & 9 \\
\hline
\end{tabular}

\begin{tabular}{|l|l|l|l|l|l|l|l|l|l|l|l|l|l|l|l|l|}
\cline { 2 - 11 } & 48 & 47 & 46 & 45 & 44 & 43 & 42 & 41 & 31 & 32 & 33 & 34 & 35 & 36 & 37 & 38 \\
\hline Estado de la corona & 9 & 0 & 0 & 2 & 0 & 0 & 0 & 1 & 0 & 0 & 0 & 0 & 1 & 2 & 1 & 9 \\
\hline Estado de la raíz & 9 & 0 & 0 & 0 & 0 & 0 & 0 & 0 & 0 & 0 & 0 & 0 & 1 & 0 & 1 & 9 \\
\hline
\end{tabular}

Figura 30. Registro interexaminador del estado del diente en dentición permanente.

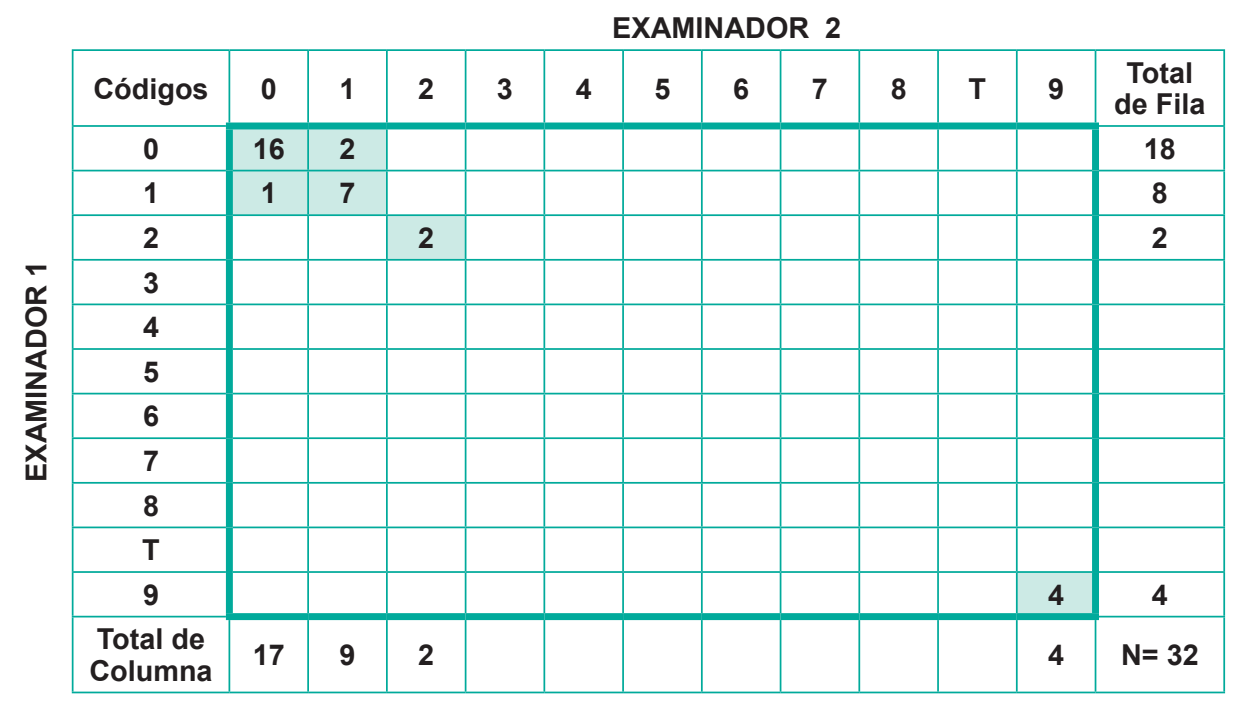

Figura 31. Tabla de contingencia del estado de la corona. 


\section{Confiabilidad en la medición de caries dental}

Siguiendo la fórmula para obtener el índice de kappa, los cálculos son los siguientes:

$$
\begin{gathered}
k=\frac{\mathrm{Po}-\mathrm{Pe}}{1-\mathrm{Pe}} \\
\mathrm{Po}=\frac{\mathrm{N}-\text { discordancias }}{\mathrm{N}} \\
\mathrm{Po}=\frac{32-3}{32}=\frac{29}{32}=\mathbf{0 . 9 0}
\end{gathered}
$$

\begin{tabular}{|c|c|c|c|c|c|c|c|c|c|c|c|c|c|}
\hline & \multicolumn{13}{|c|}{ EXAMINADOR 2} \\
\hline Códigos & 0 & 1 & 2 & 3 & 4 & 5 & 6 & 7 & 8 & $\mathbf{T}$ & 9 & $\begin{array}{l}\text { Total de } \\
\text { Fila/N }\end{array}$ & $\begin{array}{l}\text { Cálculo } \\
\text { del TF/N }\end{array}$ \\
\hline 0 & 16 & 2 & & & & & & & & & & $18 / 32$ & 0.56 \\
\hline 1 & 1 & 7 & & & & & & & & & & $8 / 32$ & 0.25 \\
\hline 2 & & & 2 & & & & & & & & & $2 / 32$ & 0.06 \\
\hline 3 & & & & & & & & & & & & & \\
\hline 4 & & & & & & & & & & & & & \\
\hline 5 & & & & & & & & & & & & & \\
\hline 6 & & & & & & & & & & & & & \\
\hline 7 & & & & & & & & & & & & & \\
\hline 8 & & & & & & & & & & & & & \\
\hline $\mathbf{T}$ & & & & & & & & & & & & & \\
\hline 9 & & & & & & & & & & & 4 & $4 / 32$ & 0.12 \\
\hline $\begin{array}{c}\text { Total } \\
\text { Columna/N }\end{array}$ & $17 / 32$ & $9 / 32$ & $2 / 32$ & & & & & & & & $4 / 32$ & $N=32$ & \\
\hline $\begin{array}{l}\text { Cálculo del } \\
\text { TC/N }\end{array}$ & 0.53 & 0.28 & 0.06 & & & & & & & & 0.12 & & \\
\hline
\end{tabular}

El cálculo de Pe requiere la obtención del Total de Fila y Total de Columna dividido entre el número de observaciones (Figura 32).

Figura 32. Cálculo del total de fila y columna del estado de la corona.

$$
\begin{aligned}
& \mathrm{Pe}=\sum[\mathrm{TF} / \mathrm{N}][\mathrm{TC} / \mathrm{N}] \\
& \mathrm{Pe}=[18 / 32][17 / 32]+[8 / 32][9 / 32]+[2 / 32][2 / 32]+[4 / 32][4 / 32] \\
& \mathrm{Pe}=[0.56][0.53]+[0.25][0.28]+[0.06][0.06]+[0.12][0.12] \\
& \mathrm{Pe}=0.29+0.07+0.0+01 \\
& \mathrm{Pe}=\mathbf{0 . 3 7}+0.010 .0 .37
\end{aligned}
$$

Interpretación: Los examinadores obtuvieron un coeficiente de kappa de 0.84, por lo tanto, tienen una concordancia casi perfecta en la evaluación del estado de la corona dental de acuerdo a los criterios de Landis y Koch. 


\section{CAPÍTULO 4 Índice para evaluar el estado de la dentición y tratamiento necesario}

Respecto a la evaluación de la raíz se lleva a cabo el cálculo del coeficiente de Kappa, para lo cual primero se elabora la tabla de contingencia par identificar la frecuencia de concordancias y discordancias (Figura 33).

\begin{tabular}{|c|c|c|c|c|c|c|c|c|c|c|c|c|}
\hline & \multicolumn{12}{|c|}{ EXAMINADOR 2} \\
\hline Códigos & 0 & 1 & 2 & 3 & 4 & 5 & 6 & 7 & 8 & $\mathbf{T}$ & 9 & $\begin{array}{l}\text { Total } \\
\text { de Fila }\end{array}$ \\
\hline 0 & 26 & 1 & & & & & & & & & & 27 \\
\hline 1 & & 1 & & & & & & & & & & 1 \\
\hline 2 & & & & & & & & & & & & \\
\hline 3 & & & & & & & & & & & & \\
\hline 4 & & & & & & & & & & & & \\
\hline 5 & & & & & & & & & & & & \\
\hline 6 & & & & & & & & & & & & \\
\hline 7 & & & & & & & & & & & & \\
\hline 8 & & & & & & & & & & & & \\
\hline$T$ & & & & & & & & & & & & \\
\hline 9 & & & & & & & & & & & 4 & 4 \\
\hline $\begin{array}{c}\text { Total de } \\
\text { Columna/N }\end{array}$ & 26 & 2 & & & & & & & & & 4 & $\mathrm{~N}=32$ \\
\hline
\end{tabular}

Figura 33. Tabla de contingencia del estado de la raíz.

Con base en las frecuencias de la Figura 33 se calcula Po:

$$
\begin{gathered}
P_{0}=\frac{N-\text { discordancias }}{N} \\
P_{O}=\frac{32-1}{32}=\frac{31}{32}=\mathbf{0 . 9 6}
\end{gathered}
$$

Posteriormente se calcula Pe, para lo cual se requiere calcular el total de fila y el total de columna (Figura 34).

$$
\begin{aligned}
& \mathrm{Pe}=\sum[\mathrm{TF} / \mathrm{N}][\mathrm{TC} / \mathrm{N}] \\
& \mathrm{Pe}=[27 / 32][26 / 32]+[1 / 32][2 / 32]+[4 / 32][4 / 32] \\
& \mathrm{Pe}=[0.84][0.81]+[0.03][0.06]+[0.12][0.12] \\
& \mathrm{Pe}=0.68+0.0+0.01 \\
& \mathrm{Pe}=\mathbf{0 . 6 9}
\end{aligned}
$$

Por lo tanto:

$$
k=\frac{P o-P e}{1-P e}=\frac{0.96-0.69}{1-0.69}=\frac{0.27}{0.31}=0.87
$$

Interpretación: Los examinadores obtuvieron un coeficiente de kappa de 0.87 , por lo tanto, tienen una concordancia casi perfecta en la evaluación del estado de raíz de acuerdo a los criterios de Landis y Koch. 


\section{Confiabilidad en la medición de caries dental}

\begin{tabular}{|c|c|c|c|c|c|c|c|c|c|c|c|c|c|}
\hline \multicolumn{14}{|c|}{ EXAMINADOR 2} \\
\hline Códigos & 0 & 1 & 2 & 3 & 4 & 5 & 6 & 7 & 8 & $\mathbf{T}$ & 9 & $\begin{array}{l}\text { Total de } \\
\text { Fila/N }\end{array}$ & $\begin{array}{l}\text { Cálculo } \\
\text { del TF/N }\end{array}$ \\
\hline 0 & 26 & 1 & & & & & & & & & & $27 / 32$ & 0.84 \\
\hline 1 & & 1 & & & & & & & & & & $1 / 32$ & 0.03 \\
\hline 2 & & & & & & & & & & & & & \\
\hline 3 & & & & & & & & & & & & & \\
\hline 4 & & & & & & & & & & & & & \\
\hline 5 & & & & & & & & & & & & & \\
\hline 6 & & & & & & & & & & & & & \\
\hline 7 & & & & & & & & & & & & & \\
\hline 8 & & & & & & & & & & & & & \\
\hline $\begin{array}{llllll} & \end{array}$ & & & & & & & & & & & & & \\
\hline 9 & & & & & & & & & & & 4 & $4 / 32$ & 0.12 \\
\hline $\begin{array}{c}\text { Total de } \\
\text { Columna/N }\end{array}$ & $26 / 32$ & $2 / 32$ & & & & & & & & & $4 / 32$ & $\mathrm{~N}=32$ & \\
\hline $\begin{array}{l}\text { Cálculo del } \\
\text { TC/N }\end{array}$ & 0.81 & 0.06 & & & & & & & & & 0.12 & & \\
\hline
\end{tabular}

Figura 34. Cálculo del Total de Fila y Columna del estado de la raíz.

Es interesante realizar el índice de kappa para cada uno de los componentes del índice porque en ocasiones se puede tener concordancia en la evaluación de la corona y no así en la evaluación de la raíz.

En este caso se recomienda contrastar los registros observando nuevamente con el individuo y discutir con un experto la condición correspondiente. 


\section{CAPÍ́TULO 4 Índice para evaluar el estado de la dentición y tratamiento necesario}

\section{Bibliografia}

1. Piovano S, Squassi A, Bordoni N. Estado del arte de indicadores para la medición de caries dental. Rev. Fac. Odontol UBA. 2010;25(58): 29-43.

2. Bordoni N, Squassi A. Caries dental: una mirada actual para una vieja problemática. Univ Odontol. 2013;32(68):81-97.

3. Klein H, Palmer CE, Knutson JW. Studies on dental caries: I. Dental Status and Dental Needs of Elementary school children. Public Health Reports. 1938;53(19):751-765.

4. De la Cruz CD, Andrade PM. Indicadores de prevalencia y de predicción de riesgo de caries dental. VERTIENTES. 2014;17(1):61-72.

5. ICDAS Foundation. actualizada 2015. Disponible en: https://www.icdas.org/frequently-raised-questions-and-answers

6. Organización Mundial de la Salud. Encuesta de salud bucodental, Métodos Básicos. 4a. ed. OMS: Ginebra; 1997.

7. World Health Organization. Oral Health Surverys. Basic Methods. 5th ed. Geneve. WHO; 2013.

8. Murrieta PJ, López RY, Juárez LL. Índices epidemiológicos de morbilidad bucal. México: Ed. Ideograma; 2006.

9. Adriano AM, Caudillo JT, Gómez CA. Epidemiología estomatológica, situación actual y perspectiva. 2a. ed. México: FES Zaragoza; 2001.

10. Angel P, Fresno MC, Cisternas P, Lagos M, Moncada G. Prevalencia de caries, pérdida de dientes y necesidad de tratamiento en población adulta Mapuche-Huilliche de Isla Huapi. Rev. Clin. Periodoncia Implantol. Rehabil. Oral. 2010;3(2): 69-72.

11. Molina FN, Oropeza OA, Pierdant RA, Marques DM, Castañeda CE. Experiencia de caries dental y necesidades de tratamiento en adolescentes. Rev Mex Pediatr. 2008;75(5):209-212.

12. Herrera MS, Medina SCE, Rosado VG, Minaya SM, Vallejos SAA, Casanova RJF. Prevalencia, severidad de caries y necesidad de tratamiento en preescolares de una comunidad suburbana de Campeche 2001. Bol Med Hosp Infant Mex. 2003;60:189-169.

13. Caudillo JT, Adriano AP, Caudillo AP. Prevalencia de caries dental y necesidad de tratamiento en una población escolar de la Delegación Iztapalapa Distrito Federal. Odonto Pediatría Actual. 2014;(3):36-40.

14. Caudillo JT, Adriano AP, Diagnóstico del perfil epidemiológico bucal en escolares de la zona de influencia de la Facultad de Estudios Superiores Zaragoza UNAM. Odontología Actual. 2014;(133):4-10.

15. Martínez-Pérez MK, Monjarás-Ávila AJ, Patiño-Marín N, Loyola-Rodríguez JP, Mandeville BP, Medina-Solís CE, et. al. Estudio epidemiológico sobre caries dental y necesidades de tratamiento en escolares de 6 a 12 años de edad de San Luis Potosí. Investigación Clínica. 2010;62(3):206-213.

16. Gómez-Osorno AM, Bernal-Álvarez T, Posada-López A, Agudelo-Suárez AA. Caries dental, higiene bucal y necesidades de tratamiento en población de 3 a 5 años de una institución educativa de Medellín y sus factores relacionados. Rev Nac Odontol. 2015;11(21):23-35.

17. Agreda M, Simancas $\mathrm{Y}$, E-Salas $\mathrm{m}$, Díaz $\mathrm{N}$, Romero $\mathrm{Y}$. Prevalencia y experiencia de caries en niños en edad escolar. Acta Bioclínica. 2014;4(7):50-65.

18. Barrios Z, Salas EM, Simancas Y, Ablan BL, Ramírez P, Prato R. Prevalencia, experiencia y necesidades de tratamiento de caries de la infancia temprana en niños con labio y paladar hendido. Rev. Odontológica de los Andes. 2014;9(1):23-31.

19. Medina-Castro JF, Alvarado-Menacho S. Prevalencia de caries dental y necesidades de tratamiento en pacientes adultos con demanda de atención diagnóstica. Odontol. Clín. Cient. 2012; 11(2):155-158.

20. Piovano S, Bordoni N, Doño R, Argentieri AB, Cohen A, Klemonskis G, et. al. Estado dentario en niños, adolescentes y adultos de la Ciudad Autónoma de Buenos Aires. Revista de la Fac Odont (UBA). 2008;23(54): 34-42.

21. Colavida JM, Robledo T, Calvo JC, Salazar FS, Osés AJ, Vicente GA, et al. Criterios mínimos de los estudios epidemiológicos de salud dental en escolares. Rev Esp Salud Pública. 1997;71(3):231-242.

22. Lizmar DV, Acevedo AM, Rojas SF. Métodos convencionales y no convencionales para la detección de la lesión inicial de caries. Revisión bibliográfica. Acta Odontológica Venezolana. [en línea]. 2011 [citado 15 agosto 2015];49(2):1-14. Disponible en: http://actaodontologica.com/ediciones/2011/2/ pdf/art21.pdf.

23. Cerda LJ, Villaroel del PL. Evaluación de la concordancia inter-observador en investigación pediátrica: Coeficiente de Kappa. Rev Chil Pediatr. 2008;79(1):54-58.

\section{Consultar el video de apoyo del Capítulo 4: "Índice para evaluar el estado de la dentición y tratamiento necesario", en la pestaña del Módulo Estomatología Social II http://www.zaragoza.unam.mx/herramientas-para-el-aprendizaje/}





\title{
CAPítuldo s
}

\section{Sistema Internacional de Detección de Caries: ICDAS}

\author{
MARÍA LILIA ADRIANA JUÁREZ LÓPEZ \\ REMEDIOS GUADALUPE VALDEZ PENAGOS
}

\section{Generalidades}

La caries dental ha sido definida como una enfermedad compleja, resultado del desequilibrio en el proceso dinámico de desmineralización y remineralización de las estructuras dentarias por la interacción entre la biopelícula bacteriana, el sustrato alimenticio y la estructura dentaria, en un tiempo determinado. Esta enfermedad afecta poblaciones de todas las edades y los indicadores epidemiológicos que se han utilizado para evaluar a nivel individual y comunitario su afectación CPO-D para dientes permanentes y el ceo-d para dientes primarios ambos consideran como caries cuando existe la pérdida de continuidad de la superficie dentaria; es decir, la presencia de una cavidad..$^{1,2}$

Antes del colapso de la estructura dentaria que se manifiesta por una fractura microscópica que antecede la cavidad, la lesión cariosa atraviesa por un proceso inicial. La lesión incipiente de caries en etapa temprana tiene la apariencia de una mancha blanca, resultado de la pérdida mínima de minerales, con la capa superficial intacta, histológicamente, presenta diferentes estratos: translucido, obscuro, el cuerpo y el superficial que permanece intacto. ${ }^{3,4}$

El Sistema Internacional de Detección y Diagnóstico de Caries con sus siglas en inglés ICDAS (International Caries Detection and Assessment System) surgió de una reunión internacional de investigación clínica en caries (ICW-CCT) realizada en Escocia donde se precizó la necesidad de la detección precoz de lesiones de cariosas no cavitadas con énfasis en las evidencias científicas sobre la posibilidad de detener y revertir el proceso carioso. ${ }^{5-7}$

Actualmente, los criterios de ICDAS son utilizados con fines clínicos, de investigación, así como académicos con el objetivo primordial de obtener un diagnóstico Integral de la enfermedad para lo que debe realizarse:

- Un diagnóstico por superficie dentaria, considerando el estado y pronóstico.

- La evaluación del riesgo cariogénico del paciente, considerando sus antecedentes y hábitos higiénicodietéticos.

- La planeación del tratamiento, considerando el nivel de cuidados básicos con actividades preventivas y restaurativas.

La importancia de ICDAS radica en que permite detectar y clasificar las lesiones cariosas no cavitada además de las cavitadas, es decir, aquellas que comúnmente habían sido excluidas tanto en el método clínico como en los estudios epidemiológicos.

El sistema ICDAS es un método objetivo basado en el diagnóstico visual para detectar la presencia o ausencia de la enfermedad por superficie, lo que permite caracterizar la alteración y evaluar el estado de progreso de las lesiones. ${ }^{8,9}$ 


\section{Códigos y criterios del Sistema Internacional de Detección de Caries: ICDAS}

ICDAS considera por separado el diagnóstico coronal y radicular, así como la actividad del proceso carioso..$^{6,10,11}$ Así mismo, la aplicación de ICDAS incluye el registro de las restauraciones dentales.

\section{Condición de caries en la corona dental}

Los criterios para evaluar la actividad de caries coronal se muestran en el cuadro 10.

Cuadro 10. Criterios ICDAS para evaluar la actividad de caries en la corona dental.

\begin{tabular}{|l|c|c|}
\hline \multicolumn{1}{|c|}{ Característica } & \multicolumn{2}{c|}{ Estado de la lesión } \\
\hline Biopelícula dentaria en la superficie dentaria & Activa & Detenida \\
\hline Color & Acumulación & No acumulación \\
Apariencia & Blanco & Café \\
\hline Sensación Táctil & Opaca & Brillante \\
\hline Visual y/o Táctil & Rugosa/blanda & Intacto \\
\hline Fuente: Shivakumar $\mathrm{K}^{6}$, Ismail Al ${ }^{12}$ & Ruptura & \\
\hline
\end{tabular}

Los Códigos y criterios para la aplicación de ICDAS a nivel coronal se describen en los cuadros 11 y 12 :

Cuadro 11. Códigos y condición de caries en la corona dental de acuerdo al índice ICDAS

\begin{tabular}{|c|l|}
\hline Códigos & \multicolumn{1}{c|}{ Condición } \\
\hline 0 & Sano \\
\hline 1 & Cambio visible en el esmalte-visto seco \\
\hline 2 & Cambio detectable en esmalte \\
\hline 3 & Ruptura localizada del esmalte \\
\hline 4 & Sombra obscura subyacente de dentina \\
\hline 5 & Cavidad detectable con dentina visible \\
\hline 6 & Cavidad detectable extensa con dentina visible \\
\hline Fuente: Topping GVA $^{13}$, ICDAS Foundation \\
\hline
\end{tabular}




\section{CAPÍ'TULO 5 Sistema Internacional de Detección de Caries: ICDAS}

Cuadro 12. Criterios para identificar la condición de caries en la corona.

\begin{tabular}{|c|c|}
\hline CÓDIGO & CRITERIO \\
\hline 0 & $\begin{array}{l}\text { SANA } \\
\text { Se utiliza cuando no hay evidencia de caries después del secado } \\
\text { con aire por } 5 \text { segundos. } \\
\text { Las pigmentaciones alrededor del margen de una restauración que } \\
\text { no estén asociadas con caries deben ser registradas como cero, } \\
\text { así como los defectos marginales no cariosos de menos } 0.5 \mathrm{~mm} \\
\text { de ancho. }\end{array}$ \\
\hline 1 & $\begin{array}{l}\text { CAMBIO VISIBLE EN EL ESMALTE VISTO SECO } \\
\text { Presencia de opacidad (lesión blanca o marrón), } \\
\text { restringida a la entrada de las fosas o fisuras, que no se observa } \\
\text { cuando la superficie esta húmeda pero si después del secado con } \\
\text { aire durante } 5 \text { segundos. }\end{array}$ \\
\hline 2 & $\begin{array}{l}\text { CAMBIO DETECTABLE EN EL ESMALTE } \\
\text { Cambio distintivo blanco o marrón en el esmalte, visible en húmedo } \\
\text { o seco extendiéndose más allá del área de la fisura. }\end{array}$ \\
\hline 3 & $\begin{array}{l}\text { RUPTURA LOCALIZADA DEL ESMALTE } \\
\text { Localización de esmalte fracturado. No se aprecia dentina en la } \\
\text { zona de la fisura. } \\
\text { Cavidad menor de } 0.5 \mathrm{~mm} \text { en el margen de la restauración o sellante } \\
\text { y opacidad o decoloración consistentes con desmineralización. }\end{array}$ \\
\hline 4 & $\begin{array}{l}\text { SOMBRA OBSCURA SUBYACENTE DE DENTINA } \\
\text { Sombra oscura semiescondida de la dentina, visible a través de } \\
\text { esmalte intacto con o sin localización de esmalte fractura. }\end{array}$ \\
\hline
\end{tabular}




\section{Confiabilidad en la medición de caries dental}

\begin{tabular}{|c|l|}
\hline CÓDIGO & \multicolumn{1}{|c|}{ CRITERIO } \\
\hline 5 & $\begin{array}{l}\text { CAVIDAD DETECTABLE CON DENTINA VISIBLE } \\
\text { Cavidad distintiva con dentina expuesta en la base, presente en } \\
\text { menos de la mitad de la superficie dental. }\end{array}$ \\
\hline 6 & $\begin{array}{l}\text { CAVIDAD DETECTABLE EXTENSA CON DENTINA VISIBLE } \\
\text { Cavidad extensiva con dentina visible en la base y paredes de la } \\
\text { Cavidad, la pulpa puede estar involucrada. }\end{array}$ \\
\hline
\end{tabular}

\section{Condición de caries en zona radicular}

La aplicación de los criterios de ICDAS para la zona radicular del diente es una opción que puede ser utilizada en caso de ser necesario, sin embargo, este sistema de codificación no ha sido validado como el sistema de codificación de caries coronal.

Para la evaluación de la caries radicular se considera la suma de diferentes aspectos como la textura, el contorno y el color de la lesión ${ }^{15-17}$ (Cuadro 13).

Cuadro 13. Criterios ICDAS para evaluar la actividad de caries en la raíz dental.

\begin{tabular}{|l|l|l|}
\hline \multicolumn{1}{|c|}{ Textura y aspecto } & \multicolumn{2}{c|}{ Estado de la lesión } \\
\hline Lisa/brillante & Dura & Detenida \\
\hline Rugosa/mate & Similar al cuero & Detenida \\
\hline Rugosa/mate & Blanda & Activa \\
\hline Fuente: Xaus G ${ }^{15}{ }^{\text {ICDAS Coordinating Committe. }{ }^{16}}$ \\
\hline
\end{tabular}

Los Códigos y criterios para la aplicación de ICDAS a nivel radicular se muestran en los cuadros 14 y 15 :

Cuadro 14. Códigos y condición de caries radicular de acuerdo al índice ICDAS.

\begin{tabular}{|c|l|}
\hline Códigos & \multicolumn{1}{|c|}{ Condición } \\
\hline 0 & SANO \\
\hline 1 & CAMBIO DE COLOR VISIBLE EN LA UNIÓN CEMENTO-ESMALTE \\
\hline 2 & CARIES ACTIVA, SIN CAVIDAD \\
\hline 3 & CARIES CAVITADA INACTIVA $>0.5 \mathrm{~mm}$ \\
\hline 4 & CARIES CAVITADA ACTIVA $>0.5 \mathrm{~mm}$ \\
\hline Fuente: Shivakumar $\mathrm{K}^{6}$ & \\
\hline
\end{tabular}




\section{CAPÍ'TULO 5 Sistema Internacional de Detección de Caries: ICDAS}

Cuadro 15. Criterios para identificar la condición de caries radicular.

\begin{tabular}{|c|c|c|}
\hline CÓDIGO & CRITERIO & \\
\hline 0 & $\begin{array}{l}\text { SANO } \\
\text { La superficie de la raíz no presenta ninguna coloración inusual que } \\
\text { lo distingue de los alrededores o las áreas adyacentes de la } \\
\text { raíz, ni exhibir un defecto de la superficie, ya sea en la unión } \\
\text { amelocementaria o totalmente en la superficie de la raíz. }\end{array}$ & 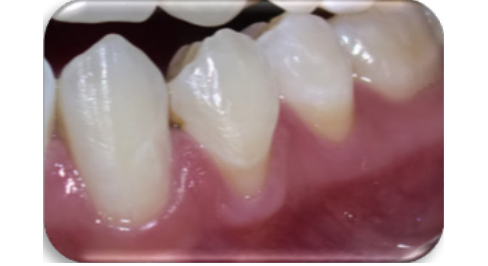 \\
\hline 1 & $\begin{array}{l}\text { CAMBIODE COLOR VISIBLEEN LAUNIÓNAMELOCEMENTARIA } \\
\text { Existe una zona claramente delimitada en la superficie de la raíz o } \\
\text { en la unión amelocementaria que es de color (claro, oscuro, marrón } \\
\text { y negro), pero no hay cavidad presente, (pérdida del contorno } \\
\text { anatómico menor a } 0.5 \mathrm{~mm} \text { ) detectable con sonda periodontal. Y la } \\
\text { caries detectada se encuentra detenida. }\end{array}$ & \\
\hline 2 & $\begin{array}{l}\text { CARIES ACTIVA, SIN CAVIDAD } \\
\text { Caries activa delimitada en la superficie de la raíz o en la unión } \\
\text { amelocementaria de color (claro, oscuro, marrón y negro), no hay } \\
\text { cavidad presente, (pérdida del contorno anatómico menor a } 0.5 \\
\text { mm) detectable con sonda periodontal. }\end{array}$ & 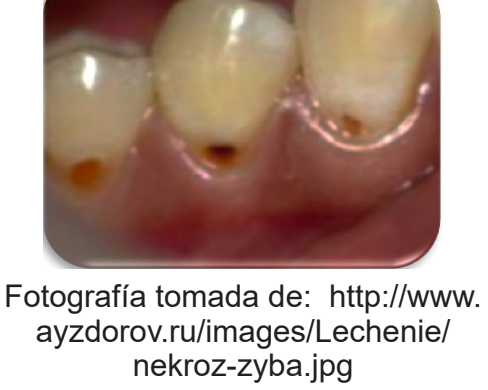 \\
\hline 3 & $\begin{array}{l}\text { CARIES CAVITADA > } 0.5 \mathrm{~mm} \\
\text { Hay una zona claramente delimitada en la superficie de la raíz o en la } \\
\text { unión amelocementaria que es una cavidad de color (claro, oscuro, } \\
\text { marrón y negro) y hay presencia de pérdida del contorno } \\
\text { anatómico mayor a } 0.5 \mathrm{~mm} \text {. (cavidad presente) detectable también } \\
\text { con sonda periodontal. Y la caries detectada se encuentra detenida. }\end{array}$ & \\
\hline 4 & $\begin{array}{l}\text { CARIES CAVITADA ACTIVA }>0.5 \mathrm{~mm} \\
\text { Cavidad claramente delimitada en la superficie de la raíz o } \\
\text { amelocementaria de color claro, oscuro, marrón y/o negro; pérdida } \\
\text { del contorno anatómico mayor a } 0.5 \mathrm{~mm} \text { con proceso carioso activo. }\end{array}$ & $\begin{array}{l}\text { Fotografía cortesía de } \\
\text { Pérez-Ibarra EA }\end{array}$ \\
\hline
\end{tabular}




\section{Confiabilidad en la medición de caries dental}

El sistema ICDAS se ha comparado con los criterios del Iceberg de la caries dental, ambos métodos ofrecen una perspectiva adecuada del proceso carioso, el ICDAS describe las características clínicas de la enfermedad y el Iceberg expresa el proceso de la enfermedad. ${ }^{18.19}$ El cuadro 16 muestra las similitudes entre ellos.

Cuadro 16. Comparación de ICDAS con criterios iceberg.

\begin{tabular}{|l|l|}
\hline \multicolumn{1}{|c|}{ ICDAS } & \multicolumn{1}{|c|}{$\begin{array}{c}\text { ICEBERG DE LA CARIES DENTAL } \\
\text { (umbrales diagnósticos) }\end{array}$} \\
\hline $\begin{array}{l}\text { 1: Primer cambio visual en esmalte (lesión blanca o café), } \\
\text { visto después de secar con aire. } \\
\text { 2: Cambio blanco o café en esmalte visto en el diente húmedo. }\end{array}$ & $\begin{array}{l}\text { D1: Lesiones detectables clínicamente en } \\
\text { esmalte, pero cuya superficie está aparentemente } \\
\text { intacta. }\end{array}$ \\
\hline 3: Fractura localizada del esmalte sin dentina visible. & $\begin{array}{l}\text { D2: Cavidades limitadas al esmalte, detectables } \\
\text { clínicamente. }\end{array}$ \\
\hline \begin{tabular}{l} 
4: Sombra gris subyacente (vista más fácilmente cuando el \\
diente está húmedo) en dentina, con o sin fractura localizada \\
del esmalte. \\
5: Cavidad con dentina expuesta en su base. \\
$\begin{array}{l}\text { 6: Cavidad extensa (involucra al menos la mitad de una } \\
\text { superficie dental o posiblemente está en contacto con la } \\
\text { pulpa) con dentina visible en su base y paredes. }\end{array}$ \\
\hline Fuente: Rojas A, Montero O. ${ }^{18}$
\end{tabular} \\
\hline
\end{tabular}

Por otra parte la diferenciación de la caries dental inicial con la fluorosis, se debe de observar aspectos diferenciales con la fluorosis dental, dado que las lesiones iniciales de la caries dental pueden ser confundidas con las lesiones fluoróticas leve y muy leve. ${ }^{20}$ (Figura 35 y cuadro 17).

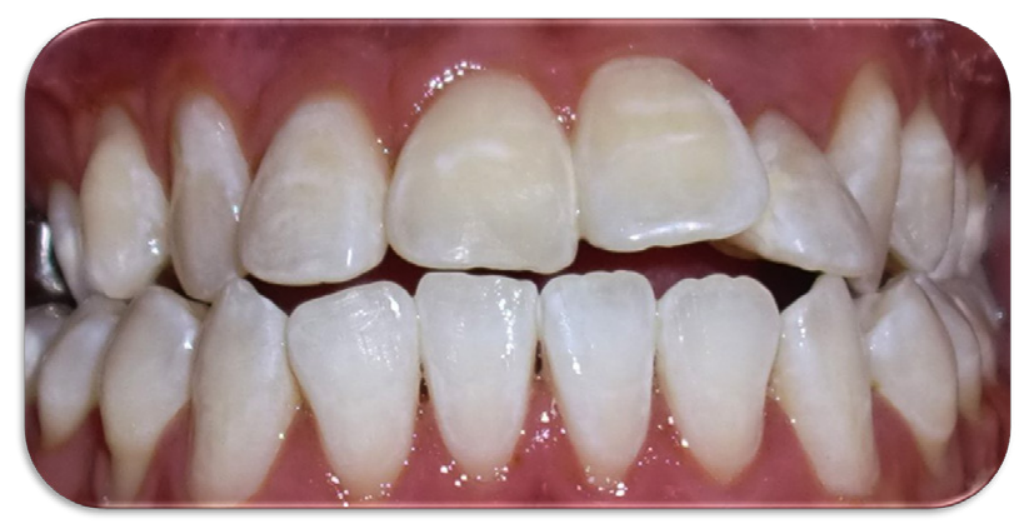

Figura 35. Dientes con fluorosis. Fotografía cortesía Valdez-Penagos AG. 


\section{CAPÍ́TULO 5 Sistema Internacional de Detección de Caries: ICDAS}

Cuadro 17. Características diferenciales entre las lesiones cariosas y las lesiones por fluorosis.

\begin{tabular}{|c|c|c|}
\hline Característica & Fluorosis & Caries \\
\hline ÁREA AFECTADA & $\begin{array}{l}\text { Usualmente cúspides y bordes } \\
\text { incisales. }\end{array}$ & $\begin{array}{l}\text { Usualmente superficies lisas (cervicales e } \\
\text { interproximales) y fosas y fisuras. }\end{array}$ \\
\hline FORMA & $\begin{array}{l}\text { Líneas que siguen las líneas } \\
\text { incrementales del esmalte. } \\
\text { En las cúspides semeja un capuchón. }\end{array}$ & Normalmente redondas u ovales. \\
\hline DEMARCACIÓN & $\begin{array}{l}\text { Sombra difusa entremezclada con } \\
\text { esmalte normal. }\end{array}$ & $\begin{array}{l}\text { Claramente se diferencia del esmalte normal } \\
\text { adyacente. }\end{array}$ \\
\hline COLOR & $\begin{array}{l}\text { Levemente más opaco que el esmalte } \\
\text { normal (blanco mate). }\end{array}$ & $\begin{array}{l}\text { Crema-amarillo-anaranjado. } \\
\text { La superficie del esmalte puede parecer } \\
\text { grabada. }\end{array}$ \\
\hline DIENTES AFECTADOS & $\begin{array}{l}\text { Frecuentemente se presenta en } \\
\text { bicúspides y cúspides. Usualmente } \\
\text { presente en } 6 \text { u } 8 \text { dientes homólogos. } \\
\text { Extremadamente raro en dentición } \\
\text { primaria. }\end{array}$ & $\begin{array}{l}\text { Cualquier pieza dental puede estar afectada. } \\
\text { Se puede presentar de forma aislada } \\
\text { (usualmente en } 1 \text { a } 3 \text { piezas). Es común en } \\
\text { la dentición primaria. }\end{array}$ \\
\hline \multicolumn{3}{|l|}{ Fuente: Pendrys DG ${ }^{20}$} \\
\hline
\end{tabular}

\section{Evaluación de restauraciones en la superficie dental}

A la nomenclatura ICDAS se le agrega otro dígito correspondiente a los códigos de ICDAS II, éste señala la presencia de restauración o sellante y distingue nueve categorías que se codifican del 0 al 8 (Cuadro 18). ${ }^{13,21}$ En caso de no encontrarse el diente presente, se debe utilizar el código 9.

Los Códigos y criterios que se agregan en ICDAS II se muestran en las Cuadro 18 y 19 :

Cuadro 18. Códigos asignados a la presencia de restauraciones en la superficie dental de acuerdo al índice ICDAS II.

\begin{tabular}{|c|l|}
\hline Códigos & \multicolumn{1}{|c|}{ Presencia de restauraciones } \\
\hline 0 & SIN SELLADOR O RESTAURACIÓN \\
\hline 1 & SELLADOR PARCIAL \\
\hline 2 & SELLADOR COMPLETO \\
\hline 3 & RESTAURACIÓN COLOR DIENTE \\
\hline 4 & RESTAURACIÓN EN AMALGAMA \\
\hline 5 & CORONA DE ACERO INOXIDABLE \\
\hline 6 & CORONA O CARILLA EN PORCELANA, ORO O METAL-PORCELANA \\
\hline 7 & RESTAURACIÓN PERDIDA O FRACTURADA \\
\hline 8 & RESTAURACIÓN TEMPORAL \\
\hline Fuente: Topping GVA, ${ }^{13}$ Pendrys DG ${ }^{20}$ \\
\hline
\end{tabular}


Cuadro 19. Códigos asignados a la presencia de selladores y restauraciones dentales.

\begin{tabular}{|c|c|}
\hline CÓDIGO & PRESENCIA DE SELLADOR Y RESTAURACIONES \\
\hline 0 & NO SELLANTE, NI RESTAURACIÓN \\
\hline 1 & SELLADO PARCIALMENTE \\
\hline 2 & SELLADO COMPLETO \\
\hline 3 & RESTAURACIÓN COL \\
\hline 4 & RESTAURACIÓN CON AMALGAMA \\
\hline
\end{tabular}




\section{CAPÍTULO 5 Sistema Internacional de Detección de Caries: ICDAS}

\begin{tabular}{|c|c|}
\hline CÓDIGO & PRESENCIA DE SELLADOR Y RESTAURACIONES \\
\hline 5 & CORONA INOXIDABLE \\
\hline 6 & CARILLA DE PORCELANA \\
\hline 7 & RESTAURACIÓN PERDIDA \\
\hline 8 & RESTAURACIÓN TEMPORAL \\
\hline 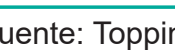 & \\
\hline
\end{tabular}

\section{Consideraciones especiales de codlificación ICDAS.13}

1. Dientes no vitales: Ignore el hecho de que el diente es no vital y registre la caries como si fuera un diente vital.

2. Dientes con banda o brackets: Examine todas las superficies y registre usualmente la o las superficies descubiertas. Todas las superficies visibles deben ser examinados lo mejor posible y anotada en la forma 


\section{Confiabilidad en la medición de caries dental}

habitual. Cuando una superficie está completamente cubierta por una banda o un soporte y no hay evidencia de caries dental el código de estado es $\mathbf{0}$.

3. En el caso de los dientes supernumerarios, el examinador debe decidir qué diente es el legítimo ocupante del espacio. Sólo un diente debe ser anotado. Restauraciones de cubrimiento total: Todas las superficies restauradas con una cobertura total debe ser codificada como corona.

4. Cuando ambos un diente primario y permanente ocupan el mismo espacio, sólo el diente permanente será codificado.

5. Restauraciones de cubrimiento parcial: Si una superficie ha sido restaurada con un cubrimiento parcial, las demás superficies deben ser registradas en forma separada. Y la superficie cubierta debe ser codificada como superficie excluida 96.

6. Corona dental destruida por caries: Todas las superficies de las raíces retenidas deben se codificadas como 06.

7. Una superficie de la raíz adyacente a un borde de la corona que está libre de caries debe ser anotada como sana.

8. más de una lesión está presente en la misma superficie, la lesión más grave será anotada.

9. Todas las superficies de los restos radiculares deben codificarse como 06.

\section{Procedimiento de recolección}

La aplicación del índice ICDAS demanda que el observador tenga una excelente visibilidad de las superficies dentales ya que requiere un fino registro, los pasos a seguir durante la inspección clínica son:

Retirar todas las prótesis o aparatos removibles de la boca del paciente.

Verificar que los dientes estén limpios y libres de cálculo, biopelícula dental o sustancia reveladora, por lo tanto, si es necesario se llevará a cabo una profilaxis dental, de lo contrario el cepillado dental y utilización del hilo dental serán suficiente.

Posteriormente se realizará un aislado relativo con rollos de algodón y se removerá el exceso de saliva para examinar visualmente la superficie húmeda de los dientes desde el 18 al 28 y del 38 al 48, la aplicación de éste índice incluye la observación de los 32 dientes permanentes y los 20 dientes temporales, por separado o su combinación en dentición mixta, según sea el caso.

La secuencia sugerida para la observación de las superficies es:

- Mesial

- Oclusal

- Distal

- Vestibular y

- Lingual/Palatina

Para detectar las lesiones iniciales de caries es necesario secar la superficie de los dientes con aire durante 5 segundos, para confirmar el diagnóstico se puede utilizar la sonda periodontal utilizada para el IPC. ${ }^{18,22}$

En caso de detectar cavidad, debe determinarse la profundidad. Si existe duda, el examinador deberá anotar en la ficha de registro ${ }^{13}$ (Anexo 5) el código más bajo. Para evitar la sobrestimación de caries.

Es necesario hacer una distinción entre los dientes no erupcionados, los dientes extraídos por caries y los que se perdieron por otras razones utilizando los códigos del Cuadro $20 .{ }^{13}$ 


\section{CAPÍ'TULO 5 Sistema Internacional de Detección de Caries: ICDAS}

Cuadro 20. Códigos para dientes no presentes de acuerdo al índice ICDAS.

\begin{tabular}{|c|l|}
\hline Códigos & \multicolumn{1}{c|}{ Condición } \\
\hline 97 & DIENTE PERDIDO DEBIDO A CARIES. \\
\hline 98 & DIENTES PERDIDO POR OTRAS RAZONES. \\
\hline 99 & NO ERUPCIONADO. \\
\hline Fuente: Topping GVA & \\
\hline
\end{tabular}

Cuando se observe más de una lesión de caries en una superficie, la lesión más severa debe ser anotada.

Si una fosa o fisura en una superficie oclusal no está claramente involucrada por una lesión cariosa procedente de mesial o distal, la superficie oclusal debe ser codificada como sana.

El examinador no debe determinar el origen de la superficie de una lesión de caries y la superficie de cada diente debe ser anotada por separado tal y como aparece. La superficie de los dientes está limitada por el ángulo diedro de dos superficies dentales cuando se ve en una dirección perpendicular.

Para determinar si existe una cavidad en la superficie del esmalte (código 3) la punta de bola de la sonda periodontal detecta una zanja en la superficie del diente que cubre parcialmente el extremo esférico de la sonda. Si todo el extremo de la bola de la sonda puede entrar en la zanja, entonces el área se codifica como código 5, a menos que el examinador concluya que la lesión se encuentra en el esmalte, entonces el código es 3.

La sombra oscura debajo de una cresta marginal o alrededor de una fosa o fisura debe ser de color gris oscuro para codificarla como un código 4.

Cuando la superficie de la corona y la raíz estén afectada por caries deben ser identificadas independientemente. En caso de duda porque la lesión de caries se encuentra en la unión cemento-esmalte (UCE) debe analizarse que superficie está más afectada o que se extienda por lo menos $1 \mathrm{~mm}$ o más allá del límite de la UCE, en ambas direcciones cervico-incisal y cervical apical, debe considerase cual es la más extensa aplicando la regla del $50 \%$, si existe igualdad, el examinador debe decidir si la lesión es codificada como de raíz o de corona, o en su defecto puede aplicar ambas.

Todas las superficies restauradas con una cobertura total deben ser codificadas como corona. Si un diente ha sido restaurado con menos de la cobertura total "Inlay / Onlay" , las superficies involucrados en la restauración se codifican por separado.

Si parte de una restauración se ha perdido en una superficie, la superficie debe ser codificado como 7 , aun cuando parte de la restauración se encuentre.

Si es el caso de la recolección de datos a través de este índice, comúnmente se utiliza la ficha para evaluar caries coronal (Anexo 5) en el cual se registran 2 códigos para cada superficie, el primer dígito corresponde a la presencia de restauraciones y el segundo dígito del 0 a 6 corresponde al código de caries de esmalte y dentina, ${ }^{21}$ de tal manera que se registran 148 superficies para cada componente del índice en dentición permanente y 88 en dentición temporal. 


\section{Confiabilidad en la medición de caries dental}

Por ejemplo, en el registro que se muestra en la figura 36 se observa:

1. Diente 18 y 17 :

Código 99 = no erupcionados.

2. Diente 16:

Código 20 en oclusal $=$ sellador completo - superficie sana.

Código 30 en vestibular $=$ restauración color diente - superficie sana.

3. Diente 55:

Código 73 en oclusal = restauración perdida o fracturada - superficie con ruptura localizada del esmalte asociada a caries.

4. Diente 14 y 13:

Código $00=$ sin restauraciones - superficies sanas.

5. Diente 12:

Código 02 en palatino $=$ sin restauraciones - superficie con cambio de coloración del esmalto asociada a caries.

6. Diente 11:

Código 30 en palatino $=$ restauración color diente - superficie sana .

\begin{tabular}{|c|c|c|c|c|c|c|c|c|}
\hline \multirow{2}{*}{ 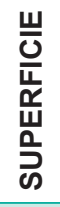 } & \multicolumn{3}{|c|}{$\begin{array}{l}\text { Cuadrante } \\
\text { superior derecho }\end{array}$} & \multirow{2}{*}{$\begin{array}{l}55 \\
15\end{array}$} & \multirow{2}{*}{$\begin{array}{l}54 \\
44\end{array}$} & \multirow{2}{*}{$\begin{array}{l}53 \\
43\end{array}$} & \multirow{2}{*}{$\begin{array}{l}52 \\
42\end{array}$} & \multirow{2}{*}{$\begin{array}{l}51 \\
44\end{array}$} \\
\hline & 48 & 47 & 46 & & & & & \\
\hline M & 99 & 99 & 00 & 00 & 00 & 00 & 00 & 00 \\
\hline 0 & 99 & 99 & 20 & 73 & 00 & - & - & - \\
\hline D & 99 & 99 & 00 & 00 & 00 & 00 & 00 & 00 \\
\hline V & 99 & 99 & 30 & 00 & 00 & 00 & 00 & 00 \\
\hline $\mathbf{P}$ & 99 & 99 & 00 & 00 & 00 & 00 & 02 & 30 \\
\hline
\end{tabular}

Figura 36. Registro de ICDAS.

\section{Recursos para el levantamiento epidemiológico}

\section{Físicos}

Espacio clínico o de campo utilizado para el levantamiento epidemiológico.

\section{Materiales}

- Relación de individuos que serán revisados.

- Mesas y sillas.

- Toallas húmedas desinfectantes.

- Campos para las mesas y para cubrir las piernas.

- Almohadas pequeñas.

- Jabón de manos antibacterial.

- Toallas de papel desechable.

- Barreras de protección (bata, gorros, lentes, cubrebocas, guantes).

- Lámparas tipo minero de luz blanca o lámpara de luz halógena.

- Espejos planos del número 5.

- Sondas periodontales utilizadas para el IPC..$^{13}$

- Cajas para esterilización del instrumental.

- Fichas de registro del índice (Anexo 5 ). 
- Lápices y gomas.

- Cepillos dentales.

- Pieza de baja velocidad.

- Cepillo profiláctico.

- Pasta profiláctica.

- Hilo dental.

- Gasas.

- Curetas para profilaxis dental.

- Micromotor /compresor portátil (robotín).

- Jeringa triple de unidad dental / jeringa triple de robotín.

- Rollos de algodón.

- Eyector de saliva.

\section{Humanos}

- Examinadores.

- Anotadores.

- Apoyo para organizar la actividad.

\section{Concordancia de la medición}

Es importante recordar antes de la aplicación de cualquier índice que los examinadores deberán realizar un ejercicio de estandarización de criterios, ${ }^{23,24}$ en el caso de ICDAS este ejercicio se puede dividir en dos apartados: el primero para identificar la concordancia para evaluar la presencia de selladores y restauradores, y el segundo para evaluar la concordancia para evaluar la condición de caries coronal por lo cual se muestra el siguiente ejercicio.

\section{Ejemplo 8.}

Se presentan los registros de dos observadores que utilizaron el Sistema Internacional de Detección de Caries bajo las mismas condiciones en el mismo individuo (Figura 37 y 38 ).

Recuerde que en el odontograma la evaluación de cada superficie incluye dos dígitos, el primer dígito corresponde a la presencia de selladores y restauraciones y el segundo digito a la condición de caries dental.

Para facilitar la identificación de concordancias primero se muestran los registros de la arcada superior de cada observador (Figura 37), seguidas de los registros de la arcada inferior (Figura 38).

Odontograma arcada superior, registro de examinadro 1.

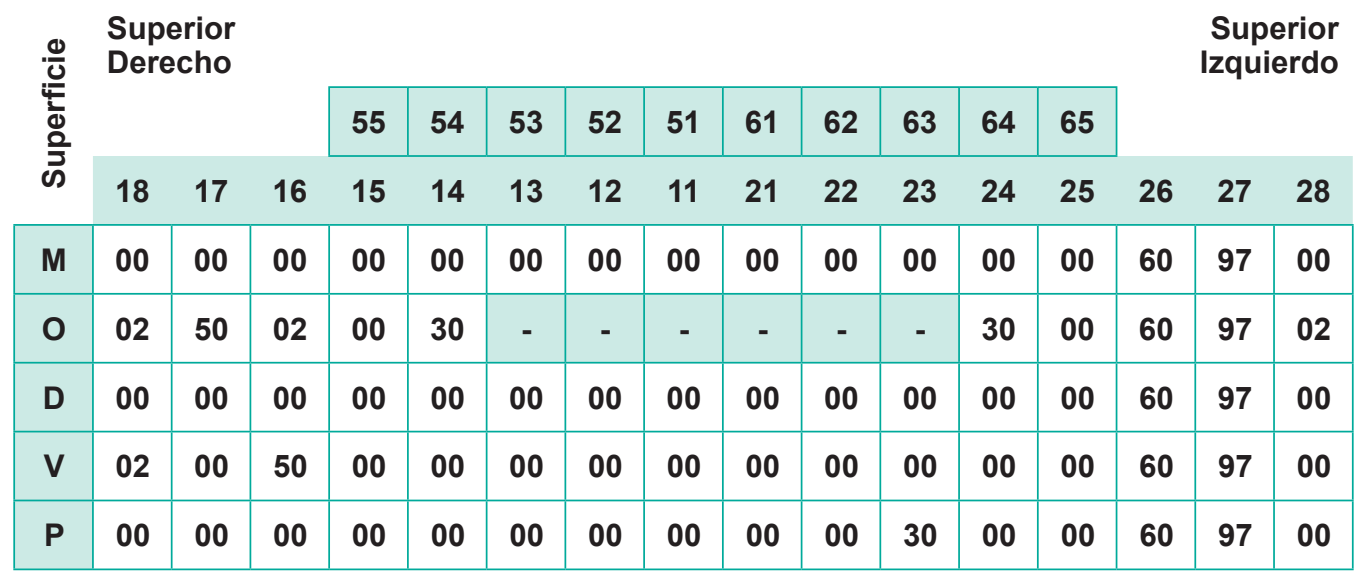

Figura 37. Registro interexaminador de la arcada superior, ICDAS. 
Odontograma arcada superior, registro de examinador 2.

\begin{tabular}{|c|c|c|c|c|c|c|c|c|c|c|c|c|c|c|c|c|}
\hline \multirow{3}{*}{ 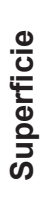 } & \multicolumn{13}{|c|}{$\begin{array}{l}\text { Superior } \\
\text { Derecho }\end{array}$} & \multicolumn{3}{|c|}{$\begin{array}{l}\text { Superior } \\
\text { Izquierdo }\end{array}$} \\
\hline & & & & 55 & 54 & 53 & 52 & 51 & 61 & 62 & 63 & 64 & 65 & & & \\
\hline & 18 & 17 & 16 & 15 & 14 & 13 & 12 & 11 & 21 & 22 & 23 & 24 & 25 & 26 & 27 & 28 \\
\hline $\mathbf{M}$ & 10 & 00 & 00 & 00 & 00 & 00 & 00 & 00 & 00 & 00 & 00 & 00 & 00 & 60 & 98 & 00 \\
\hline 0 & 12 & 50 & 22 & 10 & 30 & - & - & - & - & - & - & 30 & 10 & 60 & 98 & 22 \\
\hline D & 00 & 00 & 00 & 00 & 00 & 00 & 00 & 00 & 00 & 00 & 00 & 00 & 00 & 60 & 98 & 00 \\
\hline $\mathbf{V}$ & 02 & 00 & 50 & 00 & 00 & 00 & 00 & 00 & 00 & 00 & 00 & 00 & 00 & 60 & 98 & 00 \\
\hline $\mathbf{P}$ & 00 & 00 & 00 & 00 & 00 & 00 & 00 & 00 & 00 & 00 & 30 & 00 & 00 & 60 & 98 & 00 \\
\hline
\end{tabular}

Figura 37. Registro interexaminador de la arcada superior, ICDAS (continuación).

Odontograma arcada inferior, registro de examinador 1.

\begin{tabular}{|c|c|c|c|c|c|c|c|c|c|c|c|c|c|c|c|c|}
\hline \multirow{3}{*}{$\begin{array}{l}\frac{0}{0} \\
\frac{2}{0} \\
\frac{0}{2} \\
\infty\end{array}$} & \multicolumn{13}{|c|}{$\begin{array}{l}\text { Inferior } \\
\text { derecho }\end{array}$} & \multicolumn{3}{|c|}{$\begin{array}{r}\text { Inferior } \\
\text { Izquierdo }\end{array}$} \\
\hline & & & & & 84 & 83 & 82 & 81 & 71 & 72 & 73 & 74 & 75 & & & \\
\hline & 48 & 47 & 46 & 45 & 44 & 43 & 42 & 41 & 31 & 32 & 33 & 34 & 35 & 36 & 37 & 38 \\
\hline M & 99 & 60 & 00 & 00 & 60 & 00 & 00 & 01 & 00 & 00 & 00 & 00 & 60 & 00 & 00 & 99 \\
\hline 0 & 99 & 60 & 03 & 00 & 60 & - & - & - & - & - & - & 00 & 60 & 74 & 00 & 99 \\
\hline D & 99 & 60 & 00 & 00 & 60 & 00 & 02 & 01 & 00 & 00 & 00 & 00 & 60 & 04 & 00 & 99 \\
\hline V & 99 & 60 & 00 & 00 & 60 & 00 & 00 & 00 & 00 & 00 & 00 & 00 & 60 & 00 & 00 & 99 \\
\hline L & 99 & 60 & 00 & 00 & 60 & 00 & 02 & 00 & 00 & 00 & 30 & 00 & 60 & 00 & 00 & 99 \\
\hline
\end{tabular}

Odontograma arcada inferior, registro de examinador 2.

\begin{tabular}{|c|c|c|c|c|c|c|c|c|c|c|c|c|c|c|c|c|}
\hline \multirow{3}{*}{$\begin{array}{l}\frac{0}{U} \\
\frac{L}{0} \\
\frac{0}{2} \\
\omega\end{array}$} & \multirow{2}{*}{\multicolumn{3}{|c|}{$\begin{array}{l}\text { Inferior } \\
\text { derecho }\end{array}$}} & \multirow{3}{*}{$\begin{array}{l}85 \\
45\end{array}$} & \multirow{3}{*}{$\begin{array}{l}84 \\
44\end{array}$} & \multirow{3}{*}{$\begin{array}{l}83 \\
43\end{array}$} & \multirow{3}{*}{$\begin{array}{l}82 \\
42\end{array}$} & \multirow{3}{*}{$\begin{array}{l}81 \\
41\end{array}$} & \multirow{3}{*}{$\begin{array}{l}71 \\
31\end{array}$} & \multirow{3}{*}{$\begin{array}{l}72 \\
32\end{array}$} & \multirow{3}{*}{$\begin{array}{l}73 \\
33\end{array}$} & \multirow{3}{*}{$\begin{array}{l}74 \\
34\end{array}$} & \multirow{3}{*}{$\begin{array}{l}75 \\
35\end{array}$} & \multicolumn{3}{|c|}{$\begin{array}{r}\text { Inferior } \\
\text { Izquierdo }\end{array}$} \\
\hline & & & & & & & & & & & & & & & & \\
\hline & 48 & 47 & 46 & & & & & & & & & & & 36 & 37 & 38 \\
\hline M & 98 & 60 & 01 & 00 & 60 & 00 & 00 & 01 & 00 & 00 & 00 & 00 & 60 & 00 & 00 & 98 \\
\hline 0 & 98 & 60 & 13 & 01 & 60 & - & - & - & - & - & - & 00 & 60 & 74 & 10 & 98 \\
\hline D & 98 & 60 & 00 & 01 & 60 & 00 & 12 & 01 & 00 & 00 & 00 & 00 & 60 & 04 & 00 & 98 \\
\hline $\mathbf{v}$ & 98 & 60 & 00 & 00 & 60 & 00 & 00 & 00 & 00 & 00 & 00 & 00 & 60 & 00 & 00 & 98 \\
\hline L & 98 & 60 & 00 & 00 & 60 & 00 & 02 & 00 & 00 & 00 & 00 & 00 & 60 & 00 & 00 & 98 \\
\hline
\end{tabular}

Figura 38. Registro interexaminador de la arcada inferior, ICDAS. 


\section{CAPÍTU LO 5 Sistema Internacional de Detección de Caries: ICDAS}

Identificaremos primero el grado de concordancia referente a la presencia de selladores o restauraciones para elaborar la tabla de contingencia (Figura 39), en este caso de 10 por 10 debido a que se utilizaron códigos de ausencia de diente.

\begin{tabular}{|c|c|c|c|c|c|c|c|c|c|c|c|}
\hline \multicolumn{12}{|c|}{ EXAMINADOR 2} \\
\hline Códigos & 0 & 1 & 2 & 3 & 4 & 5 & 6 & 7 & 8 & 9 & $\begin{array}{l}\text { Total } \\
\text { de Fila }\end{array}$ \\
\hline 0 & 98 & 6 & 2 & & & & & & & & 106 \\
\hline 1 & & & & & & & & & & & \\
\hline 2 & & & & & & & & & & & \\
\hline 3 & & 1 & & 3 & & & & & & & 4 \\
\hline 4 & & & & & & & & & & & \\
\hline 5 & & & & & & 2 & & & & & 2 \\
\hline 6 & & & & & & & 20 & & & & 20 \\
\hline 7 & & & & & & & & 1 & & & 1 \\
\hline 8 & & & & & & & & & & & \\
\hline 9 & & & & & & & & & & 15 & 15 \\
\hline $\begin{array}{l}\text { Total de } \\
\text { Columna }\end{array}$ & 98 & 7 & 2 & 3 & & 2 & 20 & 1 & & 15 & $N=148$ \\
\hline
\end{tabular}

Figura 39. Tabla de contingencia de la evaluación de presencia de selladores o restauraciones del ejemplo 8.

Siguiendo la fórmula para obtener el índice de kappa, los cálculos son los siguientes:

$$
k=\frac{\mathrm{Po}-\mathrm{Pe}}{1-\mathrm{Pe}}
$$

Primero se consigue Po

$$
\begin{gathered}
\text { Po }=\frac{N-\text { discordancias }}{N} \\
P o=\frac{148-9}{148}=\frac{139}{148}=\mathbf{0 . 9 3}
\end{gathered}
$$

El cálculo de Pe requiere la obtención del Total de Fila y Total de Columna como se observa en la Figura 40. 
EXAMINADOR 2

\begin{tabular}{|c|c|c|c|c|c|c|c|c|c|c|c|c|}
\hline Códigos & 0 & 1 & 2 & 3 & 4 & 5 & 6 & 7 & 8 & 9 & $\begin{array}{c}\text { Total } \\
\text { de } \\
\text { Fila/N }\end{array}$ & $\begin{array}{l}\text { Cálculo } \\
\text { de TF/N }\end{array}$ \\
\hline 0 & 98 & 6 & 2 & & & & & & & & $106 / 148$ & 0.71 \\
\hline 1 & & & & & & & & & & & & \\
\hline 2 & & & & & & & & & & & & \\
\hline 3 & & 1 & & 3 & & & & & & & $4 / 148$ & 0.02 \\
\hline 4 & & & & & & & & & & & & \\
\hline 5 & & & & & & 2 & & & & & $2 / 148$ & 0.01 \\
\hline 6 & & & & & & & 20 & & & & $20 / 148$ & 0.13 \\
\hline 7 & & & & & & & & 1 & & & $1 / 148$ & 0.00 \\
\hline 8 & & & & & & & & & & & & \\
\hline 9 & & & & & & & & & & 15 & $15 / 148$ & 0.10 \\
\hline $\begin{array}{c}\text { Total de } \\
\text { Columna/ } \\
\mathbf{N}\end{array}$ & $98 / 148$ & $7 / 148$ & $2 / 148$ & $3 / 148$ & & $2 / 148$ & $20 / 148$ & $1 / 148$ & & $15 / 148$ & $N=148$ & \\
\hline $\begin{array}{c}\text { Cálculo } \\
\text { de } \\
\text { TC/N }\end{array}$ & 0.66 & 0.04 & 0.01 & 0.02 & & 0.01 & 0.13 & 0.00 & & 0.10 & & \\
\hline
\end{tabular}

Figuraa 40. Cálculo del Total de Fila y Columna de la evaluación de presencia de selladores o restauraciones del ejemplo 8.

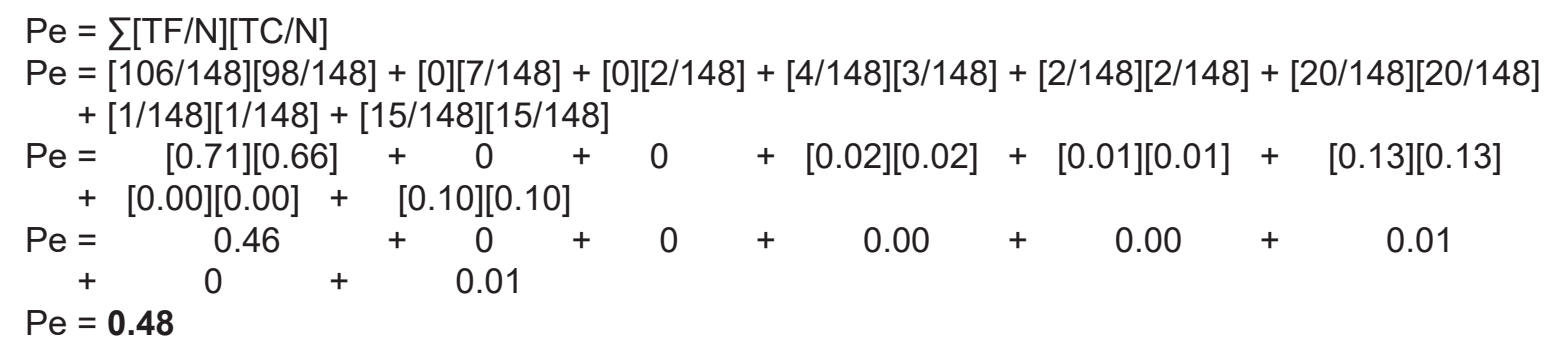

Por lo tanto el coeficiente de kappa:

$$
k=\frac{P o-P e}{1-P e}=\frac{0.90-0.37}{1-0.37}=\frac{0.53}{0.63}=\mathbf{0 . 8 4}
$$

Interpretación: Los examinadores obtuvieron un índice de kappa de 0.86 , por lo tanto, tienen una concordancia casi perfecta en la evaluación de la presencia de selladores y restauraciones de acuerdo a los criterios de Landis y Koch. 


\section{CAPÍTU LO 5 Sistema Internacional de Detección de Caries: ICDAS}

A continuación se elabora la tabla de contingencia (Figura 41) para identificar la concordancia en la evaluación de la condición de caries coronal, en esta tabla se incluyeron los códigos asociados a la ausencia dental: el "7" que corresponden a diente perdido por caries, el "8" que se refieren a la perdida del diente por otra razón que no es caries y el "9" que se anota en caso de diagnosticar un diente no erupcionado.

EXAMINADOR 2

\begin{tabular}{|c|c|c|c|c|c|c|c|c|c|c|c|}
\hline Códigos & 0 & 1 & 2 & 3 & 4 & 5 & 6 & 7 & 8 & 9 & $\begin{array}{c}\text { Total } \\
\text { de } \\
\text { Fila }\end{array}$ \\
\hline 0 & 119 & 3 & & & & & & & & & 122 \\
\hline 1 & & 2 & & & & & & & & & 2 \\
\hline 2 & & & 6 & & & & & & & & 6 \\
\hline 3 & & & & 1 & & & & & & & 1 \\
\hline 4 & & & & & 2 & & & & & & 2 \\
\hline 5 & & & & & & & & & & & \\
\hline 6 & & & & & & & & & & & \\
\hline 7 & & & & & & & & & 5 & & 5 \\
\hline 8 & & & & & & & & & & & \\
\hline 9 & & & & & & & & & 10 & & 10 \\
\hline $\begin{array}{l}\text { Total de } \\
\text { Columna }\end{array}$ & 119 & 5 & 6 & 1 & 2 & & & & 15 & & $\mathrm{~N}=148$ \\
\hline
\end{tabular}

Figura 41. Tabla de contingencia para evaluar la condición de caries coronal del ejemplo 8.

Inicialmente se calcula Po:

$$
\begin{gathered}
P o=\frac{N-\text { discordancias }}{N} \\
P o=\frac{148-18}{148}=\frac{130}{148}=\mathbf{0 . 9 3}
\end{gathered}
$$

Posteriormente se calcula Pe, por lo tanto se requiere calcular el Total de Fila y el Total de Columna (Figura 42). 


\section{Confiabilidad en la medición de caries dental}

\begin{tabular}{|c|c|c|c|c|c|c|c|c|c|c|c|c|}
\hline \multicolumn{13}{|c|}{ EXAMINADOR 2} \\
\hline Códigos & 0 & 1 & 2 & 3 & 4 & 5 & 6 & 7 & 8 & 9 & $\begin{array}{c}\text { Total } \\
\text { de } \\
\text { Fila/N }\end{array}$ & $\begin{array}{l}\text { Cálculo } \\
\text { de TF/N }\end{array}$ \\
\hline 0 & 119 & 3 & & & & & & & & & $122 / 148$ & 0.82 \\
\hline 1 & & 2 & & & & & & & & & $2 / 148$ & 0.01 \\
\hline 2 & & & 6 & & & & & & & & $6 / 148$ & 0.04 \\
\hline 3 & & & & 1 & & & & & & & $1 / 148$ & 0.00 \\
\hline 4 & & & & & 2 & & & & & & $2 / 148$ & 0.01 \\
\hline 5 & & & & & & & & & & & & \\
\hline 6 & & & & & & & & & & & & \\
\hline 7 & & & & & & & & & 5 & & $5 / 148$ & 0.03 \\
\hline 8 & & & & & & & & & & & & \\
\hline 9 & & & & & & & & & 10 & & $10 / 148$ & 0.00 \\
\hline $\begin{array}{l}\text { Total de } \\
\text { Columnal } \\
\mathbf{N}\end{array}$ & $119 / 148$ & $5 / 148$ & $6 / 148$ & $1 / 148$ & $2 / 148$ & & & & $15 / 148$ & & $N=148$ & \\
\hline $\begin{array}{l}\text { Cálculo } \\
\text { de TC/N }\end{array}$ & 0.80 & 0.03 & 0.04 & 0.00 & 0.01 & & & & 0.10 & & & \\
\hline
\end{tabular}

Figura 42. Cálculo del total de Fila y Columna para la evaluación de la condición de caries coronal del ejemplo 8.

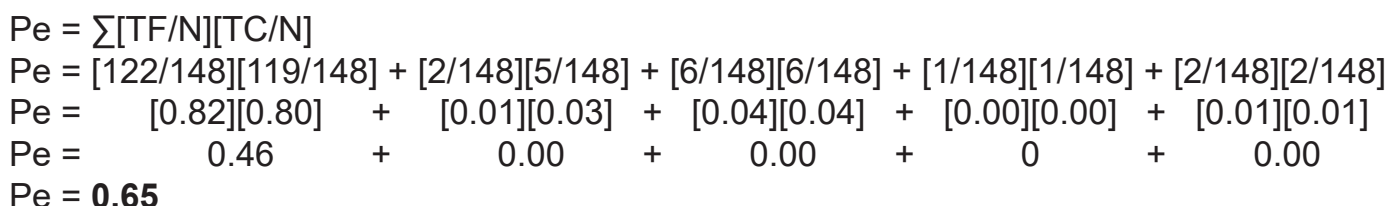

Por lo tanto:

$$
k=\frac{P o-P e}{1-P e}=\frac{0.87-0.65}{1-0.65}=\frac{0.22}{0.35}=\mathbf{0 . 6 2}
$$

Interpretación: Los observadores obtuvieron un coeficiente de kappa de 0.62, por lo tanto, tienen una concordancia sustancial en la evaluación del estado de raíz de acuerdo a los criterios de Landis y Koch.

La prueba de kappa nos indica que los registros entre los observadores respecto a la condición de caries coronal no alcanzan la confiabilidad requerida de acuerdo a los Criterios de Landis y Koch. ${ }^{25}$

Al observar los códigos en los cuales se registró el mayor número de discordancias podemos identificar que éstas se deben a una inferencia en la decisión diagnóstica puesto que corresponden a dientes ausentes.

Por ejemplo, mientras que el observador 1 registró 5 superficies con código correspondiente a diente perdido por caries, el observador 2 las registró con código relacionado con diente perdido por otra razón que no fue caries. 


\section{CAPÍTU LO 5 Sistema Internacional de Detección de Caries: ICDAS}

Otra discordancia se observa cuando el observador 1 registró 10 superficies con código relacionado a diente no erupcionado y el observador 2 con código propio para diente perdido por otras razón diferente a caries.

Por lo tanto, este ejercicio nos muestra la importancia de atender con especial cuidado el registro de los dientes ausentes porque esto conlleva el registro de 5 superficies y en el caso de existir discordancia, un registro diferente que corresponde a 3 dientes se traduce en una diferencia de 15 superficies, afectando la confiabilidad de los datos recolectados.

\section{Planeación del tratamiento considerando los criterios ICDAS}

La recolección de información a través del índice ICDAS implica ser meticuloso y esmerado, solo aquel que busca anticiparse a la enfermedad o limitar el daño que la caries a ocasionado se apegará al protocolo para alcanzar su objetivo.

La clasificación de lesiones acorde a los criterios ICDAS permiten planear la aplicación de diferentes programas preventivos y tratamientos no invasivos, cuyo objetivo principal es la conservación de la estructura dental. ${ }^{22,26}$ Las figuras 43 a 45 muestran las alternativas de tratamientos acorde al tipo de lesión encontrada.

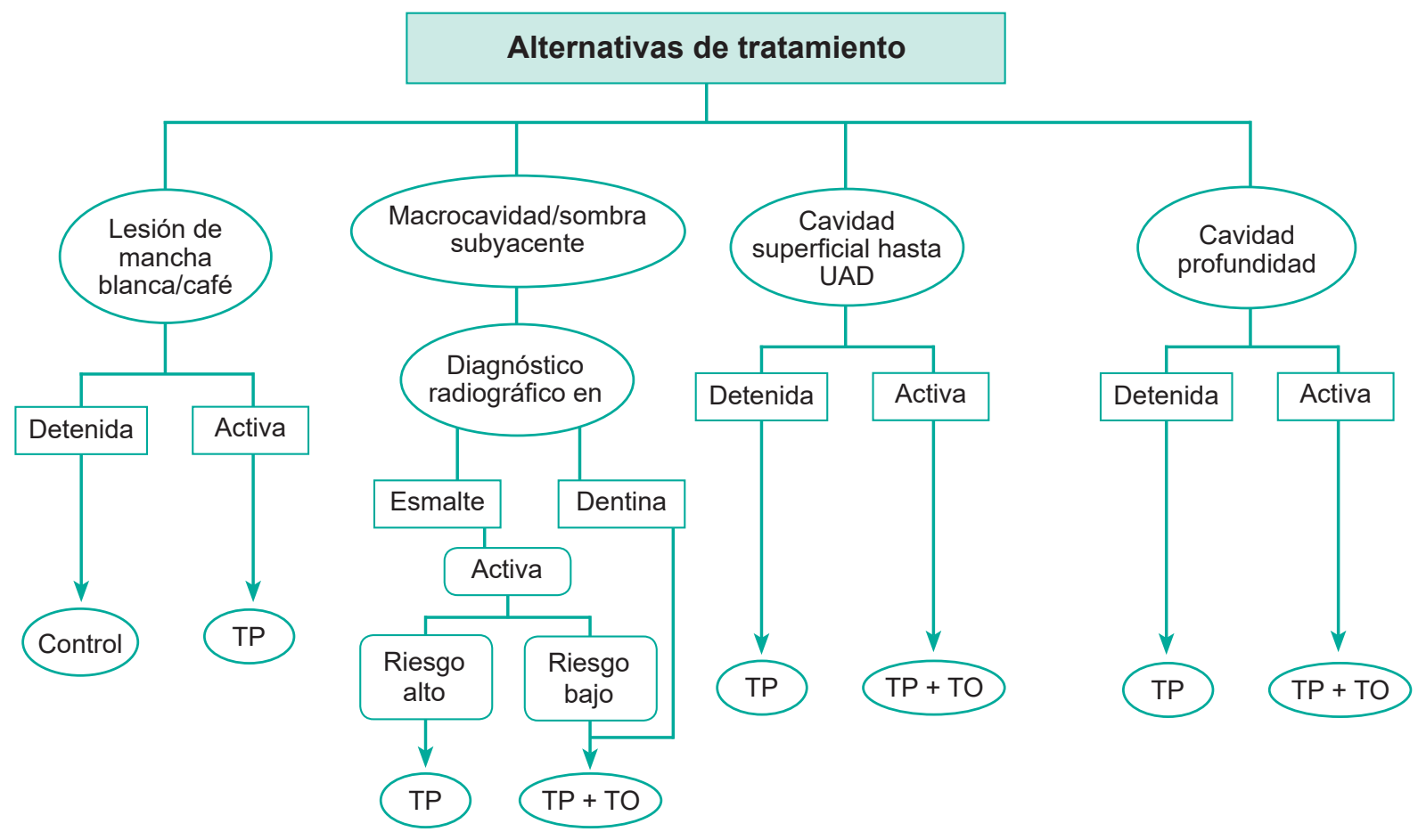

Figura 43. Guía de tratamiento considerando el tipo de lesión observada Unión-Amelo-Dentina UAD; TP Tratamiento Preventivo; TO Tratamiento operatorio. 


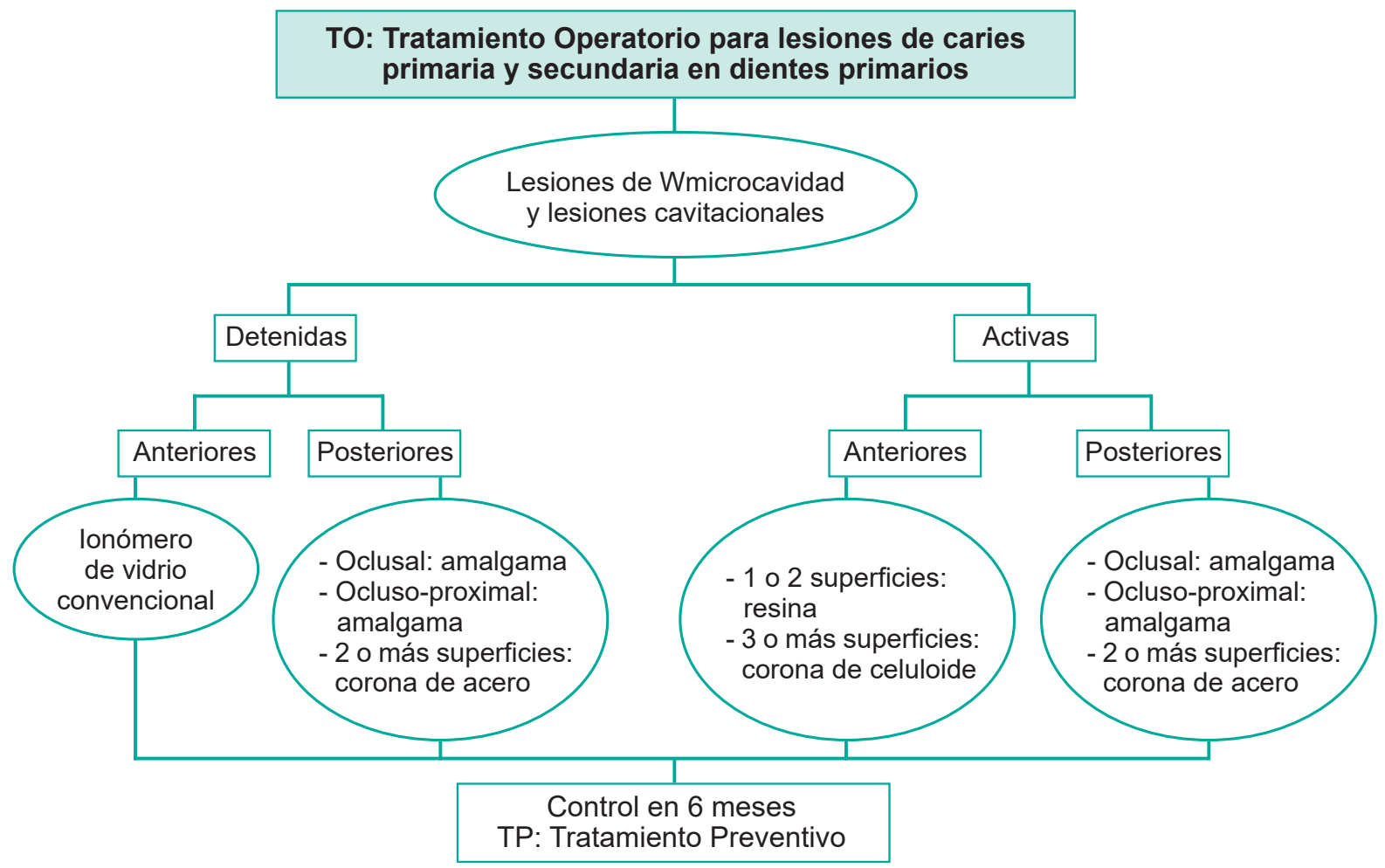

Figura 44. Guía de tratamiento en dientes primarios.

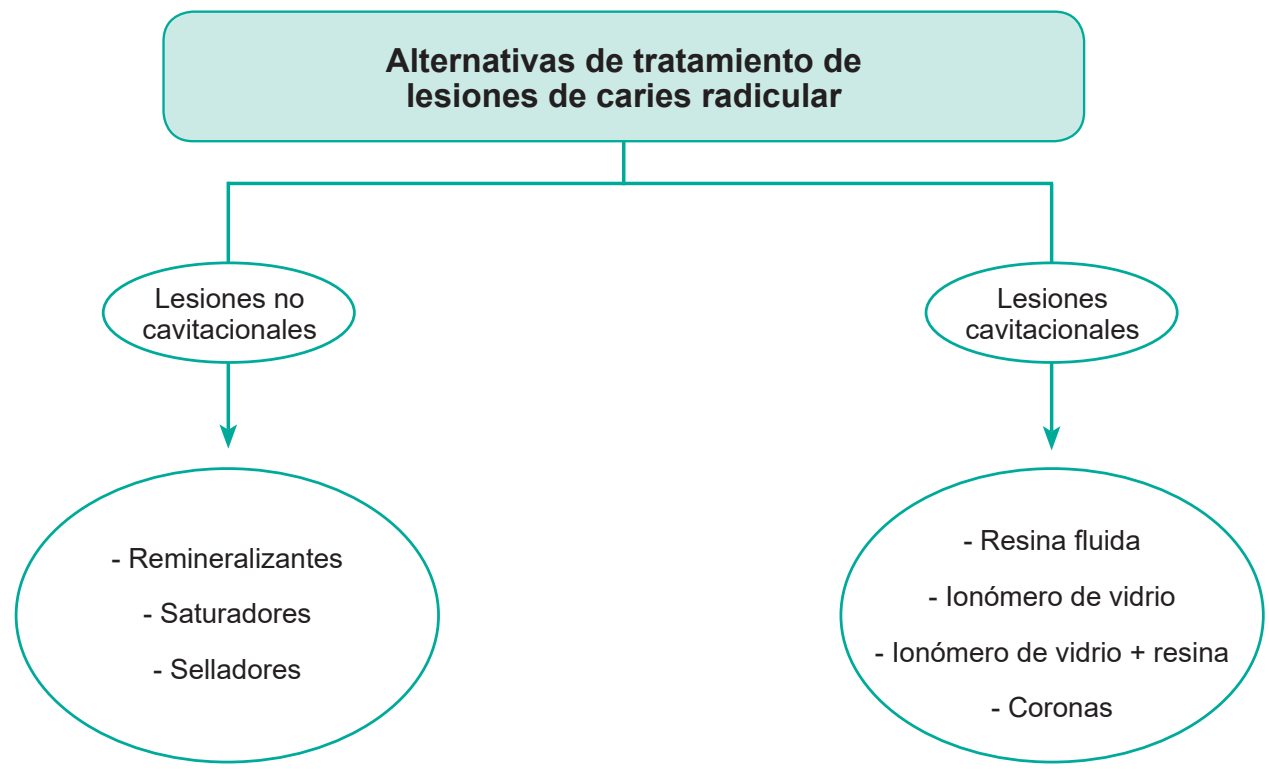

Figura 45. Guía de tratamiento de caries radicular. 


\section{CAPÍTU LO 5 Sistema Internacional de Detección de Caries: ICDAS}

\section{Bibliografia}

1. Fejerskov O, Kidd E. Dental Caries, the disease and its clinical management. Oxford UK: Blackwell Munksgaard. 2003.

2. Organización Mundial de la Salud. Encuesta de salud bucodental, Métodos Básicos. 4a. ed. OMS: Ginebra; 1997.

3. Denis M, Atlan A, Vennat E, Tirlet G, Attal JP. White defects on enamel: diagnosis and anatomopathology: two essential factors for proper treatment (part 1). Int Orthod. 2013;11(2):139-65.

4. Cotta F, de Castilho LS, Moreira AN, Paiva SM, Ferreira EF, Ferreira L, Magalhães CS. Lesion Activity Assessment (LAA) in conjunction with International Caries Detection and Assessment System (ICDAS) for Occlusal Caries Diagnosis in Permanent Teeth. Oper Dent. 2015; 40(5):189-96.

5. Pitts N. ICDAS an international system for caries detection and assessment being developed to facilitate caries epidemiology, research and appropriated clinical management. Community Dental Health. 2004; 21 (3): 193-198.

6. Shivakumar K, Prasad S, Chandu G. International Caries Detection and Assessment System: A new paradigm in detection of dental caries. Journal of Conservative Dentistry : JCD. 2009;12(1):10-16.

7. Braga MM, Oliveira LB, Bonini GA, Bonecker M, Mendes FM. Feasibility of the International Caries Detection and Assessment System (ICDAS-II) in epidemiological surveys and comparability with standard World Health Organization criteria. Caries Res. 2009;43(4):245-249.

8. Juárez López LA, Ortíz O, Murrieta-Pruneda F, Molina N. Estudio comparativo entre dos métodos de diagnóstico de caries incipientes. Odontología Actual. 2011;8(199):20-24.

9. Jablonski-Momeni A, Stachniss V, Ricketts DN, Heinzel-Gutenbrunner M, Pieper K. Reproducibility and accuracy of the ICDAS-II for detection of occlusal caries in vitro. Caries Res. 2008;42(2):79-87.

10. Ismail Al, Sohn W, Tellez M, Amaya A, Sen A, Hasson H, Pitts NB. The International Caries Detection and Assessment System (ICDAS): an integrated system for measuring dental caries. Community Dent Oral Epidemiol 2007; 35: 170- 78.

11. Piovesan C, Moro BL, Lara JS, Ardenghi TM, Guedes RS, Haddad AE, Braga MM, Mendes FM. Laboratorial training of examiners for using a visual caries detection system in epidemiological surveys. BMC Oral Health. $2013(3): 13: 49$.

12. Ismail Al, Sohn W, Tellez M, Willem JM, Betz J, Lipkowski J. Risk indicators for dental caries using the International Caries Detection and Assessment System (ICDAS) Community Dent Oral Epidemiol 2008; 36: 55-68.

13. Topping GVA, Hally J, Bonner B, Pitts, NB. International Caries Detection and Assessment System (ICDAS) e-learning Package. Interactive CD ROM and Web-based software. Smile-on 2008, London.

14. ICDAS Foundation. Actualizada 2015. Disponible En: https://www.icdas.org/frequently-raised-questions-andanswers.

15. Xaus G, Leighton C, Martin J, Martignon S, Moncada G. Validez y reproducibilidad del uso del Sistema ICDAS en la detección In Vitro de lesiones de Caries Oclusal en molares y premolares permanentes. Revista Dental de Chile 2010; 101 (1) 26-33.

16. International Caries Detection and Assessment System (ICDAS) Coordinating Committee, Criteria Manual. Bogota, Colombia and Budapest, Hungary, 2009, Disponible en: http://www.icdas .org/

17. Resumenes de presentaciones ICDAS. Bogota Colombia 2008. Disponible en: http://www.colgateprofesional. com.ec/LeadershipEC/NewsArticles/NewsMedia/MMCariologia_ICDAS_Espanol.pdf

18. Rojas A, Montero O. Equivalencia entre el método ICDAS y la Caries del Iceberg Dental. Rev Científica Odontológica 2012;8(1):1-6.

19. Bader JD, Shugars DA, Bonito AJ. Systematic review of selected dental caries diagnostic and management methods. J Dent Educ 2001; 65: 960-8.

20. Pendrys DG. The differential diagnosis of fluorosis. J Public Health Dent. 1999 Fall;59(4):235-8.

21. Iruretagoyena M. Resumen de las guías para Diagnóstico de ICDAS. Disponible en: http://www.sdpt.net/ CCMS/ICDAS/PDF/Resumen\%20diagnostico\%20de\%20ICDAS.pdf

22. Juárez L, Uribe JL, López G, León A, Servín S, Zepeda T. Atención Estomatológica del niño en la primera 
infancia. México: UNAM, FES Zaragoza. 2013. pp. 71-90.

23. Cerda J, Villaroel L. Concordancia interobservador en investigación pediátrica. Coeficiente de Kappa. Rev Chil Pediatr. 2008;79(1): 54-58.

24. Cohen J: A Coefficient of agreement for nominal scales. Educational and psychological measurement 1960; 20: 37-46. 4.

25. Landis J, Koch G: The measurement of observer agreement for categorical data. Biometrics 1977; 33: 159-74

26. Henostroza-Haro G. Caries dental. Principios y procedimientos para el diagnóstico. Madrid España: Médica Ripano. 2007.

Consultar el video de apoyo del Capítulo 5: "Sistema internacional de detección de caries: ICDAS", en la pestaña del Módulo Estomatología Social II http://www.zaragoza.unam.mx/herramientas-para-el-aprendizaje/ 


\section{ANEXOS}

\section{Fichas de registro}




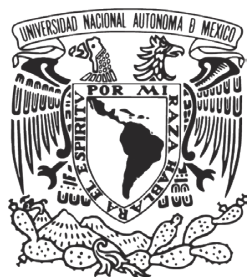

UNIVERSIDAD NACIONAL AUTÓNOMA DE MÉXICO

FACULTAD DE ESTUDIOS SUPERIORES ZARAGOZA

CARRERA DE CIRUJANO DENTISTA

FICHA DE REGISTRO

CPOD-cpod

ANEXO 1

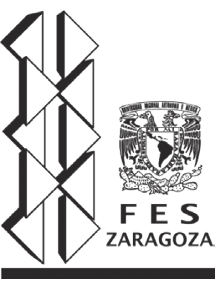

Comunidad:

Fecha de recolección:

Nombre del individuo:

Folio:

Edad: Sexo:

Examinador:

Anotador:

\section{ODONTOGRAMA}

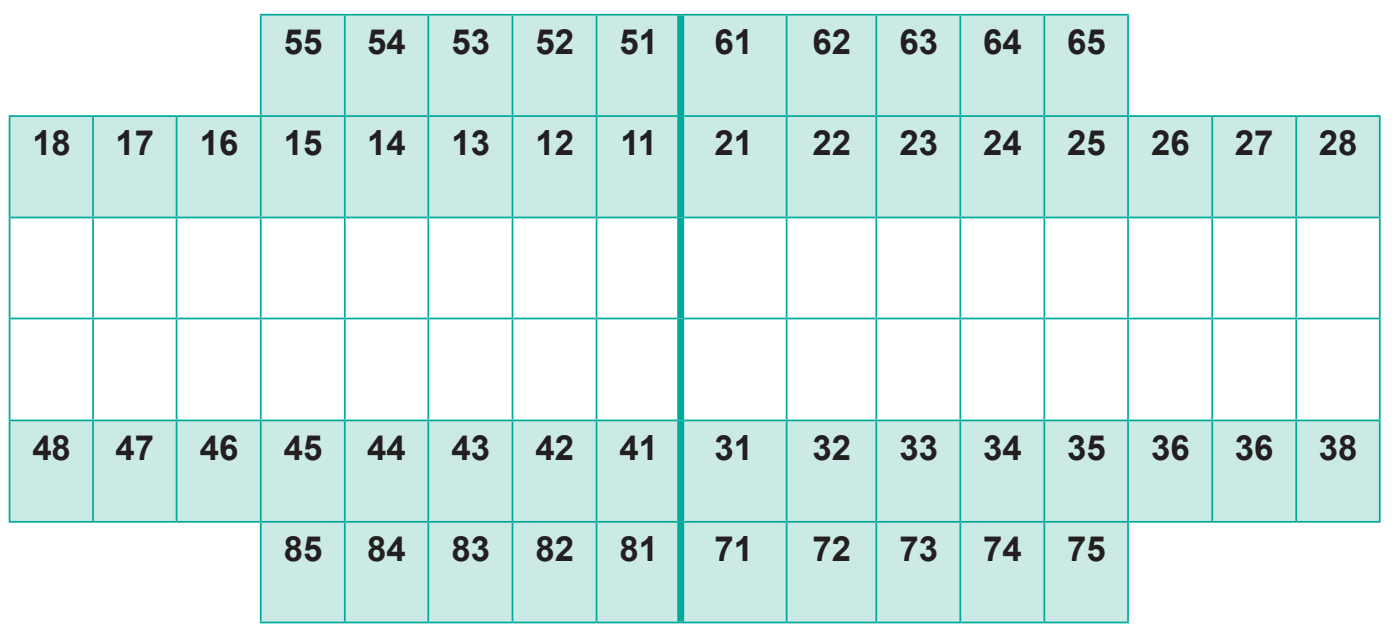

CÁLCULO

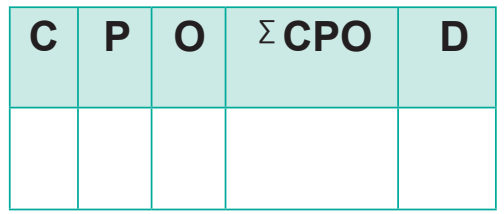

\begin{tabular}{|l|l|l|l|l|}
\hline $\mathbf{C}$ & $\mathbf{p}$ & $\mathbf{o}$ & $\Sigma \mathrm{cpo}$ & $\mathbf{d}$ \\
\hline & & & & \\
\hline
\end{tabular}

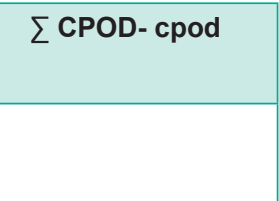

Observaciones 


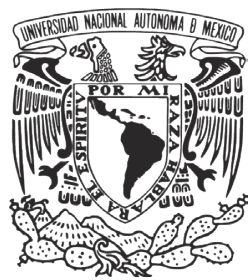

\section{UNIVERSIDAD NACIONAL AUTÓNOMA DE MÉXICO \\ FACULTAD DE ESTUDIOS SUPERIORES ZARAGOZA \\ CARRERA DE CIRUJANO DENTISTA}

FICHA DE REGISTRO

CPOS-cPos

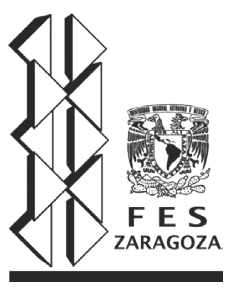

Comunidad:

Fecha de recolección:

Nombre del individuo: Folio:

Edad: Sexo:

Examinador:

Anotador:

\section{ODONTOGRAMA}

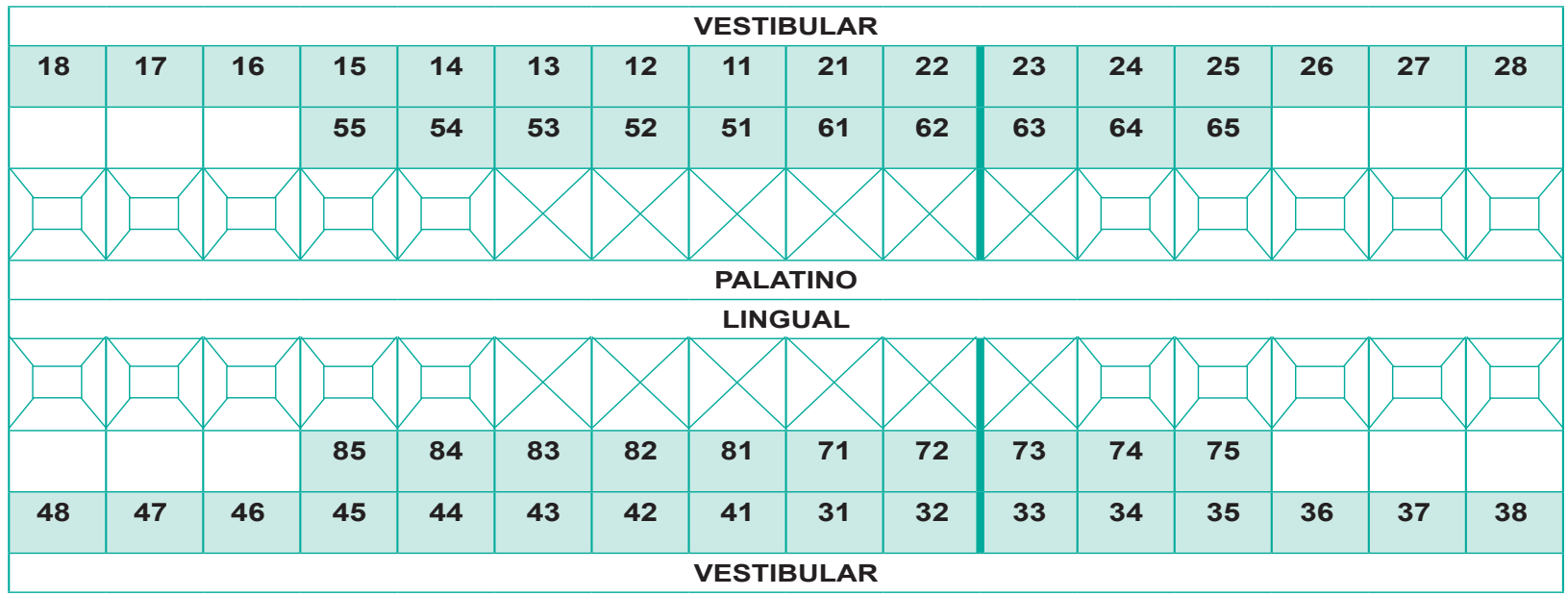

\section{CÁLCULO}

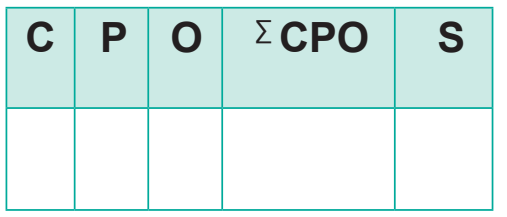

\begin{tabular}{|l|l|l|l|l|}
\hline $\mathbf{C}$ & $\mathbf{p}$ & $\mathbf{0}$ & $\sum \mathrm{cpo}$ & $\mathbf{S}$ \\
\hline & & & & \\
\hline
\end{tabular}

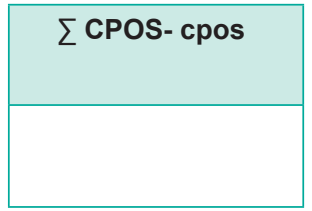

\section{Observaciones}




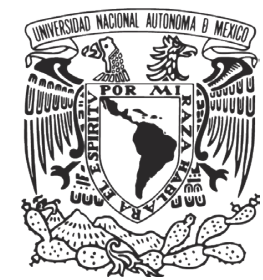

\section{UNIVERSIDAD NACIONAL AUTÓNOMA DE MÉXICO FACULTAD DE ESTUDIOS SUPERIORES ZARAGOZA CARRERA DE CIRUJANO DENTISTA}

FICHA DE REGISTRO CPOS-cPos

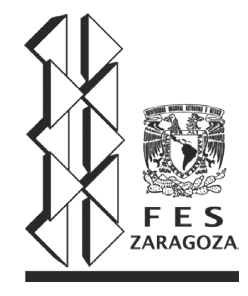

Comunidad:

Nombre del individuo:

Edad:

Examinador:
Fecha de recolección: Sexo:

Folio:

\section{ODONTOGRAMA}

\begin{tabular}{|c|c|c|c|c|c|c|c|c|c|c|c|c|c|c|c|c|}
\hline & & & & \multirow{3}{*}{\begin{tabular}{|c|}
55 \\
15
\end{tabular}} & \multirow{3}{*}{\begin{tabular}{|l|}
54 \\
14
\end{tabular}} & \multirow{3}{*}{\begin{tabular}{|c|}
53 \\
13 \\
\end{tabular}} & \multirow{3}{*}{\begin{tabular}{|l|}
52 \\
12
\end{tabular}} & \multirow{3}{*}{$\begin{array}{l}51 \\
11\end{array}$} & \multirow{3}{*}{$\begin{array}{l}61 \\
21\end{array}$} & \multirow{3}{*}{$\begin{array}{l}62 \\
22\end{array}$} & \multirow{3}{*}{\begin{tabular}{|l|}
63 \\
23
\end{tabular}} & \multirow{3}{*}{$\begin{array}{l}64 \\
24\end{array}$} & \multirow{3}{*}{$\begin{array}{l}65 \\
25\end{array}$} & \multirow[b]{3}{*}{26} & \multirow[b]{3}{*}{27} & \multirow[b]{3}{*}{28} \\
\hline & & & & & & & & & & & & & & & & \\
\hline & 18 & 17 & 16 & & & & & & & & & & & & & \\
\hline \multicolumn{17}{|l|}{ Oclusal } \\
\hline \multicolumn{17}{|l|}{ Mesial } \\
\hline \multicolumn{17}{|c|}{ Vestibular } \\
\hline \multicolumn{17}{|c|}{ Distal } \\
\hline \multicolumn{17}{|l|}{ Palatina } \\
\hline & & & & 85 & 84 & 83 & 82 & 81 & 71 & 72 & 73 & 74 & 75 & & & \\
\hline & 48 & 47 & 46 & 45 & 44 & 43 & 42 & 41 & 31 & 32 & 33 & 34 & 35 & 36 & 37 & 38 \\
\hline \multicolumn{17}{|l|}{ Oclusal } \\
\hline \multicolumn{17}{|l|}{ Mesial } \\
\hline \multicolumn{17}{|c|}{ Vestibular } \\
\hline \multicolumn{17}{|c|}{ Distal } \\
\hline Lingual & & & & & & & & & & & & & & & & \\
\hline
\end{tabular}

\section{CÁLCULO}

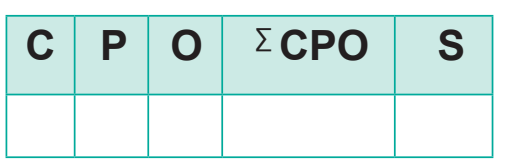

\begin{tabular}{|l|l|l|l|l|}
\hline $\mathbf{C}$ & $\mathbf{p}$ & $\mathbf{O}$ & $\Sigma \mathrm{cpo}$ & $\mathbf{S}$ \\
\hline & & & & \\
\hline
\end{tabular}

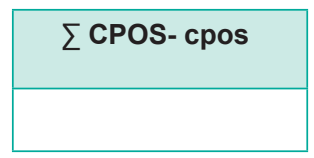

Observaciones 

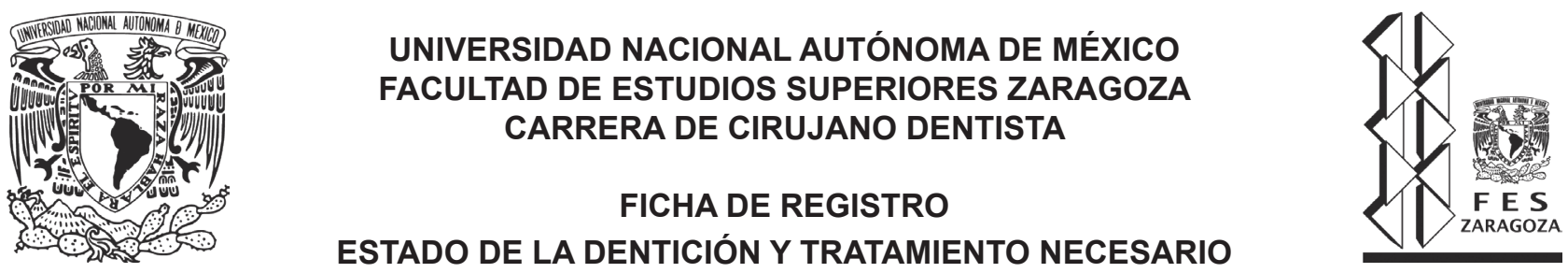

Comunidad: Fecha de recolección:

Nombre del individuo: Folio:

Edad: Sexo:

Examinador: Anotador:

\section{ODONTOGRAMA}

\begin{tabular}{|c|c|c|c|c|c|c|c|c|c|c|c|c|c|c|c|c|}
\cline { 2 - 14 } \multicolumn{1}{c|}{} & 18 & 17 & 16 & 15 & 14 & 13 & 12 & 11 & 21 & 22 & 23 & 24 & 25 & 26 & 27 & 28 \\
\hline Corona & & & & & & & & & & & & & & & & \\
\hline Raíz & & & & & & & & & & & & & & & & \\
\hline $\begin{array}{c}\text { Tratamiento } \\
\text { necesario }\end{array}$ & & & & & & & & & & & & & & & & \\
\hline
\end{tabular}

\begin{tabular}{|c|c|c|c|c|c|c|c|c|c|c|c|c|c|c|c|c|}
\hline \multicolumn{1}{l|}{} & 48 & 47 & 46 & 45 & 44 & 43 & 42 & 41 & 31 & 32 & 33 & 34 & 35 & 36 & 37 & 38 \\
\hline Corona & & & & & & & & & & & & & & & & \\
\hline Raíz & & & & & & & & & & & & & & & & \\
\hline $\begin{array}{c}\text { Tratamiento } \\
\text { necesario }\end{array}$ & & & & & & & & & & & & & & & & \\
\hline
\end{tabular}



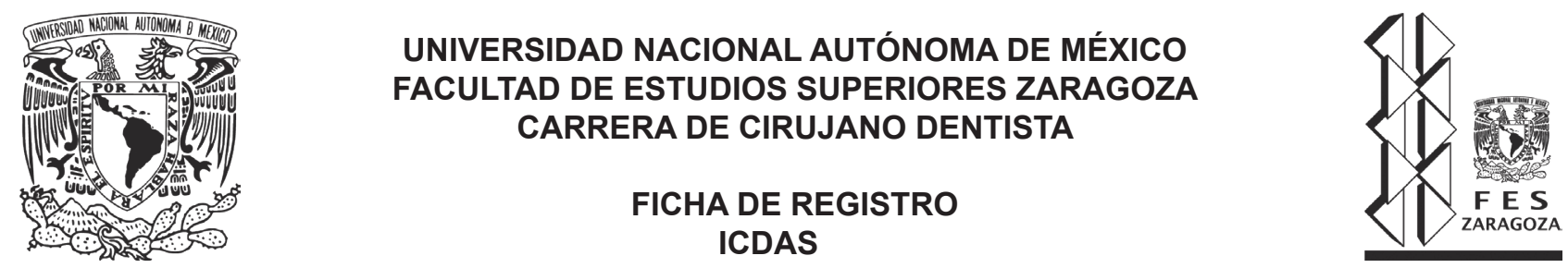

Comunidad:

Nombre del individuo:

Edad: Sexo:

Examinador:
Fecha de recolección:

Folio:

Anotador:

\section{ODONTOGRAMA}

\begin{tabular}{|c|c|c|c|c|c|c|c|c|c|c|c|c|c|c|c|c|}
\hline \multirow{3}{*}{ 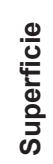 } & & & & \multirow{3}{*}{$\begin{array}{r}55 \\
15 \\
\end{array}$} & \multirow{3}{*}{$\begin{array}{l}54 \\
14\end{array}$} & \multirow{3}{*}{$\begin{array}{l}53 \\
13\end{array}$} & \multirow{3}{*}{$\begin{array}{l}52 \\
12\end{array}$} & \multirow{3}{*}{$\begin{array}{l}51 \\
11\end{array}$} & \multirow{3}{*}{$\begin{array}{l}61 \\
21\end{array}$} & \multirow{3}{*}{$\begin{array}{l}62 \\
22\end{array}$} & \multirow{3}{*}{$\begin{array}{l}63 \\
23\end{array}$} & \multirow{3}{*}{$\begin{array}{l}64 \\
24\end{array}$} & \multirow{3}{*}{$\begin{array}{l}65 \\
25\end{array}$} & & & \\
\hline & & & & & & & & & & & & & & \multirow[b]{2}{*}{26} & \multirow[b]{2}{*}{27} & \multirow[b]{2}{*}{28} \\
\hline & 18 & 17 & 16 & & & & & & & & & & & & & \\
\hline \multicolumn{17}{|l|}{$\mathbf{M}$} \\
\hline 0 & & & & & & - & - & - & - & - & - & & & & & \\
\hline \multicolumn{17}{|l|}{ D } \\
\hline \multicolumn{17}{|l|}{$\mathbf{V}$} \\
\hline $\mathbf{P}$ & & & & & & & & & & & & & & & & \\
\hline
\end{tabular}

\begin{tabular}{|c|c|c|c|c|c|c|c|c|c|c|c|c|c|c|c|c|}
\hline \multirow{2}{*}{ 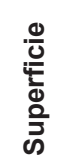 } & & & & \multirow{2}{*}{\begin{tabular}{|l|}
85 \\
45 \\
\end{tabular}} & \multirow{2}{*}{$\begin{array}{l}84 \\
44\end{array}$} & \multirow{2}{*}{$\begin{array}{l}83 \\
43\end{array}$} & \multirow{2}{*}{$\begin{array}{l}82 \\
42\end{array}$} & \multirow{2}{*}{$\begin{array}{l}81 \\
41\end{array}$} & \multirow{2}{*}{$\begin{array}{l}71 \\
31\end{array}$} & \multirow{2}{*}{$\begin{array}{l}2 \\
32\end{array}$} & \multirow{2}{*}{\begin{tabular}{|l|}
73 \\
33
\end{tabular}} & \multirow{2}{*}{$\begin{array}{l}74 \\
34\end{array}$} & \multirow{2}{*}{$\begin{array}{l}75 \\
35\end{array}$} & \multirow[b]{2}{*}{36} & \multirow[b]{2}{*}{37} & \multirow[b]{2}{*}{38} \\
\hline & 48 & 47 & 46 & & & & & & & & & & & & & \\
\hline M & & & & & & & & & & & & & & & & \\
\hline 0 & & & & & & - & - & - & - & - & - & & & & & \\
\hline D & & & & & & & & & & & & & & & & \\
\hline $\mathbf{V}$ & & & & & & & & & & & & & & & & \\
\hline L & & & & & & & & & & & & & & & & \\
\hline
\end{tabular}




\section{Confiabilidad en la medición de caries dental}

El proceso caries dental es una alteración de salud bucal que ha alcanzado el nivel de pandemia, sin duda, requiere ser abordada a través de la participación de los diversos actores sociales: la población, el gremio estomatológico, el Sistema Nacional de Salud, la Secretaría de Educación Pública, las empresas productoras de alimentos y auxiliares de higiene bucal y por supuesto el gobierno a través de las Políticas Públicas.

El alumno de la Carrera de Cirujano Dentista tendrá presente que la frecuencia y magnitud de la caries dental es determinada por: el contexto político, la situación socioeconómica en la cual se encuentra el individuo, sus condiciones de vida, su comportamiento social, factores psicológicos y factores biológicos, así como el tipo de sistema de salud al cual tiene acceso el individuo.

Por lo tanto, la comprensión de esta problemática permitirá al futuro Cirujano Dentista planear y ejecutar programas preventivos y de rehabilitación, así como utilizar o crear materiales y tecnología innovadora para tener una práctica odontológica basada en la prevención, o bien, crear espacios alternativos en los cuales se integre a la población con la intención de resolver las necesidades que plantea cada escenario.

Para ello, es importante que el alumno de la Carrera de Cirujano Dentista reconozca que el primer paso en cualquier abordaje es realizar un diagnóstico confiable de la población seleccionada, por lo tanto, se apoyará en indicadores cualitativos que le ayuden a explicar el por qué y cómo se producen algunas situaciones de salud y en indicadores cuantitativos que responden al qué, cuánto y cuándo respecto a la valoración de lesiones o experiencia de caries.

En relación a los indicadores epidemiológicos para valorar caries dental existe múltiples sistemas, sin embargo, en el presente libro se abordarán el CPOD-cpod, el índice para evaluar el estado de la dentición y tratamiento necesario y el Sistema Internacional de Detección de Caries (ICDAS), mismos que forman parte del Plan de Estudios de la Carrera de Cirujano Dentista por ser de los más utilizados y por generar información que da cuenta de la magnitud y severidad de caries en diversos grupos poblacionales.

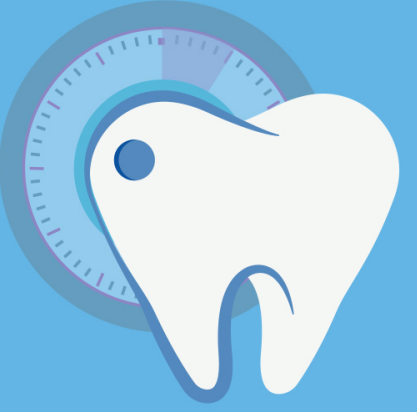

Facultad de Estudios Superiores Zaragoza, Campus I. Av. Guelatao No. 66 Col. Ejército de Oriente, Campus II. Batalla 5 de Mayo s/n Esq. Fuerte de Loreto. Col. Ejército de Oriente.

Iztapalapa, C.P. 09230 México D.F.

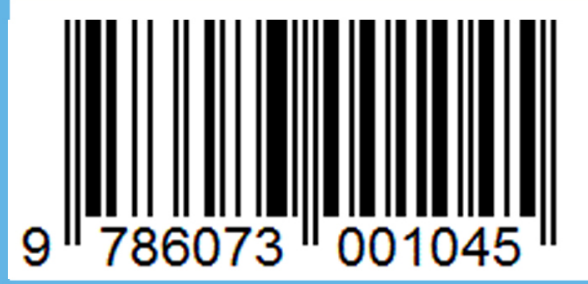

